Andrews University

Digital Commons @ Andrews University

\title{
The Effects Of Chinese Calligraphy On Reducing Anxiety And Comorbid Depression Levels Among Breast Cancer Patients In Hong Kong
}

Anna Liu

Andrews University, liua@andrews.edu

Follow this and additional works at: https://digitalcommons.andrews.edu/dissertations

Part of the Arts and Humanities Commons, and the Clinical Psychology Commons

\section{Recommended Citation}

Liu, Anna, "The Effects Of Chinese Calligraphy On Reducing Anxiety And Comorbid Depression Levels Among Breast Cancer Patients In Hong Kong" (2017). Dissertations. 1636.

https://digitalcommons.andrews.edu/dissertations/1636

https://dx.doi.org/10.32597/dissertations/1636

This Dissertation is brought to you for free and open access by the Graduate Research at Digital Commons @ Andrews University. It has been accepted for inclusion in Dissertations by an authorized administrator of Digital Commons@ Andrews University. For more information, please contact repository@andrews.edu. 


\begin{abstract}
THE EFFECTS OF CHINESE CALLIGRAPHY ON REDUCING ANXIETY AND COMORBID DEPRESSION LEVELS AMONG BREAST CANCER PATIENTS IN HONG KONG
\end{abstract}

by

Anna Liu

Chair: Carole Woolford-Hunt 


\title{
ABSTRACT OF GRADUATE STUDENT RESEARCH
}

Dissertation

\author{
Andrews University
}

School of Education

\section{Title: THE EFFECTS OF CHINESE CALLIGRAPHY ON REDUCING ANXIETY AND COMORBID DEPRESSION LEVELS AMONG BREAST CANCER PATIENTS IN HONG KONG}

Name of researcher: Anna Liu

Name and degree of faculty chair: Carole Woolford-Hunt, Ph.D.

Date completed: June 2017

\section{Problem}

Breast cancer is the most common cancer among women worldwide. Anxiety is a prevalent psychological concern in breast cancer patients and has negative impact on the course of their disease, treatment and recovery. This study was to investigate the effects of Chinese calligraphy on reducing the anxiety and comorbid depression levels among Hong Kong breast cancer patients with an intention to support the needs of breast cancer patients by providing alternative therapy that is culturally receptive. The primary objective of the study was to examine to what extent Chinese calligraphy intervention can 
reduce the anxiety and comorbid depression levels among the breast cancer patients in Hong Kong.

\section{Method}

A one group repeated measures design was applied to the study. Participants were required to join eight-90 minute sessions of Chinese calligraphy intervention.

Physiological measurements including blood pressure, heart rate and respiratory rate and self-reported psychological measurements including the full version of State-Trait Anxiety Inventory (STAI) and the short version Depression Anxiety Stress Scale (DASS 21) were used. Blood pressure, heart rate and respiratory rate were measured at the baselines, before and after each intervention. The STAI and DASS 21 were measured at the baselines, after 4 weeks and after 8 weeks of Chinese calligraphy intervention. A total of 45 female Hong Kong breast cancer patients participated in the research, and 30 of them finished all eight interventions.

\section{Results}

The results showed that calligraphy significantly reduced heart rate, respiratory rate, systolic blood pressure, as well as self-reported state-trait anxiety levels, depression levels and stress levels in breast cancer patients who received an eight-90 minute Chinese calligraphy intervention. Two hypotheses were supported by the results of the research:

1) There was a physiological slowing effect in blood pressure, heart rate and respiratory rate among breast cancer patients after the intervention; 2) Breast cancer patients had reduced scores on self-reported measures on anxiety and comorbid depression levels after the intervention. 


\section{Conclusions}

These data suggest that Chinese calligraphy may be an effective alternative intervention to reduce the anxiety and comorbid depression levels among breast cancer patients in Hong Kong. 
Andrews University

School of Education

\title{
THE EFFECTS OF CHINESE CALLIGRAPHY ON REDUCING ANXIETY AND COMORBID DEPRESSION LEVELS AMONG BREAST CANCER PATIENTS IN HONG KONG
}

\author{
A Dissertation \\ Presented in Partial Fulfillment \\ Of the Requirement for the Degree \\ Doctor of Philosophy
}

by

Anna Liu

June 2017 
(C) Copyright by Anna Liu 2017

All Right Reserved 


\title{
THE EFFECTS OF CHINESE CALLIGRAPHY ON REDUCING ANXIETY AND COMORBID DEPRESSION LEVELS AMONG BREAST CANCER PATIENTS IN HONG KONG
}

\author{
A dissertation \\ presented in partial fulfillment \\ of the Requirement for the degree \\ Doctor of Philosophy
}

\section{by}

Anna Liu

\section{APPROVAL BY THE COMMITTEE:}

Chair: Carole Woolford-Hunt

Member: Jeannie Montagono

Member: Jimmy Kijai

External: Lionel Matthews
Dean, School of Education

Robson Marinho 


\section{TABLE OF CONTENTS}

LIST OF FIGURES .......................................................................... vi

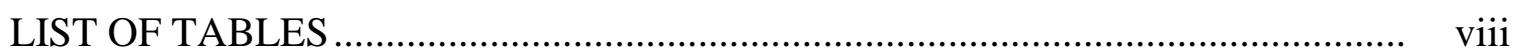

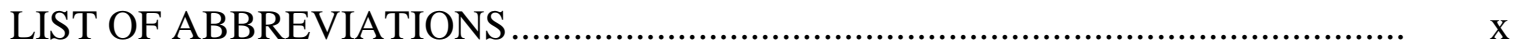

\section{Chapter}

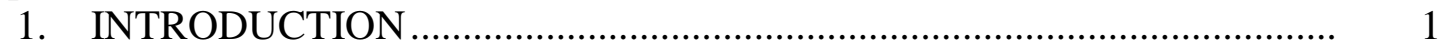

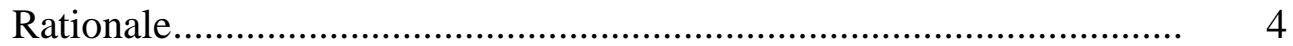

Purpose of the Study ..................................................................... 7

Conceptual Framework ................................................................ 7

Existential Anxiety .............................................................. 7

Mediation and Mindfulness Theories............................................. 8

Research Question.................................................................... 10

Research Hypotheses............................................................... 10

Significance of Study ................................................................... 11

Definition of Terms ................................................................ 13

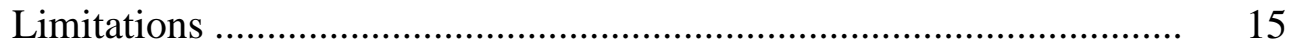

Overview of the Research Methodology ......................................... 16

Organization of the Study ............................................................. 16

2. REVIEW OF LITERATURE .......................................................... 18

Introduction ............................................................................ 18

Chinese Calligraphy: Historical Perspective .................................... 18

The Effect of Chinese Calligraphy on Non-clinical and Clinical

Populations ........................................................................... 22

Non-clinical Populations......................................................... 22

Clinical Populations ............................................................. 24

Children with Childhood Disorders and Posttraumatic

Stress Disorder (PTSD) ................................................. 24

Patients with Elderly Disorders .......................................... 25

Patients with Psychosomatic Diseases.................................. 25

Patients with Mental and Mood Disorders.............................. 26

Cancer Patients.................................................................. 27

General Approaches to Treatment of Anxiety .................................... 28

Cognitive-Behavior Therapy (CBT) .......................................... 28

Acceptance and Commitment Therapy $(\mathrm{ACT})$............................. 28 
Other Forms of Psychotherapy..................................................... 29

Pharmacotherapy ..................................................................... 29

Current Effective Interventions on Anxiety Reduction for Cancer

Patient............................................................................. 30

Relaxation and Imagery Interventions ......................................... 31

Group Intervention ............................................................... 33

Music Therapy ..................................................................... 34

Mindfulness Based Stress Reduction Program (MBSR) ................ $\quad 35$

Calligraphy and Mindfulness ................................................................ $\quad 39$

Discussion .............................................................................. 40

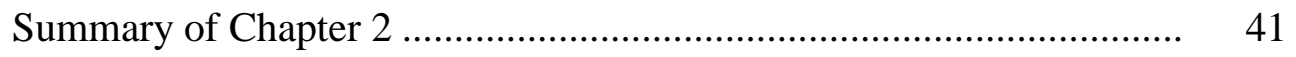

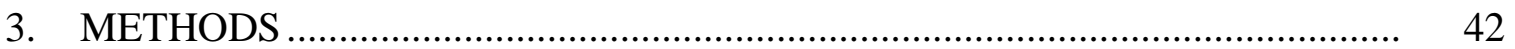

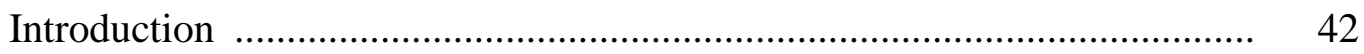

Research Question .......................................................................... 42

Research Design ................................................................................. 43

Population and Sample .......................................................................... 44

Instrumentation: The Measurement of Anxiety …………………………... 45

Physiological Measures ................................................................... 46

Self-Reported Measures ................................................................ 46

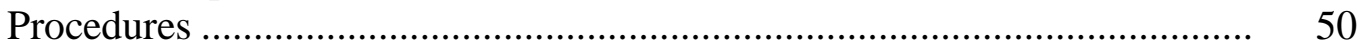

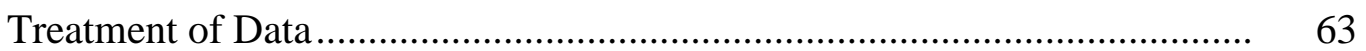

Data Analysis.................................................................................... 63

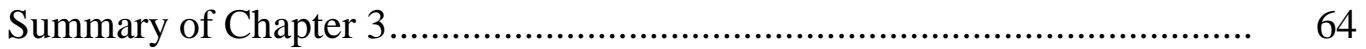

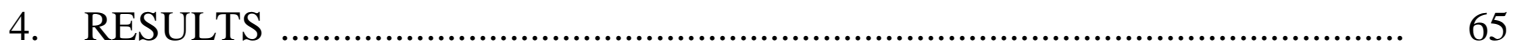

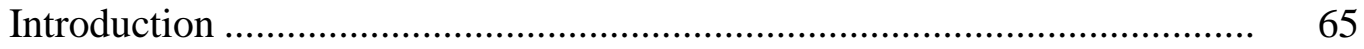

Participant Characteristics .................................................................... 65

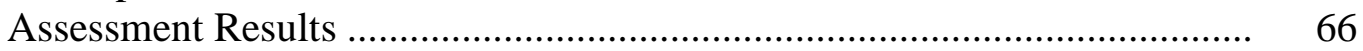

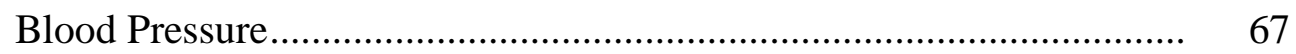

Systolic Measures (pre-tests) ………………………................... 67

Systolic Measures (post-tests)......................................................... 67

Diastolic Measures (pre-tests) ........................................................ 71

Diastolic Measures (post-tests) …………………………….......... 71

Heart Rate ................................................................................ 74

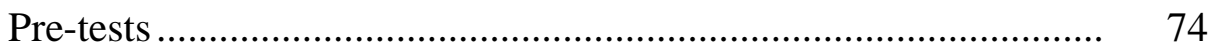

Post-tests ...................................................................... 76

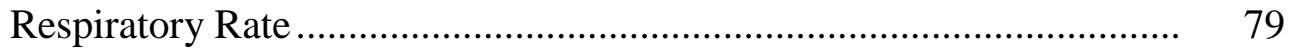

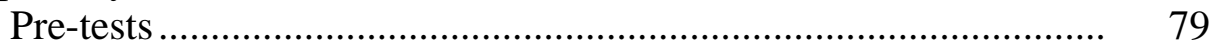

Post-tests .......................................................................... 80

State-Trait Anxiety Inventory Results.................................................. $\quad 82$

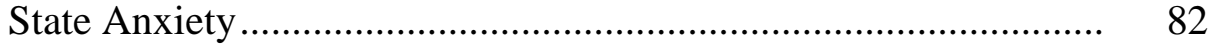

Trait Anxiety ....................................................................... 84 
Depression Anxiety Stress Scale 21 Results ......................................... 86

Depression Scores .................................................................. 86

Anxiety Scores .................................................................... 87

Stress Scores ………........................................................... 90

Qualitative Data: Interviews ............................................................... 92

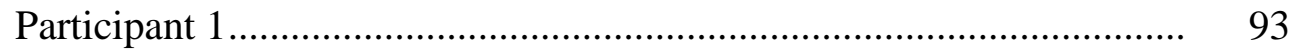

Participant 2 ..................................................................... 94

Participant 3 ........................................................................ 96

Participant 4 .......................................................................... 9

Participant 5 ...................................................................... 98

Testing of Hypotheses ............................................................................ 100

Summary of Major Findings ................................................................ 101

Blood Pressure.......................................................................... 101

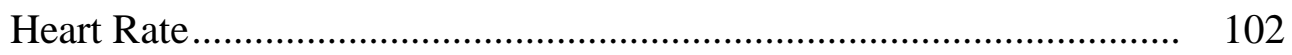

Respiration Rate ………............................................................ 103

STAI Results .......................................................................... 104

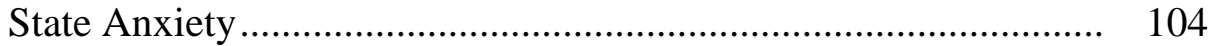

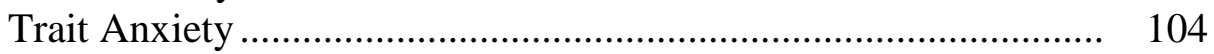

DASS 21 Results ....................................................................... 105

Depression Subscale ................................................................... 105

Anxiety Subscale .................................................................. 105

Stress Subscale ..................................................................... 106

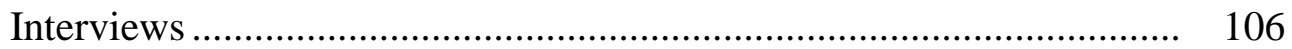

\section{CONCLUSIONS, DISCUSSIONS, IMPLICATIONS, AND}

RECOMMENDATIONS ..................................................................... 108

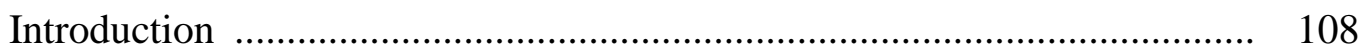

Summary: Purpose of the Study ......................................................... 108

Summary of Literature Review ………………………......................... 109

Summary of Procedures ……………………………......................... 110

Summary of Major Results..................................................................... 111

Physiological Measures .................................................................. 111

Blood Pressure (Systolic and Diastolic)........................................ 112

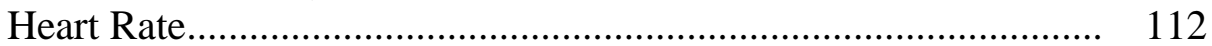

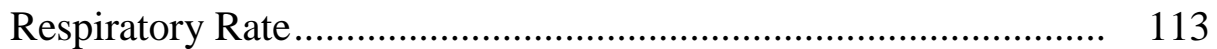

Self-reported Psychological Measures ..................................................... 113

State and Trait Anxiety- STAI ...................................................... 113

Depression, Anxiety, and Stress Scales- DASS 21 ....................... 114

Interviews ............................................................................... 114

Discussion of Major Findings ................................................................ 114

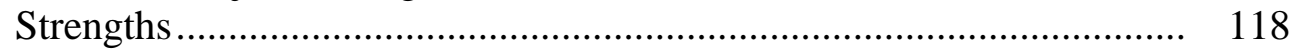

Limitations ...................................................................... 119

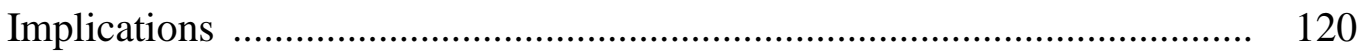

Implications for Applied Practice ..................................................... 120

Recommendations for Future Research.................................................... 122 
Summary of Chapter 5 .

Appendix

A. INFORMED CONSENT FORM _.................................................... 126

B. STAI- Y1 \& Y2 FORM (ENGLISH \& CHINESE VERSIONS) ................ 129

C. DASS 21 (ENGLISH \& CHINESE VERSIONS) .................................. 134

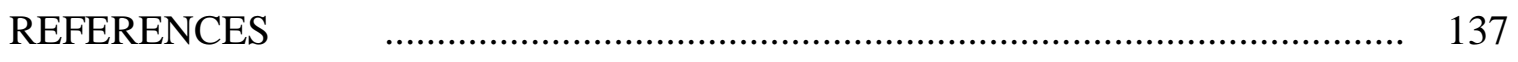

VITA 


\section{LIST OF FIGURES}

1. The Evolution of Chinese Characters [from left (ancient) to right (modern)] ... 20

2. The Five Major Writing Styles of Calligraphy of the Character "Wind":

1) Seal, 2) Clerical, 3) Standard, 4) Running, \& 5) Cursive Script

(from Left to Right)

3. Basic Horizontal, Vertical, and Hooked Strokes and Dots Written

by Participant in the $1^{\text {st }}$ and $2^{\text {nd }}$ Week of Intervention

4. Basic Horizontal, Vertical, Hooked Strokes and Dots and Combining into the Chinese Character "Yong" (永, meaning "eternal") Written by Participant in the $1^{\text {st }}$ and $2^{\text {nd }}$ Week of Intervention

5. Basic Strokes Written by Participant in the $1^{\text {st }}$ and $2^{\text {nd }}$ Week of Intervention ...

6. Sample of Work Done by Participant in the $3^{\text {rd }}$ Week

7. Sample of Work Done by Participant in the $4^{\text {th }}$ Week

8. Sample of Work Done by Participant in the $5^{\text {th }}$ Week

9. Sample of Work Done by Participant in the $6^{\text {th }}$ Week ....................................... 58

10. Sample of Work Done by Participant in the $7^{\text {th }}$ Week

11. Sample of Work Done by Participant in the $8^{\text {th }}$ Week

12. Example of Chinese Calligraphy Handbook Used for Imitation

13. Example of Chinese Calligraphy Handbook Used for Imitation

14. Blood Pressure (Systolic- Pre- \& Posttest)

15. Blood Pressure (Diastolic- Pre- \& Posttest)

16. Heart Rate (Pre- \& Posttest).

17. Respiratory Rate (Pre- \& Posttest). 


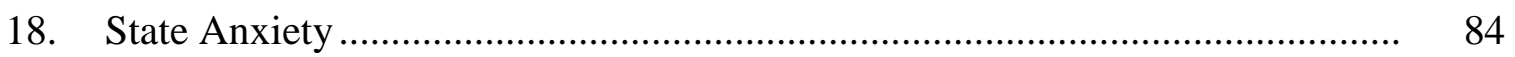

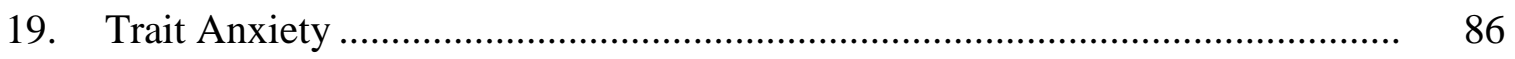

20. Depression Subscale in DASS 21 ............................................................. 88

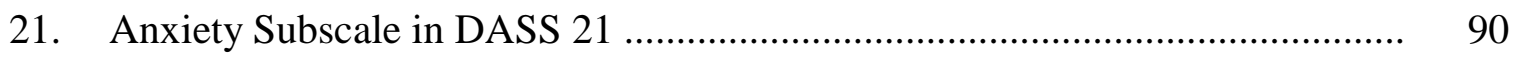

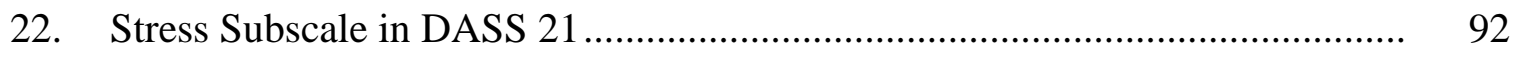




\section{LIST OF TABLES}

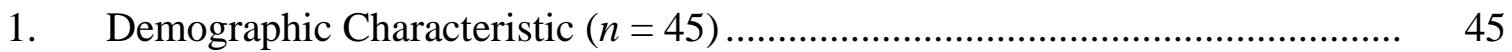

2. Mean, Standard Deviation of Blood Pressure (Systolic-Pretests) ..................... 68

3. ANOVA Summary Table of Blood Pressure (Systolic-Pretests) ....................... 68

4. Mean, Standard Deviation of Blood Pressure (Systolic-Posttest).................... 69

5. ANOVA Summary Table of Blood Pressure (Systolic-Posttest)..................... 69

6. Paired t-tests Results of Systolic Pressure at the $3^{\text {rd }}, 4^{\text {th }} \& 6^{\text {th }}$ Interventions ..... 70

7. Mean, Standard Deviation of Blood Pressure (Diastolic-Pretest).................... 71

8. $\quad$ ANOVA Summary Table of Blood Pressure (Diastolic-Pretest) ..................... 72

9. Mean, Standard Deviation of Blood Pressure (Diastolic-Posttest) .................. 72

10. ANOVA Summary Table of Blood Pressure (Diastolic-Posttest) .................... 73

11. Mean, Standard Deviation of Heart Rate (Pretest) ..................................... 74

12. ANOVA Summary Table of Heart Rate (Pretest)...................................... 75

13. Mean, Standard Deviation of Heart Rate (Posttest) ..................................... 77

14. ANOVA Summary Table of Heart Rate (Posttest) ....................................... 77

15. Paired t-test Results of Heart Rate (Pre- \& Posttest)...................................... 78

16. Mean, Standard Deviation of Respiration Rate (Pretest) ............................. 79

17. ANOVA Summary Table of Respiration Rate (Pretest) ................................ 79

18. Mean, Standard Deviation of Respiration Rate (Posttest)............................ 80

19. ANOVA Summary Table of Respiration Rate (Posttest) ............................... 81

20. $\quad$ Paired t-tests Results of Respiration Rate (Pre- \& Posttest) ........................... 82 
21. Mean, Standard Deviation of State Anxiety ....................................................... 83

22. ANOVA Summary Table of State Anxiety................................................. 83

23. Pairwise Comparison (State Anxiety) …………………................................. 83

24. Mean, Standard Deviation of Trait Anxiety ....................................................... 85

25. ANOVA Summary Table of Trait Anxiety .................................................... 85

26. Pairwise Comparison (Trait Anxiety) ………….............................................. 85

27. Mean, Standard Deviation of Depression Subscale in DASS 21 …................. 87

28. ANOVA Summary Table of Depression Subscale in DASS 21 ...................... 87

29. Pairwise Comparison (Depression) ………………………………......... 88

30. Mean, Standard Deviation of Anxiety Subscale in DASS $21 \ldots \ldots \ldots \ldots \ldots \ldots \ldots \ldots \ldots \ldots . . . \quad 89$

31. ANOVA Summary Table of Anxiety Subscale in DASS $21 \ldots \ldots \ldots \ldots \ldots \ldots \ldots \ldots \ldots \ldots . . . \quad 89$

32. Pairwise Comparison (Anxiety) …………………………………......... 90

33. Mean, Standard Deviation of Stress Subscale in DASS 21 .............................. 91

34. ANOVA Summary Table of Stress Subscale in DASS $21 \ldots \ldots \ldots \ldots \ldots \ldots \ldots \ldots \ldots \ldots \ldots . . . \quad 91$

35. Pairwise Comparison (Stress) ……………………................................ 92 


\section{LIST OF ABBREVIATIONS}

ACT

ADHD

AIDS

BDI

CBT

CFI

CVI

DASS 21

EEG

MAOI

MBMT

MBSR

NPC

PTSD

SNRI

SPSS

SSRI

STAI

TCA
Acceptance Commitment Therapy

Attention Deficit Hyperactivity Disorder

Acquired Immune Deficiency Syndrome

Beck Depression Inventory

Cognitive Behavior Therapy

Comparative Fit Index

Content Validity Index

Depression, Anxiety, Stress Scale Short Version

Electroencephalogram

Monoamine Oxidase Inhibitor

Mindfulness Based Music Therapy

Mindfulness Based Stress Reduction

Nasopharyngeal Carcinoma

Posttraumatic Stress Disorder

Serotonin Norepinephrine Reuptake Inhibitors

Statistical Package for the Social Science

Selective Serotonin Reuptake Inhibitors

State-Trait Anxiety Inventory

Tricyclic Antidepressant 


\section{CHAPTER 1}

\section{INTRODUCTION}

Breast cancer is the most common cancer among women in both developed and less developed countries (World Health Organization, 2014). In addition, it is also the most common cause of cancer death in women, with 508,000 reported deaths in 2011 (World Health Organization, 2014). In the United States and Canada, excluding skin cancer, breast cancer is the most common cancer among women, affecting 1 in 8 women in North America, accounting for $29 \%$ of newly diagnosed cancers in the US (American Cancer Society, 2014), and 26\% in Canada (Canadian Cancer Society, 2014).

Similarly, breast cancer is also the most common cancer among women in modern societies in the East, such as Hong Kong, Malaysia, and Singapore. In Hong Kong, 3,014 new cases of breast cancer were diagnosed in 2010, accounting for $24.1 \%$ of all newly diagnosed cancers (Centre for Health Protection, 2014). Likewise, about 1,100 women were diagnosed with breast cancer in Singapore each year, accounting for 20$25 \%$ of all cancer diagnosed in the country. Hence, there is a worldwide increase in the number of breast cancer patients and survivors (Lim, Devi, \& Ang, 2011).

Generally, cancer is named after the body part in which it originated, so breast cancer refers to the erratic growth and proliferation of cell in the breast tissue (Baqutayan, 2012). Currently, the primary medical treatment for breast cancer is surgery together with adjuvant therapies- chemotherapy, radiotherapy and hormonal therapy. 
With these treatments, many different side effects have been identified. These side effects often have different negative impacts on patients' life, affecting their physical and psychological adjustments to their illnesses in many different ways (Lim et al., 2011). With the advancement in medical technology and aggressive treatments, although the life expectancy of breast cancer patients has been increased, the challenges these patients face when adjusting to these treatments have also increased (So et al., 2009). In other words, the cancer itself and treatment related symptoms become the major factors of stress for female breast cancer patients undergoing treatment for the disease (Li, Zhou, Yan, Wang \& Zhang, 2011).

Research showed that many women experience fluctuation in emotional morbidity as they move through their illness trajectory (McGregor \& Antoni, 2009). Among all the symptoms, anxiety is a prevalent psychological concern perceived by breast cancer patients (Li et al., 2011; Payne \& Endall 1998; So et al., 2010). Anxiety is frequently comorbid with depression, particularly in clinical settings (Hales, Yudofshy, \& Roberts, 2014; Ingram, 2009). Often times, the two psychological disturbances coexist. According to Ingram (2009), some of the occurrence may be accounted for by overlapping diagnostic criteria, such as sleep disturbances, difficulty concentrating, fatigue, loss of energy etcetera. However, even when diagnostic overlap is taken into account, there is still substantial comorbidity between depressive and anxious states (Ingram, 2009). Anxiety is also recognized as a major feature of depression (Doctor, Kahn, \& Adamec, 2008).

Anxiety is a normal response to unpleasant stimuli, and it is helpful for promoting adaptive responses to new demands. However, it can also be harmful when it becomes 
excessive and chronic, for it may weaken one's ability to cope with stress (Lim et al., 2011). According to Kazdin (2000), "Anxiety is an emotion characterized by heightened autonomic system activity, specifically activation of the sympathetic nervous system (i.e., increased heart rate, blood pressure, respiration, and muscle tone), subjective feeling of tension, and cognitions that involve apprehension and worry" (p. 209). Not only are the symptoms of anxiety detrimental to cancer patients, they may also cause other related negative effects. Sharpley, Bitsika, \& Christie (2009) stated,

Some patients may develop symptoms such as fatigue, sleeping difficulties, digestive problems, elevated heart rate, restlessness, muscle tension, sweating trembling, changes in appetite and weight, and loss of energy. Other patients may show pathological worry, prolonged arousal, lowered immune functioning, feeling of helplessness and pessimism. (p. 1146)

Anxiety may also increase feelings of pain for cancer patients, and interfere with their quality of life. Severe anxiety may even shorten the patient's life (Baqutayan, 2012). In addition, anxiety is highly comorbid with other mental and physical concerns, such as mood disorders, personality disorders and physical health condition, with over $90 \%$ of persons with anxiety disorder having lifetime comorbidity with one or more of these problems (Hales et al., 2014).

Research showed that breast cancer patients often experience a high level of distress, and psychological distress is a broad construct encompassing both depression and anxiety (Ng et al., 2017). Among common displays of distress, anxiety is the most common psychological symptom among breast cancer patients, ranging from 10 to $30 \%$ (Ng et al., 2017). Anxiety has been shown to cause fatigue, poor treatment outcome, and has a negative impact on the quality of life, and affecting the immune systems of breast cancer patients (McGregor \& Antoni, 2009). Furthermore, among all types of cancer, the 
prevalence of depression is the third highest among breast cancer patients (GoldenKreutz \& Andersen, 2004). Since anxiety is high in comorbidity with other physical and mental concerns and is found to often coexist with depression common, and given the detrimental impact that anxiety poses on the treatment and recovery process of breast cancer patients, interventions focusing on reducing patient anxiety and comorbid depression levels are needed.

\section{Rationale}

As suffering from breast cancer and going through treatment create many challenges in patients' lives, an examination of literature on breast cancer research showed that anxiety is one of the major challenges and concerns among breast cancer patients (Drageset, Lindstrom, Giske, \& Underlid, 2011; Esch, Roukema, Van der Steeg \& De Vries, 2011; Li et al., 2011). It is not a surprise to know that anxiety is commonly reported in cancer patients, for they are facing a real threat to their life. Research demonstrated that anxiety and emotional distress persist throughout the disease from the moment cancer is suspected to diagnosis, treatment, and beyond (Carlson \& Bultz, 2003). Anxiety and distress can also affect treatment and play a role in a patient's overall quality of life (National Cancer Institute, 2014).

Research shows that about $42 \%$ of women who had undergone mastectomy suffered from anxiety and it is also prevalent in women with breast cancer who are undergoing adjuvant therapies, especially chemotherapy. This indicates that anxiety is a common psychological symptom that is ubiquitous in this population for all treatment stages (Lim, Devi, \& Ang, 2011). A common anxiety in breast cancer patients is an associated fear of death- death anxiety, as a result of their symptoms (Baqutayan, 2012; 
Drageset et al., 2010). According to Pollak, death anxiety is higher for people with lower senses of "effectiveness, mastery, and power", and lower for people with higher levels of self-esteem and feeling of "meaning and purpose" (Blando, 2011, p. 93). Not only is anxiety common among breast cancer patients, even after cancer treatments, patients continue to face complex emotional difficulties, such as changes in roles and responsibilities, changes in relationships (Dow, Ferrell, Haberman, \& Eaton, 1999), or changes of employment status (Hewitt, Breen, \& Devesa, 1999).

Segerstrom and Miller (2004) showed that elevated levels of anxiety can negatively affect our body in many different ways, including weakening the body's physiological regulatory mechanisms and immune system and reducing the numbers of nature killer cell cytotoxicity. Persistent anxiety in older cancer patients, may have particularly profound weakening effects, for the immune system looses flexibility with age and is less able to adapt to stressors. Hence, research also found that emotional distress has been associated with changes in gene function, damage to DNA, and poorer DNA (Baum, Revenson \& Singer, 2012). And DNA repair pathways are an integral part of the cause of breast cancer (McGregor \& Antoni, 2009).

In addition, chronic anxiety may also change patients' health behaviors, which may influence the course of their disease process. Negative health behaviors, such as more consumption of high-fat food, more alcohol intake and less exercise will lead to DNA damage and decreased DNA repair (McGregor \& Antoni, 2009). Other negative consequences of chronic or pathological anxiety may include migraines, chronic fatigue, obesity, hypertension (Lindsey, West, \& Carrienri-Kohlman, 1993), and panic disorders (Rosen \& Schulkin, 1998). 
Anxiety has been shown to coexist with depression (Ingram, 2009), and both symptoms are common and have tremendous impact on breast cancer patients (Ng et al., 2016). This is important as it has been shown that cancer patients with coexisting anxiety and depression tend to have severe symptoms, extended healing times, worse outcomes and greater burden on healthcare resources (Hirschfeld, 2001).

As anxiety and comorbid depression are common concerns among breast cancer patients, and have negative impacts on the course of their disease, treatment and recovery process, increased attention is required in the psychosocial intervention research on reducing the anxiety level of breast cancer patients (Pedersen, Sawatzky, \& Hack, 2010). Traditional psychosocial support for breast cancer has been found in mutual support groups, relaxation training and psychoeducation workshops. More recent studies showed that imagery (Freeman et al., 2008) and mindfulness-based stress reduction programs (Carlson \& Bultz, 2003) report positive outcomes in reducing distress and improving quality of life. Although there are effective interventions for stress reduction, a wider range of options are needed for those who do not benefit from the treatments available. More efficacious methods are also needed.

Although Chinese calligraphy is not a well-established method for anxiety reduction or mood improvement, recent research shows that Chinese calligraphy has a slowing effect for cancer patients' physiological arousal parameters and improving mood disturbance (Yang, Li, Hong \& Kao, 2010). Results showed that Chinese calligraphy handwriting lowered participants' systolic blood pressure, heart rate and respiratory rate (Yang et al., 2010), suggesting that Chinese calligraphy offers a promising approach to improved health in cancer patients. 
Earlier Chinese calligraphy research results also indicated that subjects experienced relaxation and emotional calmness when they were practicing Chinese calligraphy. The effects included decelerated respiratory rate, lower heart rate, and a decrease of blood pressure (Kao, 2010; Yang et al., 2010). The question is thus asked: Is the practice of Chinese calligraphy beneficial and effective in reducing anxiety and comorbid depression levels among breast cancer patients? Since there is no research has been done on calligraphy and breast cancer patients, the question is well worth exploring.

\section{Purpose of the Study}

As anxiety and comorbid depression are prevalent psychological symptoms and have negative impacts on breast cancer patients, effective intervention is needed for this population. Chinese calligraphy is found to have significant effects on participants' cognitive activation, physiology slow down and emotional stability (Kao, 2010). It may turn out to be an effective approach for breast cancer patients in terms of anxiety reduction. The purpose of this study is to examine the effects of Chinese calligraphy on reducing the anxiety and comorbid depression levels of breast cancer patients in Hong Kong.

\section{Conceptual Framework}

\section{Existential Anxiety}

Historically, philosophers and researchers have sought to explain the definition and the origin of anxiety. The Danish philosopher, Soren Kierkegaard, in The Concept of Anxiety, described anxiety or dread associated with the "dizziness of freedom" and suggested the possibility to resolve anxiety through self-conscious exercise (Gron, 1952). 
The theologian Paul Tillich characterized existential anxiety as "the state in which a being is aware of its possible nonbeing" He categorized three types of nonbeing awareness resulting anxiety: ontological (fate and death), moral (guilt and condemnation), and spiritual (emptiness and meaninglessness). Tillich regarded these forms of existential anxiety as realities in individual life (Wildman, 1994). Sigmund Freud called anxiety an affective state. He proposed that anxiety originated in response to the trauma of birth in which the first experience of "danger" occurs. According to Freud, this response "will be regularly reproduced thenceforward when such a situation occurs" (Gagnon, 1998. p.72).

Doctor et al. (2008) mentioned that fear of death and anxiety over dying, also known as thanatophobia, is one of the most universal fear, and may be the basis for many phobia. Some people fear death because of its unknown aspects. As breast cancer is a threatening disease that affects patients' physical and psychosocial wellbeing in many different ways, it is not surprising to recognize that patients are struggling with existential issues.

\section{Meditation and Mindfulness Theories}

Meditation has been shown to be helpful in the treatment of physical disease, such as cancer and Acquired Immune Deficiency Syndrome (AIDS) (Miller, 1999). Meditation practice is often identified as a relaxation technique (Miller, 1999), and has received attention within clinical practices in the United States in the past several decades to examine its impact on stress responses related to anxiety or physiological distress. Coming from Eastern traditions, where physical, psychological, and spiritual aspects of 
the self are seen as interconnected, meditation is believed to be an approach to develop mindfulness at any of the three levels (Miller, 1999).

According to Huxley, meditative practice is best understood as "tapping into universal potential for the human mind to transcend its preoccupation with negative experiences- with fear, anxiety, anger, and obsession- and to become more comfortable with the experiences of compassion, acceptance, and forgiveness" (Miller, 1999, p. 68). Meditation is found to be effective in treatment of chronic pain (Kabat-Zinn, 1982; Kabat-Zinn, Lipworth, \& Burney, 1985, addiction (Alexander, Robinson, \& Rainforth, 1994; O'Connell \& Alexander, 1994), and anxiety disorders (Kabat-Zinn et al., 1992).

One of the relaxation effects of meditation comes from its ability to help one to step aside from his/ her mental and subjective functioning, and become an observer of one's own thoughts. It is in this way that meditation is similar to a behavioral technique called self-monitoring, in which clients are asked to observe or to keep record of their ongoing thoughts or behavior (Miller, 1999). Chinese calligraphy is considered a brush meditation that can achieve relaxation and harmony of the body and the mind (Davey, 1999), which are essential for physical and psychological functioning.

Langer (1989) described a cognitive theory of mindfulness and its relation to health promotion and disease prevention. Mindfulness refers to a practice of being fully mindful in the present moment and to be aware of the full range of experiences that exist in the here and now (Matchim, Armer \& Steward, 2011). It is about bringing an individual's attention to the present experience on a moment to moment basis (Miller, 1999). Mindfulness is based on an attitude of acceptance rather than judging one's experience as good or bad, health or sickness, accepting all personal experience, 
including thoughts, emotions, or events as just "what is" in the present moment (Miller, 1999). This attitude of acceptance often helps people transcend their negativity. Rinpoche (1992) mentioned:

The practice of mindfulness defuses our negativity, aggression, and turbulent emotions... Rather than suppressing emotions or indulging in them, here it is important to view them, and your thoughts, and whatever arises with an acceptance and generosity that are as open and spacious as possible. (p.123)

Traditional Chinese calligraphy emphasizes self-cultivation and mindfulness, and provides a creative outlet for individuals to enjoy every moment of 'presentism' (Hue, 2009). With the emphasis on the 'slow down' and 'concentrate' in every brushstroke unhurriedly, Chinese calligraphy provides foundation and opportunities for practicing breathing exercises (Hue, 2009), which promotes physical relaxation and emotional calming effects for the writers.

\section{Research Question}

This study examines one question: To what extent does Chinese calligraphy reduce the anxiety and comorbid depression levels among breast cancer patients in Hong Kong?

\section{Research Hypotheses}

Two hypotheses were produced from the research question:

1. There is a physiological slowing effect in blood pressure, heart rate, and respiratory rate on breast cancer patients after practicing Chinese Calligraphy handwriting. 
2. Breast cancer patients who participate in this study will have a reduction score on their anxiety and comorbid depression level after Chinese calligraphy intervention.

\section{Significance of the Study}

Worldwide, breast cancer is the most common cancer among women. Anxiety is the most prevalent psychological symptom of breast cancer patients, negatively affecting their physical and mental health. Research showed that many breast cancer patients experienced fluctuation in emotional morbidity as they move through their illness trajectory (McGregor \& Antoni, 2009). Symptoms of anxiety include fatigue, sleep difficulties, elevated heart rate, increased blood pressure, digestive problems, restlessness, prolonged arousal, lowered immune functioning, and feelings of helplessness, etc. (Sharpley et al, 2009). Many researchers showed that chronic anxiety can negatively affect our body, such as weakening immune systems and physiological regulatory mechanism (Segerstrom \& Miller, 2004). In view of the detrimental effects of anxiety, and the growing number of female breast cancer patients, the need to investigate effective interventions for anxiety is essential.

Since research show that Chinese calligraphy has significant effects on subjects' cognitive activation, emotional stability and physiological slow down (Kao, 2010) and has long been used as a spiritual practice in promoting one's self cultivation, and selfawareness (Hue, 2009), it has the potential to be used as an intervention for anxiety reduction. Most psychotherapeutic approaches, including the psychoanalytic therapy, existential therapy, person-centered therapy, behavior and cognitive behavior therapy, family systems therapy and postmodern approaches, are developed out of the western 
culture and involve talking. In general, regardless of different theoretical orientations, psychotherapy is a collaborative treatment process based on the relationship between an individual and a therapist. The process often grounded in dialogues. Therapist provides a safe and supportive environment that allows the individual to talk openly about his/ her issues (American Psychological Association, 2017). In individualistic cultures, individuals facing problems are encouraged to be verbally expressive therefore it is not a surprise that verbal expressive therapy is common and can achieve a positive outcome.

However, in other Asian societies, verbal and even facial expression of one's emotions such as anger or sadness is not deemed appropriate and often time is considered as being immature. Research showed that collectivistic cultures like Japanese culture which emphasizes on expression suppression in social life to promote calmer states at individual life (Ehring, Caffier, Schnulle, Fischer, \& Gross, 2010). For individuals in these cultures, encouragement of verbal expression may not achieve the same positive result as it may contradict with their upbringing. Therefore, cultural consistency of an individual's culture and their selected psychotherapy treatment method and an individual's cultural receptiveness to different interventions are to be considered during therapy selection. Although psychotherapy will continue to be a verbally mediated process, the inclusion of non-verbal methods to promote positive changes with populations not very responsive to verbal expressive therapy would be valuable (Malchiodi, 2006). This research study intends to discover if Chinese calligraphy is an effective alternative approach to anxiety reduction for breast cancer patients with a Chinese cultural background. 


\section{Definition of Terms}

In this study, the following terms are defined, and presented as below:

Affective Blunting: The person's range of emotional expression is clearly

diminished; poor eye contact; reduced body language.

Alogia: A poverty of speech, such as brief, empty replies.

Anhedonia: A loss of capacity to feel pleasure.

Anxiety: An emotion that is characterized by feelings of tension, worry, and

stress as well as physiological changes such as increased blood pressure (Kazdin, 2000).

Most of the breast cancer patients defined anxiety as "a mental condition." Worry, tension, fear, and stress are interrelated to anxiety and depression among cancer patients (Baqutayan, 2009).

Avolition: Inability to initiate and persist in goal- directed activities, such as school or work.

Associality: Inability to feel intimacy and closeness.

Breast cancer: A malignant tumor in the breast issue or area. Most sufferers are female, but some men contract breast cancer.

Breast surgery: Commonly refers to mastectomy and lumpectomy, of vary extensiveness.

Chemotherapy: The use of drugs to treat cancer. These drugs often cause nausea and vomiting, and temporary baldness.

Chinese calligraphy: The writing of Chinese characters by hand using a softtipped brush, and was traditionally regarded in China and Asian countries one of the fine arts. 
Cognitive activation: Stimulation of mental process of knowing.

Comorbidity: Refers to the co-occurrence of two or more disorders.

Comorbid depression: Refers to depression that occurs in the presence of another

illness. As used in this study, the term mainly refers to depression that occurs with anxiety.

Meditation: The term of meditation refers to a broad of variety of practices that includes techniques designed to promote relaxation, build internal energy or life force and develop compassion, love, patience, generosity and forgiveness

Mindfulness: A psychological concept in which an individual brings his/ her complete attention to the present experience on a moment-to-moment basis. It is a process of regulating attention in order to bring a quality of non-elaborative awareness to current experience and a quality of relating one's experience with an orientation of curiosity, experiential openness, and acceptance (Kabat-Zinn, 2003).

Radiotherapy: The use of ionizing radiation to form ions in the cells, killing cells or changing genes such that the cell cannot grow.

Sharpening: To enhance or to become more sensitive.

Stages of Cancer: There are five basic stages of breast cancer (Doctor et al., 2008):

Stage 0: Known as carcinoma in situ. In this early stage, there are abnormal cancer cells that have not invaded the breast tissue.

Stage I: An early stage of invasive breast cancer, the tumor is two centimeters or less in size. Cancer cells have not spread beyond the breast at this stage. 
Stage II: There are 3 possible circumstances. First, the tumor may be as small as in stage I, but the cancer has spread to the underarm lymph nodes. Second, the tumor is two-five centimeters and cancer has spread to the underarm lymph nodes. Last, the tumor is greater than five centimeters but it has not spread to the underarm lymph nodes.

Stage III: Locally advanced cancer which may be large but they have not spread beyond the near-by lymph nodes or breast. This stage also includes other cancers that include a spread to the lymph nodes.

Stage IV: The most advanced stage of breast cancer, is distant metastatic cancer, which means that the cancer has spread to the other parts of the body. When cancer has metastasized, it can be treated but it cannot be cured.

State Anxiety: A temporary and changing emotional state involving feelings of tension and apprehension and increased autonomic nervous system activity. It is a response to a specific situation (Doctor et al., 2008).

Trait Anxiety: Trait anxiety refers to a general, persistent pattern of responding with anxiety. Trait anxiety resembles timidity and indicates a habitual tendency to be anxious over a period of time in many situations (Doctor et al., 2008).

Verbal expressive therapy: As used in this study, the term mainly refers to talkonly therapy.

\section{Limitations}

Since Chinese calligraphy is not an established therapy, there is no special guideline for using it as a therapeutic intervention in psychotherapy. One of the major 
limitations in this study is lack of a set of established procedures to implement in the intervention. The second limitation is that since Chinese calligraphy has a strong root in Chinese culture, there may be difficulties generalizing the results of its effects to other cultures. For people who are unfamiliar with calligraphy, the process may actually create stress (Yang, et al., 2010).

\section{Overview of the Research Methodology}

This study is a one group quasi-experimental design in which breast cancer patients' psycho-physiological arousal parameters (assessed by systolic and diastolic blood pressure, respiration rate, and heart rate) were measured repeatedly at before and after the Chinese calligraphy handwriting, per session. Participants' anxiety levels (using the State-Trait Anxiety Inventory, and the Depression, Anxiety and Stress Scales 21) were measured at baselines, during treatment (after 4-weeks intervention), and post treatment (after 8-weeks intervention). All participants in this study have received training and practice Chinese calligraphy in a quiet room. Each session of calligraphy writing lasts about 90 minutes, one session per week for 8 consecutive weeks. Participants were also encouraged to practice calligraphy at home during the study period. Repeated measures analysis of variance and paired sample t-tests were used to analyze the data.

\section{Organization of the study}

This study is organized into five chapters. Chapter 1 serves as an introduction and contains the rationales of the study, the purpose, problem statement and hypothesis, significance, theoretical framework, definition of terms, the limitation and delimitation of 
the study. Chapter 2 contains a review of the literature. Chapter 3 focuses on the methodology, including the design, sample selection, data collection methods, and data analysis. Chapter 4 presents and discusses the results. Finally, the conclusion based on the results and recommendations for further study are presented in Chapter 5. 


\section{CHAPTER 2}

\section{REVIEW OF LITERATURE}

\section{Introduction}

To explore the effects of reducing the anxiety level of breast cancer patients, the literature review addresses mainly the following: what is known regarding the effects of Chinese calligraphy and current effective interventions for breast cancer patients in anxiety reduction. In this chapter, a historical perspective and overview on Chinese calligraphy is first presented. Following are the current findings of the effects of Chinese calligraphy on both non-clinical and clinical populations. Next, other current effective interventions or treatments aimed at reducing anxiety or emotional distress for breast cancer patients are presented. Finally, related research issues are discussed.

\section{Chinese Calligraphy: Historical Perspective}

The word "calligraphy" is derived from the Greek words kallos and graphe, meaning "beautiful handwriting". The Chinese name for calligraphy is shufa, which literally means "the method of writing". It is handwriting of Chinese characters with ink using a soft-tipped brush. Historically, it was a common tool of communication in ancient China, and it was also regarded as one of the most respected traditional arts, and it is still held in high regard today (China Today, 2012). Although calligraphy is no longer a common form of communication today, it occupies a distinguished position among 
traditional arts in China (Cai, 2011), and some Asian countries, such as Japan (Davey, 1999).

In order to understand the effects of Chinese calligraphy in general, one must first realize the differences between the Eastern and Western languages in their written configurations. Most languages, including English, use limited phonetic symbols or alphabets to represent the sounds making up individual words in written forms. However, some Eastern languages, such as Chinese and Japanese, use a large amount of pictographs and symbols to represent words, concepts and ideographs, each of which has a particular meaning (Davey, 1999). Ancient Chinese characters are considered hieroglyphics. Although over the centuries, some of the characters underwent some evolutions, the meaning of the graphs, for the most part, has been maintained (Nelson, 2007). In fact, many modern Chinese characters are still literally abstract and abbreviated pictures (Davey, 1999). Figure 1 shows the evolution of some Chinese characters.

Chinese calligraphy is an art of strokes and structure of Chinese characters. Because of the abstract, pictographic characteristics of Chinese written characters, Chinese character writing involves a process of visual spatial structuring. Each character is written within an imaginary, subdivided square in which the execution of its strokes, the shaping, and the spacing and framing of the characters occur (Kao, 2006). And with the inking effects of a soft Chinese brush, rather than a ballpoint pen or pencil, calligraphy writing transforms the flat surface into an imaginary 3-dimensonal reality (Yang et al., 2010). 


\begin{tabular}{|c|c|c|c|c|}
\hline & $\begin{array}{l}\text { Oracle } \\
\text { Bone }\end{array}$ & $\begin{array}{c}\text { Greater } \\
\text { Seal }\end{array}$ & $\begin{array}{c}\text { Lesser } \\
\text { Seal }\end{array}$ & Modern \\
\hline $\begin{array}{l}\text { man } \\
\text { (rén) }\end{array}$ & $\lambda$ & & & \\
\hline $\begin{array}{l}\text { woman } \\
\text { (nǘ) }\end{array}$ & & & & \\
\hline $\begin{array}{l}\text { ear } \\
\text { (ěr) }\end{array}$ & & & & \\
\hline $\begin{array}{l}\text { fish } \\
\text { (ví) }\end{array}$ & & & & \\
\hline $\begin{array}{l}\text { sun } \\
\text { (ri) }\end{array}$ & & & & \\
\hline $\begin{array}{l}\text { moon } \\
\text { (yuè) }\end{array}$ & & & & \\
\hline $\begin{array}{l}\text { rain } \\
\text { (viü) }\end{array}$ & & min & & \\
\hline $\begin{array}{l}\text { cauldron } \\
\text { (dǐng) }\end{array}$ & M숴 & $\frac{5}{7}$ & 배 & 转 \\
\hline $\begin{array}{l}\text { well } \\
\text { (jîng) }\end{array}$ & & \# & $\frac{t}{1+}$ & \\
\hline $\begin{array}{l}\text { above } \\
\text { (shàng) }\end{array}$ & & & & \\
\hline $\begin{array}{l}\text { down } \\
\text { (xià) }\end{array}$ & & - & & \\
\hline
\end{tabular}

Figure 1. The Evolution of Chinese Characters [from left (ancient) to right (modern)] 
Over the centuries, Chinese calligraphy has been developed into five different major styles (see Figure 2): the seal script (Zhuan shu), clerical script (li shu), regular script (kai shu), running script (xing shu), and cursive script (cao shu). Each style is distinguished from the others by its own specific features (Cai, 2011), and can be further subdivided into several schools: for example, the running script's main subdivisions are regular running script and cursive running script (China Today, 2012).

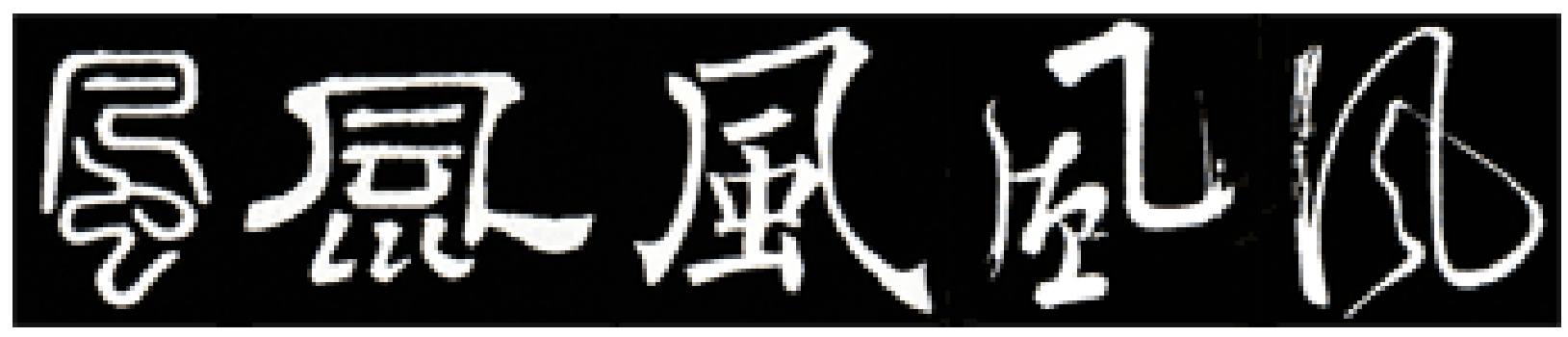

Figure 2. The Five Major Writing Styles of Calligraphy of the Character "Wind": 1) Seal, 2) Clerical, 3) Standard, 4) Running, \& 5) Cursive Script (from Left to Right).

Traditionally, other than its aesthetic values, Chinese people believe that calligraphy can enhance an individual's self-cultivation and self-reflection:

Since ancient times, Chinese people have held the opinion that practicing calligraphy cultivates one's character and nourishes the soul. The idea is deeply ingrained in the collective Chinese conscience. There is an old adage in Chinese: 'Calligraphy is a true reflection of spirit'- i.e., calligraphy reveals a person's personality and gives expression to their joys and sorrows. (China Today, 2012)

Therefore, calligraphy handwriting is often thought to be most revealing of one's personality (Yang et al, 2010).

In addition to the traditional belief that calligraphy enhances self-cultivation, Chinese calligraphy is an activity for promoting longevity and better quality of life (Hough, 2008), because the writing process requires full concentration and mind-body 
harmony of the writer. Davey (1999) mentioned, "In Asia, it has traditionally been held that shodo (calligraphy) and sumi-e experts enjoy exceptional health as well as longevity due to their cultivation of fine posture, calm and deep breathing, and physical flexibility" (p.71). The kings, leaders, and scholars throughout the history of China practiced calligraphy, because of its many benefits (Hough, 2008).

\title{
The Effects of Chinese Calligraphy on Non-clinical and Clinical Populations
}

\author{
Non-clinical Populations
}

After conducting research on Chinese calligraphy for the last three decades, Henry Kao (2010) asserts that the effects of practicing Chinese calligraphy include cognitive activation, physiological slowdown, emotional stability and perceptual sharpening. According to Kao (2010), research showed that there is much evidence in successful applications in both clinical and nonclinical samples. In nonclinical subjects, one of Kao's studies showed that participants experienced relaxation and emotional calmness during calligraphy writing (Kao, Lam, Robinson, \& Yen, 1989, cited in Kao, 2010). Major physiological effects include: 1) decreased heart rate in the first 10 seconds of brush writing; 2) greater control of breathing during writing; 3) greater reduction in blood pressure for experienced writers (10 years or more) when compared with novice writers (Kao, 2010).

Kao and others also investigated the effects of calligraphy writing in different nonclinical populations, including managers and administrators (Guan, Ng, \& Kao, 2000), university students and healthy elderly (Kao, Miao, Luo \& Gao, 2006), non-native Chinese speakers/ foreigners (Yum \& Kao, 1999), and children (Huang, Chan \& Kao, 
2000). Major benefits include: decreased state anxiety level, increased attention and concentration (university students, healthy elderly \& children), decreased inattention and impulsivity (children) and improved self-awareness, self-concept, and interpersonal interactions (children).

In the study of non-native Chinese speakers (foreigners), Yum \& Kao (1999) found that for foreigners who knew Chinese, participants' state anxiety levels were reduced. The scores on the "anxiety", "depression", "vigor", "fatigue" and "confusion" subscales were also reduced. For foreigners who did not know Chinese, there were reduction on the "anxiety", "depression", "hostility" and "confusion" subscales, after calligraphy training. These findings suggest that Chinese calligraphy improved writers' emotions.

The cognitive effects of Chinese calligraphy have also been explored. According to Kao (2010), research results suggest that Chinese calligraphy handwriting may enhance certain aspects of visual perception and cognitive function, including: (1) improved general attention; 2) facilitated the visual-spatial abilities, (3) improved performance in figure identification and discrimination tasks, and (4) improved abilities in perceptual speed and accuracy, abstract reasoning, short-term memory and pictorial memory. In a study with normal elderly individuals, the results showed that spatial ability and pictorial memory of the participants were improved (Kao, Gao, Wang, Cheung \& Chiu, 2000).

Another study found that Chinese calligrapher's Electroencephalogram (EEG) activities in the right hemisphere were significantly greater than those in the left hemisphere during writing (Kao, Shek, Chau, \& Lam, 1986, cited in Kao 2010). Overall, 
Kao (2010) concluded that the effects of Chinese calligraphy include two major areas: (1) facilitating a state of physiological slowdown and psychological quiescence, and (2) increasing cognitive activation and perceptual sharpening.

\section{Clinical Populations}

Research studies have also been done by Kao and others to explore the effects of Chinese calligraphy therapy on clinical populations, with the purpose of promoting general health and facilitate behavioral changes. Participants of these research studies can be divided into five categories: 1) children with childhood disorders (Autism, Attention Deficit Hyperactivity Disorder [ADHD], mild mental retardation and Posttraumatic Stress Disorder [PTSD]); 2) patients with elderly disorders (Alzheimer's and stroke); 3) patients with psychosomatic diseases (hypertension and diabetes); 4) patients with mental and mood disorders (schizophrenia, neurosis and depression); and 5) patients with cancer (Nasopharyngeal Carcinoma). Results suggested that the therapeutic effects of calligraphy are promising (Kao, 2010).

\section{Children with Childhood Disorders and Posttraumatic Stress Disorder (PTSD)}

Among research regarding childhood disorders, one study found that calligraphy handwriting can improve ADHD children's selective attention, spontaneous and sustained attention, as well as communication (Kao, Chen, \& Cheng, 1997). Another study, an 8-week calligraphy treatment on children with autism, showed that there were improvements on participants' general negative behavior, group negative behavior and communication within the family and at school (Kao, Lai, Fok, Gao, \& Ma, 2000e). 
In a study of children with mild mental retardation, the results showed an increase of participants' visual attention, auditory attention, reasoning, judgment and cognitive speed and accuracy, hand steadiness and control precision as well as improvement in problem behaviors (Kao, Hu, Zhang, 2000d, cited in Kao, 2010). For children with PTSD, among the three core symptoms- "super arousal", "avoidance" and "intrusion", Zhu et al (2010) found that participants' "avoidance" and "intrusion" levels were effectively alleviated after calligraphy training.

\section{Patients with Elderly Disorders}

In research studies of patients with elderly disorders, Kao (2003) found that calligraphy treatment significantly improved Alzheimer's patients' performance on verbal ability and short-term memory, while the control group showed no such improvement. Similarly, in their study of stroke patients undergoing rehabilitation, Chiu, Kao \& Ho (2002, cited in Kao, 2010) found that participants showed significant improvement in palm strength of the affected hands and fine motor coordination after a 2week calligraphy treatment. In addition, visual attention and motor agility were also enhanced.

\section{Patients with Psychosomatic Diseases}

For patients with psychosomatic diseases, Guo, Kao \& Liu (2001) found that after calligraphy writing practice, patients with hypertension showed a significant reduction in both systolic and diastolic blood pressure, comparing with the pre-writing condition. In a related study, participants' anxiety score was reduced, an increase in alpha wave patterns, and a decrease in heart rate were also indicated after calligraphy training. Specifically, 
introverted patients had greater blood pressure reduction than extroverted patients (Kao, Guo \& Liu, 2010). Stress-related conditions of Diabetes II patients were also explored. Results showed that calligraphy intervention significantly reduced their state anxiety level as well as distress level (Kao, Ding \& Cheng, 2000a cited in Kao, 2010).

\section{Patients with Mental and Mood Disorders}

The effects of Chinese calligraphy on patients with mental and mood disorders (schizophrenia, depression, and neurosis) were explored. In a study of schizophrenic patients, Fan, Kao, Wang \& Guo, (1999 cited in Kao, 2010) found that all negative symptoms of the participants, including "avolition", "alogia", "affective blunting", “anhedonia- associality" levels were improved, when there was no significant change found in the positive symptoms (i.e., delusion, hallucination, bizarre behaviors). In addition, according to Fan et al (1999), after three months of calligraphy training, schizophrenic patients' hospital behaviors, including "interpersonal relationships" as well as "moods" were also positively improved. Furthermore, participants' state anxiety levels were reduced.

Similar improvements on emotional status have also been found in patients with depression and neurosis. Participants' negative emotions, including “depressed”, "annoyed", "antagonistic", and "confused" were significantly improved (Kao, 2010). In a study of patients with anxiety disorder, Dong, Jia, Wang, \& Zhang (2006) found that using calligraphy treatment along with medications was more effective in reducing anxiety symptoms than using medications alone. 


\section{Cancer Patients}

In 2010, Yang and colleagues studied the effects of Chinese calligraphy and relaxation training in Chinese nasopharyngeal carcinoma patients (NPC). The study was a randomized control trial. Ninety NPC patients were recruited and randomized into one of the three treatment groups: 1) progressive muscle relaxation and imagery training, 2) calligraphy handwriting, 3) or a control group. Physiological arousal parameters, including heart rate, blood pressure and respiratory rate were measured at pre- and posttreatment. The Symptoms Distress Scale, the Profile of Mood State-Short Form, and the Karnofsky Performance Status were also used to measure psychological symptoms at baseline, during treatment, post-treatment and after a two-week follow-up.

Results showed that both calligraphy handwriting and relaxation training had slowdown effects on physiological arousal parameters, including slower heart rate, decreased blood pressure, and decelerated respiration. Moreover, calligraphy practice gradually lowered participants' systolic blood pressure and respiration, though with a smaller effect size compared to the relaxation group. Further, both calligraphy and relaxation training had symptom relief and mood improvement effects on NPC patients. Specifically, relaxation training was effective in relieving symptoms of insomnia, while calligraphy improved patients' concentration level, and reduced their mood disturbance

scores on the "Depression-Dejection", "Anger Hostility" and "Fatigue-Inertia" subscales (Yang et al, 2010). 


\section{General Approaches to Treatment of Anxiety}

Cognitive-Behavior Therapy (CBT)

Most patients with anxiety prefer treatment of anxiety with psychotherapy administered or in combination by medication (Hales et al., 2014). Among the therapeutic approaches for anxiety disorders, Cognitive Behavior Therapy (CBT) has the most robust evidence for efficacy (Hales et al. 2014). Cognitive Behavior Therapy is a short-term treatment approach (usually 10-20 weekly sessions) which combine both cognitive and behavioral principles and methods (Corey, 2005). Although more than twenty different therapies have been label "cognitive" or "cognitive behavioral" (Corey, 2005), the CBT approach usually has some core components, including psychoeducation, relaxation training, cognitive restructuring, and exposure therapy (Hales, et al. 2014).

Psychoeducation involves helping patients understand the normal and abnormal nature of anxiety, as well as the sources and meaning of anxiety. The cognitive model of anxiety proposes that people often overestimate the danger in a particular situation and underestimate their ability to cope with the situation (Hales et al. 2014). Techniques such as systematic desensitization- gradually exposing the individual to the anxiety-provoking situation is a common intervention. Other techniques in CBT include relaxation training through deep muscle relaxation and breathing exercise (Hales et al. 2014).

\section{Acceptance and Commitment Therapy (ACT)}

Besides CBT, there are other approaches of psychotherapy that can be considered in treating anxiety. Psychodynamic therapy may be a reasonable treatment option (Milrod et al., 2007), although more research is needed on its treatment effectiveness. Acceptance and Commitment Therapy (ACT) is another possible good option (Hales et al., 2014). 
Acceptance and Commitment Therapy is developed by Hayes and colleagues in 1999, and has 3 main phases (Martin \& Pear, 2015). First, through the use of metaphors, paradox, stories, and other verbal techniques presented by the therapist, the client learns that past attempts to control troublesome thought and emotions have often increase the frequency of such thought and emotions. Second, through the use of mindfulness training and acceptance exercises, the client learns to experience nonjudgmentally embrace thoughts and emotion, including those that are troublesome. This phase is the "Acceptance" portion of the therapy. In this phase, the client learns to "be with"accepting worrisome thoughts and unpleasant feeling. Third, regardless of whether the troublesome thoughts and emotions are eliminated, clients are encouraged to identify values in various life domains. In other words, they are encouraged to identify valued goals in their lives. This phase is the "Commitment" portion of the therapy (Martin \& Pear, 2015).

\section{Other Forms of Psychotherapy}

Newer psychotherapies such as Mindfulness Based Stress Reduction (MBSR), and various therapies that target emotion regulation are considered as possible good choices (Hales et al. 2014). MBSR is a relatively new and effective intervention of anxiety reduction for cancer patients. The approach and related research of MBSR on breast cancer patients will be presented in the next section of this chapter.

\section{Pharmacotherapy}

Pharmacotherapy is considered a good option for many patients with anxiety disorders, either in combination with CBT or as a stand-alone treatment (Ravindran and 
Stein, 2010). The Selective Serotonin Reuptake Inhibitors (SSRIs) are considered as the first-line pharmacotherapy agents for patients with anxiety because of their overall levels of efficacy, safety, and tolerability. Serotonin Norepinephrine Reuptake Inhibitors (SNRIs) (venlafaxine ER, desvenlafaxine, duloxetine, and milnacipran), are also commonly used (Hales et al. 2014).

After the introduction of SSRIs and SNRIs, former commonly used medications such as Tricyclic Antidepressants (TCAs) and Monoamine Oxidase Inhibitors (MAOIs) which are less tolerated than the SSRIs and SNRIs, are rarely used for treating patients with anxiety disorders currently. Benzodiazepines play a secondary role in terms of pharmacological treatment of choice. Although they are frequently safe and beneficial, their risks must be considered on a case-by-case basis (Hales el al. 2014).

\section{Current Effective Interventions on Anxiety Reduction for Cancer Patients}

Currently, besides standard cancer treatments, which include surgery, chemotherapy, radiotherapy and hormone therapy, there are some treatments aimed at the overall improvement of general health and wellbeing for breast cancer patients. These interventions are often referred to as complementary or adjuvant treatment, as they are used along with standard therapies (Hewitt, Herdman \& Holland, 2004). It has been well documented in the literature that a variety of psychosocial interventions have been found effective in reducing psychological and physiological symptoms of stress in cancer patient and improve overall quality of life.

After reviewing 31 randomized studies in women with breast cancer, Hewitt and colleagues (2004) gave a summary that there is evidence of the benefit of relaxation, 
hypnosis and imagery interventions in early stage breast cancer, group interventions in both early and metastatic breast, and individual intervention in the early setting. These results are also supported by non-randomized studies. Hewitt et al (2004) concluded, "Psychosocial intervention can be expected to reduce psychiatric symptoms and improve quality of life in routine clinical care of breast cancer" (p.129).

\section{Relaxation and Imagery Interventions}

Relaxation and imagery interventions were found effective in improving mood disturbance of breast cancer patients in many studies. In a study of early stage breast cancer patients in the United Kingdom, Bridge, Benson, Pietroni \& Priest (1998) randomized 154 patients who were undergoing radiotherapy to one of three treatment groups: 1) structured teaching of relaxation techniques including diaphragmatic breathing, supplemented by audiotapes; 2) the above plus imagery of a peaceful scene; or 3) a control group in which participants were seen individually and encouraged to talk about themselves.

Results showed that relaxation with imagery intervention lowered total mood disturbance on the "Profile of Mood States" than relaxation alone, and both interventions (relaxation and imagery plus relaxation) resulted in enhanced mood compared to the control group. The study showed evidence of short-term benefits of relaxation, and suggests that imagery plus muscular relaxation intervention enhances psychological benefits of the patients (Bridge et al., 1988).

In a small randomized pilot study of American breast cancer patients $(n=47)$, Richardson and colleagues (Hewitt et al., 2004) found that both the support group (focusing on reducing stress and feeling of isolation, and enhancing self-esteem) and 
relaxation/ imagery group enhanced patients' coping skills compared to the control group, with the former showing more significant improvement. In addition, results also indicate that women in the support group showed a greater acceptance of death. However, there was no evidence of improvement on quality of life, mood and immune parameters in either intervention in short-term measure, and no follow-up measurement was done for long-term effects.

In the United States, Kolcaba and Fox (1999) randomized 53 breast cancer patients who were undergoing radiotherapy treatment to one of the two groups: 1) guided imagery audiotape intervention (with 20 minutes of verbal guided imagery focusing on comfort, and 20 minutes of soft jazz), or 2) no treatment control. In this study, psychosocial followed-up continued until 3 weeks after the radiotherapy was finished. Results showed that the guided imagery intervention significantly improved comfort (psycho-spiritual, environment, social) throughout the study.

Another study in the United Kingdom, Walker et al. (1999) randomized 96 women with newly diagnosed locally advanced breast cancer to 1) relaxation training with guided imagery or 2) standard care group. Results show that the relaxation training with guided imagery reduced overall emotional repression and unhappiness, and it improved global quality of life, but had no effect on mood and no biomedical effect was found.

Similar findings regarding the effectiveness of relaxation and imagery intervention were found in a randomized study on 71 Hong Kong breast cancer patients who were receiving their first cycle of chemotherapy. Molassiotis, Yung, Yam, Chan \& Mok (2002) found that progressive muscle relaxation training and guided imagery 
intervention resulted in a significant decrease in total mood disturbance, as well as, a significant decrease in the duration and frequency of nausea and vomiting.

\section{Group Intervention}

A number of studies had been done to investigate the effectiveness of a variety of group interventions on breast cancer patients. Results show that the majority of group interventions demonstrated important psychosocial benefits. The benefits reported include improved mood, enhanced coping, reduced phobias, reduced traumatic stress symptoms, enhanced vitality, social and role functioning, reduced severity of psychiatric symptoms, enhanced quality of life, and enhanced spiritual integration (Hewitt et al., 2004).

According to Hewitt et al. (2004), the first randomized study of psychosocial intervention in metastatic breast cancer was reported by Spiegel, Bloom and Yalom (1981) in the United States. The researchers randomized 86 women to one of two groups: 1) Expressive-supportive group therapy that included hypnosis for pain control, or 2) a control group. In the treatment group, participants were asked to meet 90 minutes weekly for 1 year or longer if possible. The intervention was reported to improve mood, to reduce maladaptive coping responses, as well as to reduce phobia.

A randomized study in Australia by Edelman and colleagues in 1999 (Hewitt et al., 2004) on 121 women with metastatic breast cancer, compared the effects of group cognitive-behavioral therapy program with a control group. The treatment group met weekly for 8 weeks, then monthly for 3 weeks, and involved one family session, focusing on cognitive restructuring, relaxation, coping strategies and communication, group interaction and support, relationships, and self-image. Results show that there was 
evidence of improved mood (depression, total mood disturbance) and enhanced selfesteem at the end of the therapy.

Replicating Spiegel's earlier report, Classen et al. (2001) randomized 125

American women with metastatic breast cancer to the same weekly supportive-expressive group therapy used in Spiegel's study design. Results show that the intervention significantly reduced traumatic stress symptoms, but had no significant improvement in mood when the final assessment during patients' last year of life was included. However, when the final assessment occurring within a year of death was removed, results showed a significantly great decline in total mood disturbance, and traumatic stress symptoms.

Similar findings were found in Goodwin et al.'s (2001) study on group supportive-expressive therapy in 235 women with metastatic breast cancer. The group intervention was found being able to enhance mood (total mood, anger, anxiety, depression) and reduce pain.

\section{Music Therapy}

A recent study, Li et al. (2011) randomized 120 Chinese breast cancer patients into two groups: 1) music therapy, or 2) a control group which only received routine nursing care. The music therapy was twice a day (morning and evening), 30 minutes per session during the mastectomy and two chemotherapy periods, delivering through MP3 players. The pretest score revealed that the majority of the patients had a moderate level in state anxiety, and $15 \%$ had a severe level of state anxiety. Result showed that state anxiety of the experimental therapy group was improved significantly after music therapy, suggesting that music therapy is an effective complementary therapy on anxiety reduction for female breast cancer patients undergoing surgery and chemotherapy. 


\section{Mindfulness Based Stress Reduction Program (MBSR)}

There has been an increasing interest in mindfulness interventions in recent years. Mindfulness is a form of meditation originating from the East. The term mindfulness derives from the Pali language word sati, meaning, "to remember." It is regarded as a mode of consciousness and it commonly signifies presence of mind (Brown, Ryan \& Creswell, 2007).

The Mental Health Foundation (2010) described mindfulness as a "way of paying attention. It means consciously bringing awareness to our experience in the present moment, without making judgments about it." According to William Miller, an Emeritus Distinguished Professor of Psychology and Psychiatry, mindfulness means to be aware of the experiences that exist in the present moment- "here and now" (Miller, 1999). It is about bringing our attention to the present experience on a moment-to-moment basis. Goldstein and Kornfield stated, "Mindfulness means seeing how things are, directly and immediately seeing for oneself that which is present and true. It has a quality of fullness and impeccability to it, a bringing of our whole heart and mind, our full attention, to each moment" (Miller, 1999, p.62). In other words, mindfulness involves attention and awareness of our current thoughts, feelings and surroundings. Miller (1999) mentioned, “A major feature of mindfulness is its accepting attitude toward one's experiences (such as thoughts, emotions, and events). Mindfulness is about accepting all personal experiences as what they are, rather than judging them" (p. 68). In order to be mindful, adopting a non-judgmental attitude is necessary. Deiman stated, the individual must take an "observing self" mode which allows one to pay careful attention to one's thoughts and feelings just as "themselves," not as personal directives with which they must identify 
(Miller, 1999). According to Matchim, Armer and Steward (2011), through practicing mindfulness, an individual can focus attention on the present, not the past or worrying about the future. As a result, the individual can end his or her suffering. However, in order to build and maintain mindfulness, one is required to practice the skills repeatedly. Another key component of mindfulness is flexibility (Brown, Ryan, \& Creswell, 2007). Bays mentioned: like a zoom lens, it can move back from particular states of mind to gain a larger perspective on what is taking place, and can also zero in on situational details, according to inclination or circumstance. While being mindful, one can be fully aware of all that is currently salient. Therefore, it is not surprising to find that mindfulness requires attention control and concentrative capacity (Brown et al., 2007). Mindfulness-based stress reduction (MBSR) is a meditation program initially developed by Kabat-Zinn for chronic pain patients and stress-related conditions (Zainal \& Huppert, 2013). Kabat-Zinn is a scientist, writer, and meditation teacher. He defined mindfulness meditation as "bringing one's complete attention to the present experience on a moment-to-moment basis" and "paying attention in a particular way: on purpose, in present moment, and nonjudgmentally" (p.4). The MBSR program was introduced by Kabat-Zinn as an intervention that free from religions and cultures (Kabat-Zinn, 2003). Over the past twenty years, the program has been widely used in research and clinical settings and has been found to be beneficial for both clinical and non-clinical populations, including cancer patients (Dobkin \& Zhao, 2011; Matousek, Dobkin, \& Prusessner, 2010; Matousek, Pruessner\& Dobkin, 2010; Tacon, Caldera \& Ronaghan, 2004).

The main components of MBSR are the body scan, breathing meditation, walking meditation, mindful movement and psycho-education (Zainal et al, 2012). Zainal and 
colleagues (2012) stated that in MBSR programs, participants learn effective ways of managing moods and emotions by becoming aware of their thoughts, feeling, bodily sensations and the world around them from moment to moment. Each MBSR session includes education about stress including information on the physiology of stress, the stress response, and the effect of different interpretations of stress on its impact.

Many research have been done to explore the effectiveness of MBSR in different populations. Several studies have demonstrated the beneficial effects of MBSR on stress reduction and mental health in patients with cancer (Birnie, Garland \& Carlson, 2010; Branstrom, Kvillemo \& Moskowitz, 2011; Lerman, Jarski, Rea, Gellish \& Vicini, 2011), arthritis (Pradhan et al., 2007; Sephton et al., 2007), diabetes (Van Son, Nyklicek, Pop \& Pouwer, 2011), organ transplants (Gross et al., 2010; Kreitzer, Gross, Russas \& Treesak, 2005;) psychiatric disorders (Goldin \& Gross, 2010; Vollestad, Sivertsen \& Nielsen, 2011) and in stressed non-clinical populations (Cohen-Katz, Wiley, Capuano, Baker, \& Shapiro, 2004; Martin-Asuero \& Garcia-Banda, 2010). A literature review indicates that MBSR is effective in decreasing stress, distress, state anxiety, and mood disturbance for breast cancer survivors. These effects were maintained at 6- and 12-month follow-ups (Zanial, Booth \& Huppert, 2013).

Previous systematic review and meta-analysis of MBSR and cancer suggested that MBSR may improve cancer patients' mental health affected by their disease (Ledesma \& Kumano, 2009). Another systematic review reported five different types of mindfulnessbased interventions used in adult cancer patients indicated significant improvements in anxiety, depression, stress and sexual difficulties among patients (Shennan, Payne, \& Fenlon, 2011). 
In 2011, a systematic review on MBSR for breast cancer survivors was completed by Matchim, Armer and Stewart. They reported that there were three studies with large effect sizes on perceived stress and state anxiety, and moderate effect sizes on mood symptoms. MBSR also shows effects on enhancing immune function and decreasing blood pressure. Among the 16 MBSR studies, four of them examined the effects of physiological outcomes, including immune profile, blood pressure, heart rate, cortisol and melatonin levels. Most of the variables had small effect sizes (less than 0.5).

Another systematic review on MBSR for breast cancer patients was done by Zainel, Booth and Huppert in 2013. The results support the findings by Matchim et al. (2011) that MBSR had significant effects on alleviating stress, depression and anxiety in patients with breast cancer (Zainal et al, 2013). This meta-analysis study investigated 9 studies that were conducted in the USA or Canada. More than $90 \%$ of the participants were Caucasians. The study found that the MBSR had an important impact on improving mental health in breast cancer patients by reducing perceived stress, depression and anxiety. Among the 9 studies, four reported data on anxiety, with overall effect size of 0.733. The study found that integrating MBSR in the treatment of breast cancer patients is more effective than usual care in reducing anxiety.

More recent research were done to explore the effects of MBSR on breast cancer patients and survivors in different areas. A pilot study was done by Lesiuk in 2015 to explore the effect of Mindfulness Based Music Therapy (MBMT) on attention and mood in women receiving adjuvant chemotherapy for breast cancer. The results showed that MBSR music therapy has significantly improves the participants' attention. The results of the study also found that MBMT significantly reduced negative mood states, particularly 
the states of tension, depression, anger, fatigue, and confusion in women with breast cancer, and it significantly improved their levels of vigor and activity. Specifically, the problem of fatigue showed the greatest decrease after the MBMT sessions (Lesiuk, 2015).

Similarly, in the study of exploring the effect of group mindfulness on fatigue severity and global and specific life quality in women with breast cancer $(n=24)$, Rahmani and Talepasand (2015) also found that MBSR treatment significantly improved the overall quality of life, role, cognitive, emotion, social functions, and pain and fatigue symptoms in life quality of breast cancer patients. The results also showed that MBSR significantly improved the body image, future functions and therapy side effects in specific life quality. In addition, the level of fatigue caused by cancer was also reduced significantly (Rahmani \& Talepasand, 2015). Research also found that MBSR may be an effective treatment to improve sleep quality among breast cancer patients (Andersen et.al, 2013; Lengacher et al., 2009).

\section{Calligraphy and Mindfulness}

As mentioned earlier, calligraphy is traditionally regarded as an exercise to enhance self-reflection and self-cultivation, and the writing process requires one's full concentration, and mind-body coordination. It is not surprising to realize that practicing calligraphy also involves mindfulness. As Hue (2009), an experienced calligraphy practitioner and a researcher, mentioned:

When engaging in calligraphy, we always had to be very mindful of engaging in these aesthetic practices. Calligraphy was a way to help us enrich our aesthetic experience in a much broader sense and intensity our ability for self-awareness, and so lead us to gain insight the nature of human existence, and experience the flow of $q i$ energy running freely through our body. By engaging with brush, ink and paper, our sense of 
$q i$ energy spreading through our inner self could be developed, enhanced and brought into harmonious relationship with the pure essence of our heart and mind and with the world around us. (p. 68)

According to Hue (2009), Chinese calligraphy practice promotes mindfulness in almost every single act involved, such as flattening the rice paper, dripping water onto ink stone, grinding an ink stick, softening a brush, gripping the brush etc. Moreover, during the writing process, writers are often encouraged to move every brushstroke unhurriedly by practicing breathing exercise. This process often naturally involves: breathing in deeply and gently in the beginning, breathing out evenly and slowly when the stroke is developed, and when the stroke ends, breathing out can stop. The cycle goes on when the writer continues the practice. Because the practice emphasizes "presentism", which keeps on whatever the writer does and thinks in the "here-and-now", Hue (2009) asserts that calligraphy is an exercise to keep one's mind calm and tranquil. He stated, "Chinese calligraphy is an art inextricably linked to the practice of mindfulness" (p.69). Other writers also recognized the spiritual values of Chinese calligraphy practice (Chang, 1992; Chiang, 1973; Chung, 2006; Shen, 2004; Terayama, 2004), suggesting that calligraphy is a spiritual process that leads to cultivation and expression of an individual's inner-self.

\section{Discussion}

As mentioned in the previous sections, studies suggest that Chinese calligraphy is effective in reducing state anxiety and improving moods in a variety of healthy individuals (Guan et al., 2000; Guo, Kao, \& Liu, 2001; Huang et al, 2000; Kao \& Gao, 2000; Kao, Miao, Luo \& Gao, 2006), and clinical populations (Fan et al., 1999; Kao et al., 2000a; Kao et al., 2000b; Kao et al., 2000e; Kao, 2003; Dong et al., 2006; Kao et al., 
2010; Zhu et al, 2010), including cancer patients (Yang et al., 2010). Chinese calligraphy writing is linked to mindfulness practice (Hue, 2009), and Mindfulness-based stress reduction (MBSR) is evident in improving state-trait anxiety, depression, recurrence concerns and quality of life for breast cancer patients and survivors (Lengacher et al., 2009). The question is thus to ask: Can calligraphy practice reduce the anxiety level of breast cancer patients? Since the question has never been studied, and more effective anxiety reduction interventions for this particular clinical population are needed, the topic is well worth exploring. This proposal study is intended to investigate the effects of Chinese calligraphy on breast cancer patients with a belief that calligraphy is an exercise that links to mindfulness.

\section{Summary of Chapter 2}

In this chapter, a historical perspective and an overview of Chinese calligraphy are presented. Then, the effects on calligraphy writing on both nonclinical and clinical populations were explored. Major effects include: cognitive activation, physiological slowdown, emotional stability and perceptual sharpening. What follows is the current effective interventions or treatment in anxiety reduction and mood improvement for breast cancer patients- relaxation and imagery; support group, and mindfulness- based stress reduction programs.

Finally, the relationship between calligraphy and mindfulness was discussed. Hue (2009) asserts that calligraphy is inextricably linked with mindfulness. Others also recognized that other than its aesthetic value, calligraphy practice is a spiritual process that promotes mind-body harmony (Davey, 1999), self-cultivation and self-expression (Chang, 1992; Chiang, 1973; Chung, 2006; Shen, 2004; Terayama, 2004). 


\section{CHAPTER 3}

\section{METHODS}

\section{Introduction}

The purpose of this study was to examine whether Chinese calligraphy can reduce the anxiety and comorbid depression levels experienced by breast cancer patients. In this study, Chinese calligraphy and time were the independent variables. The levels of anxiety experienced by the breast cancer patients are the dependent variables, using both physiological (blood pressure, heart rate, and respiratory rate) and self-reported psychological measurements (the full version of State-Trait Anxiety Inventory [STAI], and the Depression, Anxiety and Stress Scale 21 [DASS 21]).

This chapter provides detailed information of the methodology used in this study, including the research design, the population and sample, the instruments used, the research procedures, as well as data treatment and the analysis process. Follow-up interviews were also conducted to further explore the experience of five participants while they practiced Chinese calligraphy.

\section{Research Question}

This study examined one question: To what extent does Chinese calligraphy reduce the anxiety and comorbid depression levels among breast cancer patients in Hong Kong? Two hypotheses were formed based on the research question: 1) There is a physiological 
slowing effect in blood pressure, heart rate and respiratory rate on breast cancer patients after practicing Chinese Calligraphy handwriting; and 2) breast cancer patients will have a reduction score on self-reported measures of anxiety and comorbid depression levels after Chinese calligraphy intervention.

\section{Research Design}

A one-group repeated-measures design was employed using a quasi-experimental method to explore the changes in anxiety levels in a sample of 45 breast cancer patients, and 30 of them had completed the whole calligraphy intervention. These patients had participated in an 8-week Chinese calligraphy program across pre-intervention, midintervention and post-intervention measures. Both physiological and self-report assessments were used. During the 8-week period, participants were taught and practiced Chinese calligraphy in a quiet room for eight 90-minute sessions. This study hypothesizes that there would be a positive relationship between practicing Chinese calligraphy handwriting and anxiety reduction.

The physiological changes, heart rate, blood pressure, and respiratory rate were measured before and after each calligraphy session. To measure psychological anxiety level, since affective states of anxiety are subjective, each patient rated her perception of anxiety using the STAI and DASS 21 at baselines (before any intervention), in the middle (at the end of the $4^{\text {th }}$ week session), and after (at the end of the $8^{\text {th }}$ week) Calligraphy intervention. 


\section{Population and Sample}

The patients who participated in this research were women diagnosed with breast cancer, with a focus on the patients who were receiving any kind of treatment, including chemotherapy, radiotherapy or hormone therapy. There were totally 45 breast cancer patients participated in this research, with 30 of them had complete all 8 sessions. Demographic information (see Table 1) collected in this study included age, marital status, education level, previous exposure to Chinese calligraphy, and handedness. Medical information included cancer stage and treatment stage. The ages of the patients ranged from thirty-eight to sixty-five. The patients came from a variety of occupational and socioeconomic backgrounds. Invitation was sent to 4 cancer support centers and 2 hospitals. Maggie's Cancer Caring Center in the New Territory of Hong Kong, which is located next to Tuen Mun hospital, was the only one that agreed to participate in the research. All participants of this research came from this center.

The recruitment of the research participants was done by Maggie's Cancer Caring

Centre. The staff at the center, mainly nurses and social worker invited the center members and visitors who met the criteria of the research (1. Women diagnosed with breast cancer, and 2. Undergoing some kind of breast cancer treatment) for participation. Brochures were also distributed to the doctors' office in Tuen Mun hospital. Medical doctors of Tuen Mun hospital were informed by the nurses of Maggie's Cancer Caring Center of the research, so that they could refer patients who met the criteria to participate in the research. Table 1a shows the demographic characteristics of the participants. 
Table 1

Demographic Characteristics $(n=45)$

\begin{tabular}{|c|c|c|c|c|c|}
\hline Characteristics & $n$ & $\%$ & Median & $M$ & $S D$ \\
\hline$\overline{\text { Age }}$ & & & 52.0 & 52.58 & 6.71 \\
\hline \multicolumn{6}{|l|}{ Marital Status } \\
\hline Single & 9 & 20 & & & \\
\hline Married & 27 & 60 & & & \\
\hline Divorce/ & 3 & 6.7 & & & \\
\hline Missing & 6 & 13.3 & & & \\
\hline \multicolumn{6}{|l|}{ Education Level } \\
\hline Primary Sch. & 6 & 13.3 & & & \\
\hline Secondary Sch. & 24 & 53.3 & & & \\
\hline University & 13 & 28.9 & & & \\
\hline Graduate Sch. & 1 & 2.2 & & & \\
\hline Missing & 1 & 2.2 & & & \\
\hline \multicolumn{6}{|l|}{ Previous Exposure } \\
\hline Yes & 41 & 8.9 & & & \\
\hline No & 4 & 91.1 & & & \\
\hline \multicolumn{6}{|l|}{ Handedness } \\
\hline Left & 2 & 4.4 & & & \\
\hline Right & 43 & 95.6 & & & \\
\hline \multicolumn{6}{|l|}{ Cancer Stage } \\
\hline $\mathrm{I}$ & 14 & 31.1 & & & \\
\hline II & 15 & 33.3 & & & \\
\hline III & 10 & 22.2 & & & \\
\hline IV & 1 & 2.2 & & & \\
\hline Unknown & 5 & 11.1 & & & \\
\hline \multicolumn{6}{|l|}{ Treatment Stage } \\
\hline Chemo & 18 & 40 & & & \\
\hline Radiotherapy & 6 & 13.3 & & & \\
\hline Hormone Therapy & 14 & 31.1 & & & \\
\hline Targeted Therapy & 6 & 13.3 & & & \\
\hline
\end{tabular}

\section{Instrumentation: The Measurement of Anxiety}

Kazdin (2000) stated that the measurement of anxiety can be divided into three major types: self-reported measures, physiological measures and behavioral measures. The self-reported measures can be subdivided into three categories: measures of trait 
anxiety, state anxiety, or situation-specific anxiety (e.g. social anxiety, test anxiety, etc.). Physiological measures of anxiety include assessments of heart rate, blood pressure, muscle tone, and respiration. Behavioral measures involve observations of behaviors in a naturalistic environment or within a laboratory setting where anxiety is induced (Kazdin, 2000).

In this study, physiological and self-reported measures were assessed. The physiological measures include systolic and diastolic blood pressure, heart rate and respiratory rate. The full battery of STAI and the DASS 21 were the self-reported measures used to assess the anxiety and comorbid depression levels of the participants.

\section{Physiological Measures}

Since anxiety involves activation of the sympathetic nervous system, an anxious person is very likely to experience increased heart rate, blood pressure, respiration and muscle tone (Kazdin, 2000). According to Kazdin (2000), unlike self-reported and behavioral measures, physiological measures are less easily regulated by the respondent, therefore, potentially more accurate assessments of anxiety. The physiological measures in this study include blood pressure, heart rate, and respiratory rate.

\section{Self-Reported Measures}

The State-Trait Anxiety Inventory (STAI) is one of the most commonly used selfreported measures of anxiety (Kazdin, 2000). It is a well-published tool used to assess anxiety, which consists of two separate self-reported scales. Each scale consists of twenty statements. The STAI State (STAI Form Y-1) evaluates how respondents feel "right now, at this moment" (e.g., "I feel at ease"; "I feel upset"), and the STAI Trait (STAI Form Y- 
2) scale assesses how respondents "generally feel" (e.g., "I am a steady person"; "I lack self-confidence"). Respondents are asked to rate themselves on each item on the basis of a 4-point Likert scale, ranging from 1, "not at all" to 4, "very much so" for the STAI State and from 1, "almost never," to 4, "almost always" for the STAI Trait. Higher scores indicate greater anxiety level (Spielberger, Sydeman, Owen \& Marsh, 1999). A cut point of 39-40 has been suggested to detect clinically significant symptoms for the State Anxiety scale (Julian, 2014).

In an investigation of the reliability generalization of the STAI, the instrument demonstrated excellent internal consistency (average $\alpha s>.89$ ), and the STAI Trait has evidenced excellent test-retest reliability (average $r=.88$ ) at multiple time intervals (Gros, Antony, Simms, \& McCabe, 2007). The State version reported a lower temporal stability (average $r=.70$ ) (Barnes, Harp, \& Jung, 2002). Overall, the measures have evident, adequate convergent and discriminant validity with other measures of state and trait anxiety. They have been shown to differentiate patients from control samples on the STAI Trait and participants in highly stressful situations from control sample on the STAI State (Gros et al, 2007). Reliability coefficients ranged from .65 to .75 over a 2month interval (Spielberger, 1989).

The STAI has been translated into over 30 languages (Spielberger, 1989). The reliability and validity of the Chinese version of STAI were tested by Ho and Lopez (2004) in children. They found that the overall test-retest reliability coefficients of the scale ranged from .76 to .92 across sex and age group. The content validity index (CVI) was $95 \%$. The construct validity of the scale was supported by hypotheses testing Comparative Fit Index (CFI) and Goodness of Fit Index (GFI) (CFI = .93, GFI = .92). 
The Depression Anxiety Stress Scale (DASS) is a 42-item self-reported measure of anxiety, depression and stress developed by Lovibond and Lovibond (1995) and has been increasingly used in different settings (Crawford \& Henry, 2003) across age groups (Osman, Wong, Bagge, Freedenthal, Gutierrez \& Lozano, 2012) and racial groups (Norton, 2007). The DASS appears to be a reliable and easy to administer measure, ideal for both clinical and research purposes (Norton, 2007). When administering the DASS to a larger non-clinical sample $(N=2,914)$, Lovibond and Lovibond (1995) found that reliability, assessed using Cronbach's alpha for non-clinical population, was acceptable for the depression, anxiety and stress scales $(.91, .84$ and .90 respectively). The results are similar to those obtained from clinical populations (Crawford \& Henry, 2003). Another study in UK showed that the reliability of the DASS is excellent ( .90 for anxiety, .95 for depression, .93 for stress and .97 for the total scale), and the measure also possessed adequate convergent and discriminant validity (Crawford \& Henry, 2003).

The DASS 21 is a 21 -item short version of the DASS of seven items labeled: depression, anxiety, and stress. It has been shown that the DASS 21 have the same factor structures as the original 42-item version (Osman et al., 2012). To complete the scale, respondents are asked to circle a number ranging from 0 (did not apply to me at all) to 3 (applied to me very much, or most of the time), indicating how much the item applied to them over the past week. The scores on each scale range from 0 to 42 , with higher scores indicating more severe level of depression, anxiety, and stress. The final score of each group needs to be multiplied by two (x2), so they are comparable to scores for the full 42 item version. Interpretations of the DASS is based on the use of cut-off scores, for example, in the depression scale, with 0-9 classified as "normal", 10- 13 as "mild", 14-20 
as "moderate", 21-27 as "severe", and 28 and above as "extremely severe". The items in the DASS 21 showed good factor loadings on their relevant factor and represented all the symptoms with each scale measured in the DASS (Wood, Nicholas, Blyth, Asghari, \& Gibson, 2010).

Research showed that both DASS and DASS 21 are psychometrically sound with good reliability and validity in both clinical and nonclinical populations across different age groups and cultures (Wood et al., 2010; Norton, 2007; Oei, Sawang, Goh \& Mukhtar, 2013). For example, in a study of a clinical population with medical patients seeking treatment to manage worry ( $\mathrm{N}=222)$, Gloster and others (2008) found that the DASS 21 has good internal consistency, excellent convergent validity, and good discriminative validity, especially for the Depression scales. It also indicated that the DASS 21 predicted the diagnostic presence of generalized anxiety disorder (GAD) depression, as other commonly used measures do (Gloster, Rhoades, Novy, Klotsche, Senior, Kunik, \& Stanley, 2008).

The DASS 21 has been translated into over 30 languages. In 2015, Wang and colleagues found that the Chinese version of DASS 21 has Cronbach's alpha of .83, .80 and .82 for the Depression, Anxiety and Stress subscales, respectively, and .92 for the total DASS. The study examined the clinical utility of the Chinese version of DASS 21 in 166 patients with schizophrenia and 90 matched healthy controls. Confirmatory factor analyses supported the original 3-factor model with 1 minor change (non-normed fit index $[\mathrm{NNFI}]=.964 ; \mathrm{CFI}=.968$; Root Mean Square Error of Approximation [RMSEA $]=$ .079) (Wang et al., 2015). In this current study, the Chinese version of DASS 21 was used. 
Other self-reported measurements, such as the Beck Depression Inventory (BDI) is commonly used for measuring depression level. Developed by A. T. Beck, the BDI is a 21-tem, self-report rating inventory that measures characteristic attitude and symptom of depression (Beck, Ward, Mendelson, Mock \& Erbaugh, 1961). Internal consistency for the BDI ranges from .73 to .92 with a mean of .86 (Beck, Steer, \& Garbin, 1988). The BDI demonstrates high internal consistency, with alpha coefficients of .86 and .81 for psychiatric and non-psychiatric population respectively (Beck et al., 1988). However, since the BDI was designed as a device to access the depth of depression only, it was not used in this current study.

\section{Procedures}

Prior to the first period of data collection, all participants were given an oral explanation of the study and then asked to read and signed the study consent form (see Appendix A). Chinese versions were used. After informed consent was obtained, the demographic information, the initial pre-intervention physiological measurement (Blood

pressure, heart rate and respiration rate) and the psychological assessments (the STAI and DASS 21) were collected for the $1^{\text {st }}$ time as baseline measurements. Then, the participants were asked to come the following week for the $2^{\text {nd }}$ time pre-intervention measurement. One week later, the $3^{\text {rd }}$ pre-intervention measurements were collected before the first calligraphy session began.

At baseline, demographic and clinical data were collected from the participants prior to the interventions. Demographic information including age, education, marital status, handedness, cancer stage and medical information regarding disease and treatment 
modality were collected on a demographic form. All personal information of the participants was kept confidential.

The intervention took place at the $3^{\text {rd }}$ week in a group format right after the preintervention measurements were collected. The participants learned and practiced Chinese calligraphy in a quiet room. The time duration of calligraphic writing was 90 minutes per session, with one session per week for 8 consecutive weeks. In the $1^{\text {st }}$ and $2^{\text {nd }}$ week of the intervention, the researcher introduced basic Chinese Calligraphy handwriting skills to the participants. Then, the participants were asked to practice the basic strokes with the brush pen on rice paper. Figures 3, 4 and 5 are the work from some participants in the $1^{\text {st }}$ and $2^{\text {nd }}$ week of intervention.

From the $3^{\text {rd }}$ week to the $8^{\text {th }}$ week, participants were instructed to practice brush handwriting with Chinese characters on rice paper. Figures 6-11 show the calligraphy written by the participants from the $3^{\text {rd }}$ to week $8^{\text {th }}$ week of intervention. Throughout the eight weeks of the intervention period, the researcher demonstrated the writing to the participants and reminded them of being mindful during the writing process, rather than focusing on the beauty of their writing.

The content of Chinese calligraphy characters from the $3^{\text {rd }}$ to $8^{\text {th }}$ week of intervention was from handbooks of calligraphy writing in standard script by famous calligraphers from Tang dynasty (See Figures $12 \& 13$ ). The calligraphy writing involved brush handwriting by imitating the strokes and structures of the characters displayed in the standard script form. Medium sized calligraphic brush pens and calligraphic rice papers were used throughout all 8 weeks of intervention. 


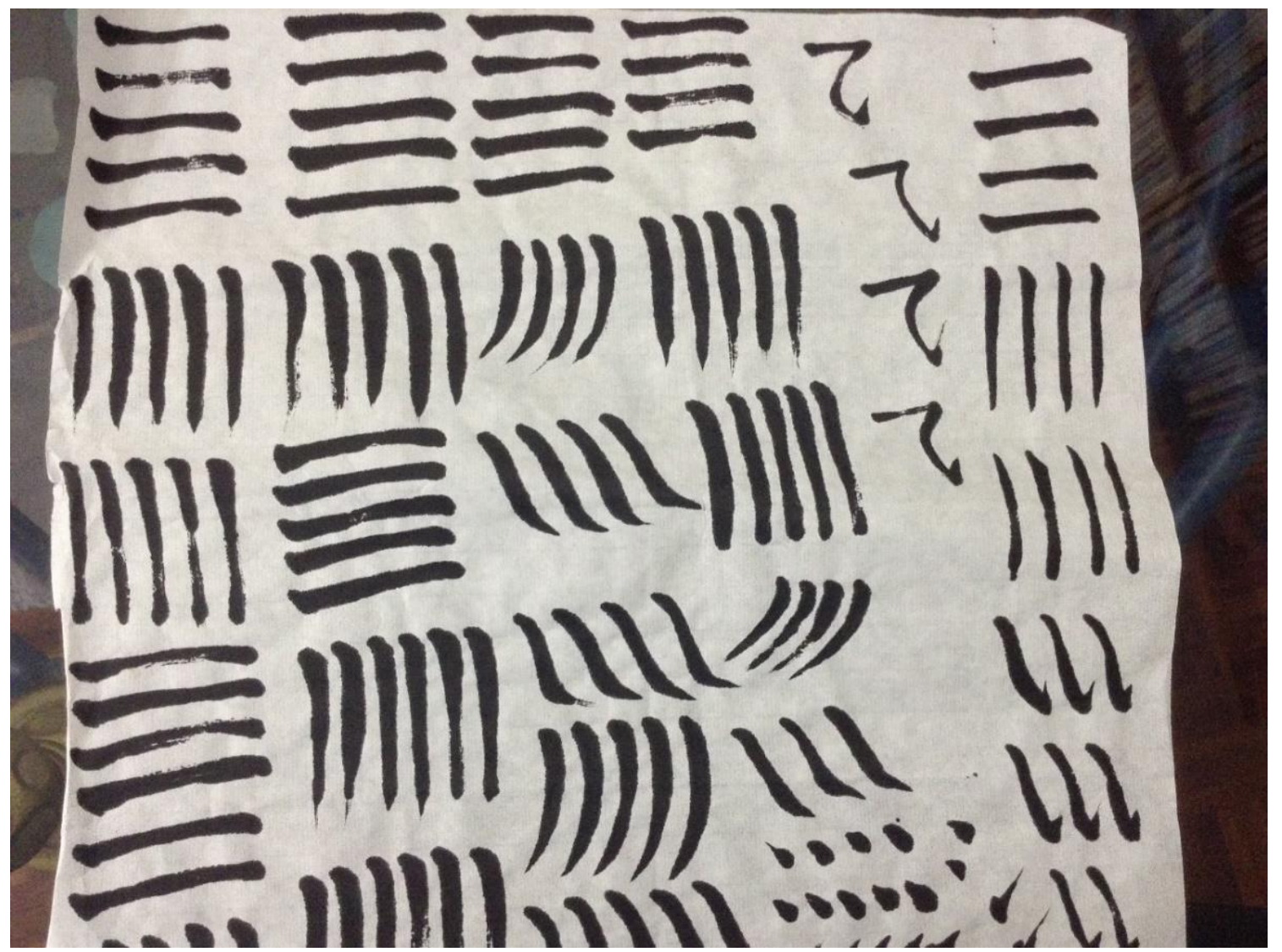

Figure 3. Basic Horizontal, Vertical, and Hooked Strokes and Dots Written by Participant in the $1^{\text {st }}$ and $2^{\text {nd }}$ Week of Intervention. Participants were taught to practice and improve on basic brush strokes that would later constitute full Chinese characters. They were taught to focus not on the beauty of the writing but on the process of brushstrokes and experiencing the 'here and now'. 


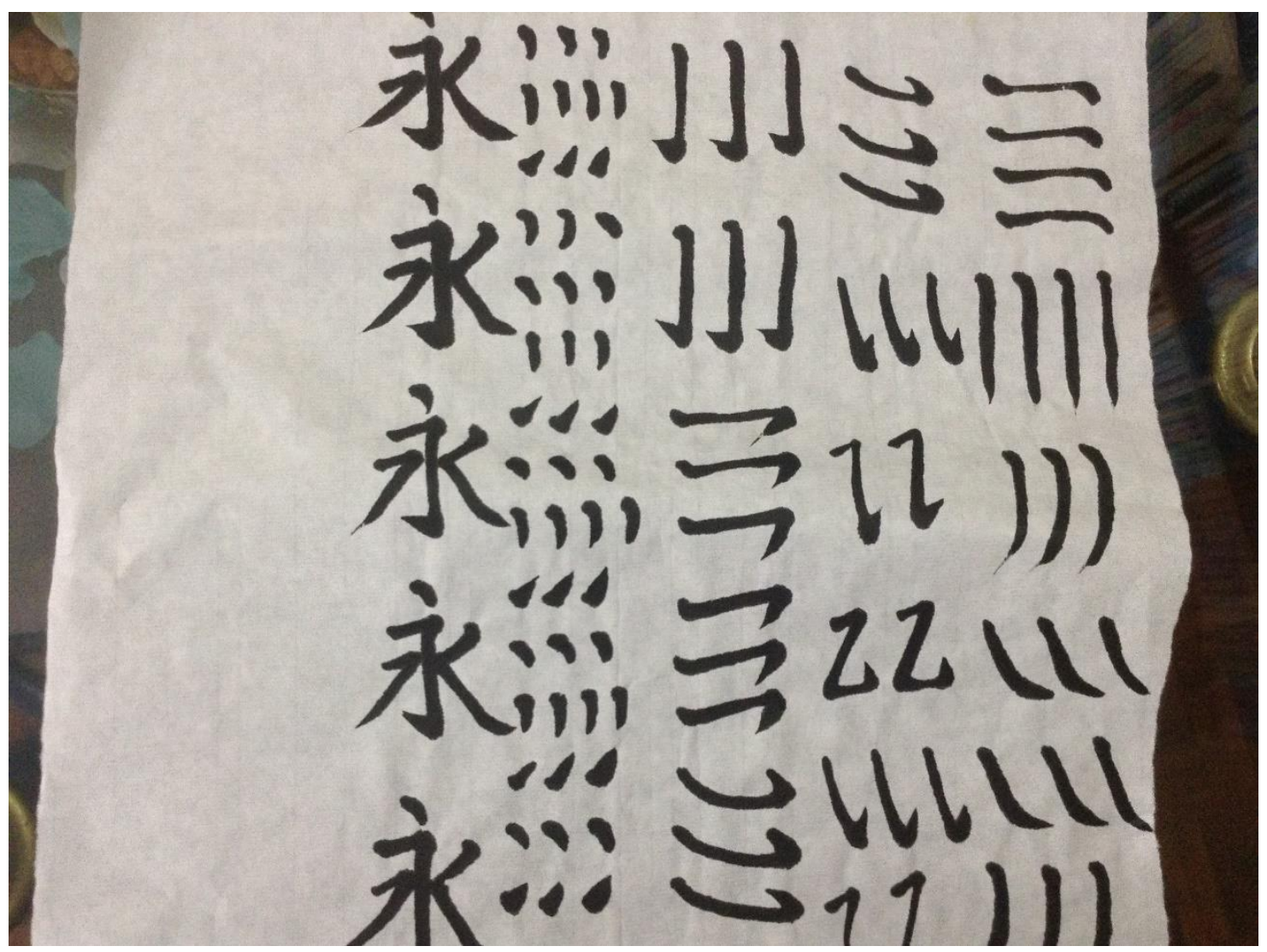

Figure 4. Basic Horizontal, Vertical, Hooked Strokes and Dots and Combining into the Chinese Character “Yong" (永, meaning "eternal") Written by Participant in the $1^{\text {st }}$ and $2^{\text {nd }}$ Week of Intervention. 


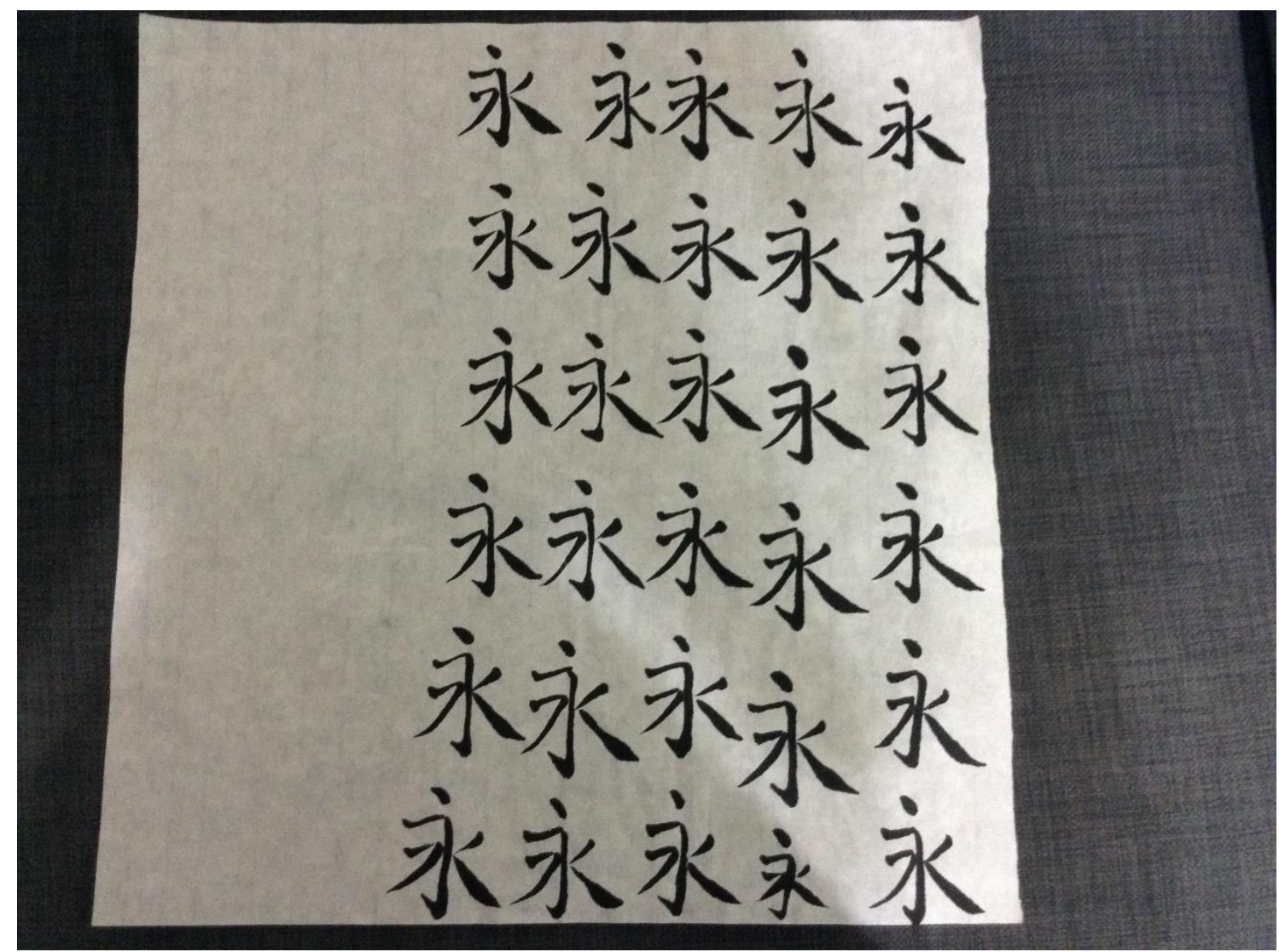

Figure 5. Basic Strokes Written by Participant in the $1^{\text {st }}$ and $2^{\text {nd }}$ Week of Intervention. The picture shows the work of a participant who practiced the "Eight Principles of Yong" which include the common eight strokes in Chinese characters found all in the one character of “yong" (永, meaning "eternal"). It is believed that the frequent practice of these principles as a beginner could ensure the beauty in one's writing. 


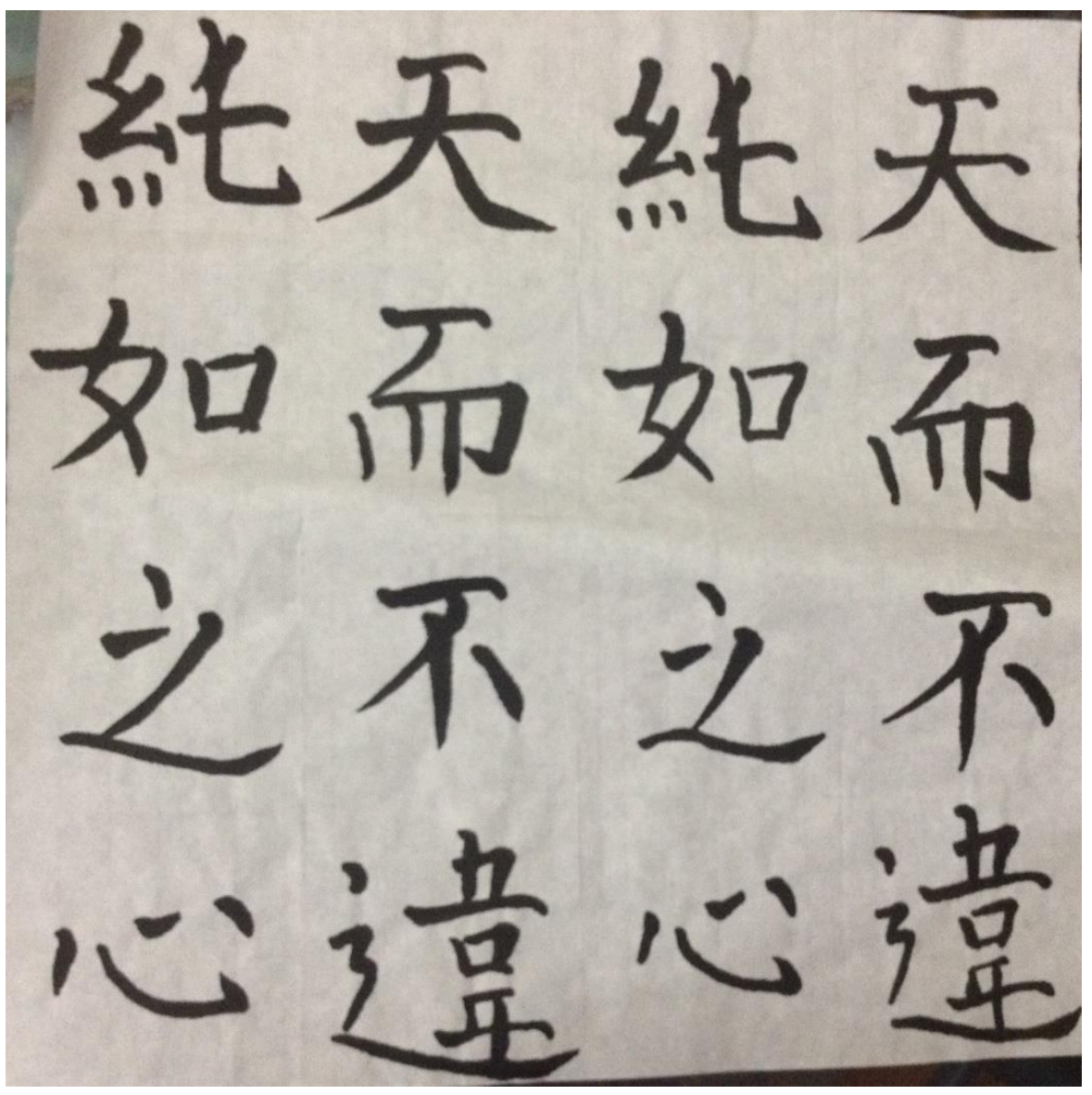

Figure 6. Sample of Work Done by Participant in the $3^{\text {rd }}$ Week. Participants are taught to practice other Chinese characters by imitating calligraphy handbooks written by famous calligraphers. 


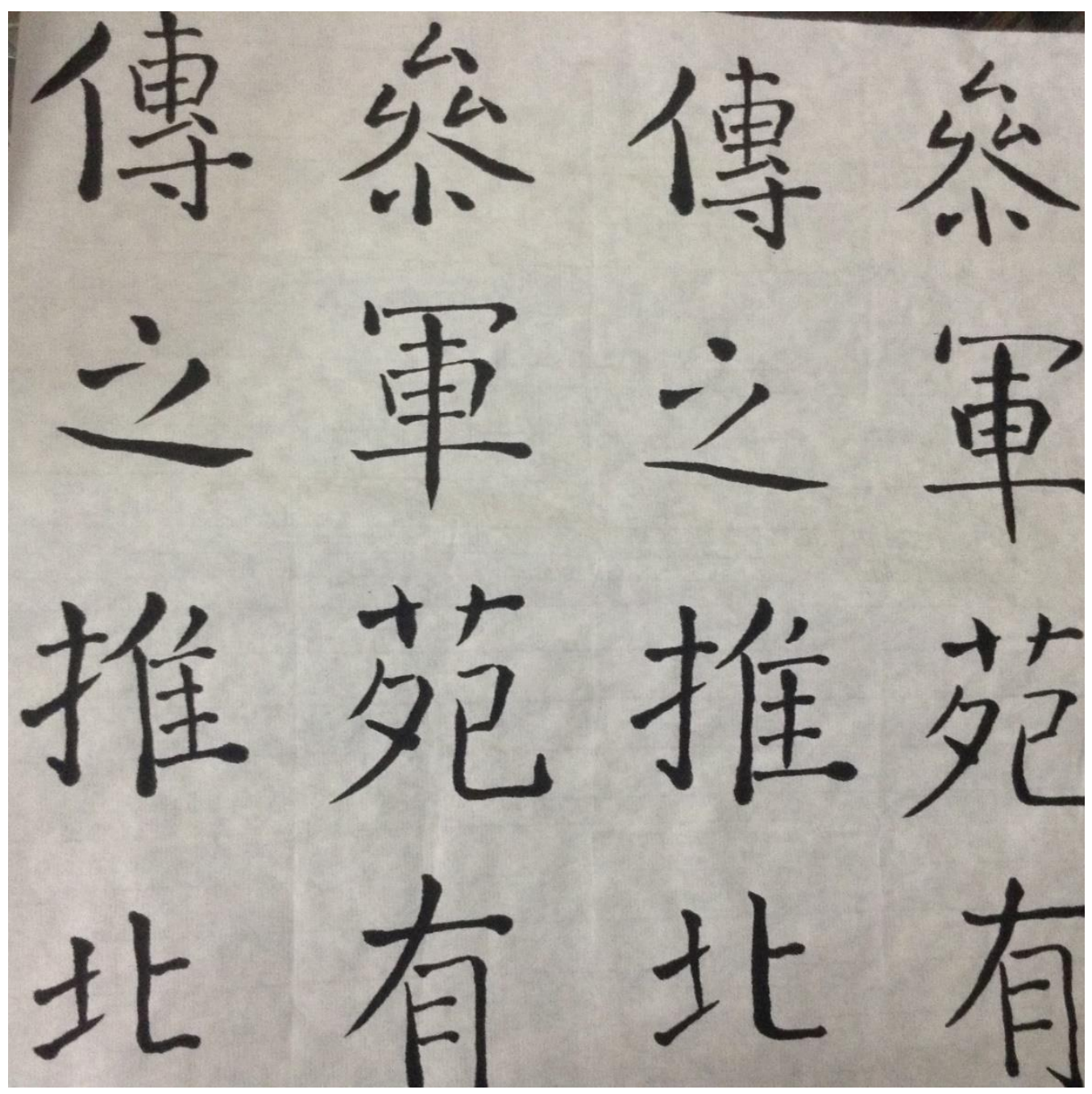

Figure 7. Sample of Work Done by Participant in the $4^{\text {th }}$ Week 


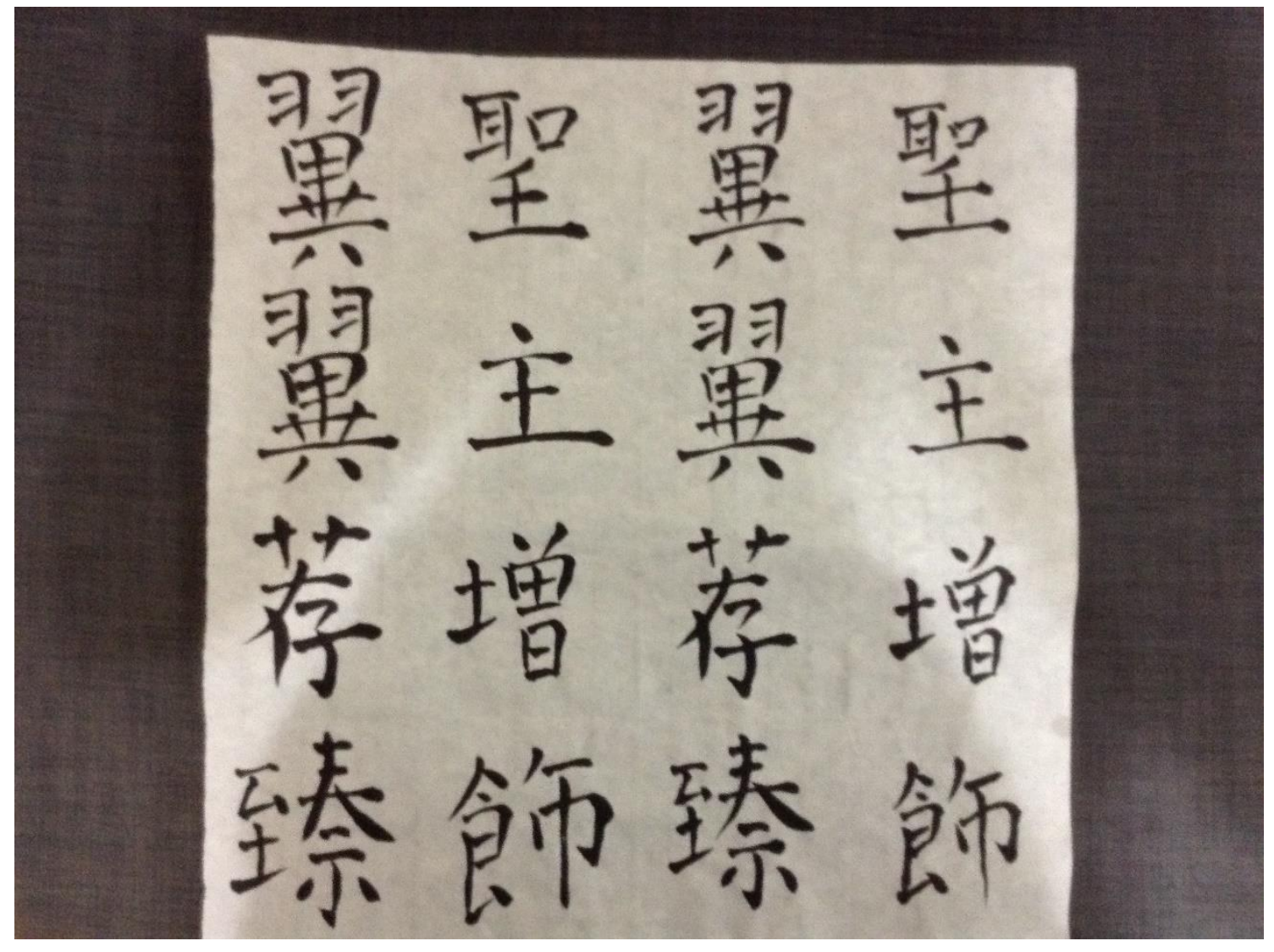

Figure 8. Sample of Work Done by Participant in the $5^{\text {th }}$ Week 


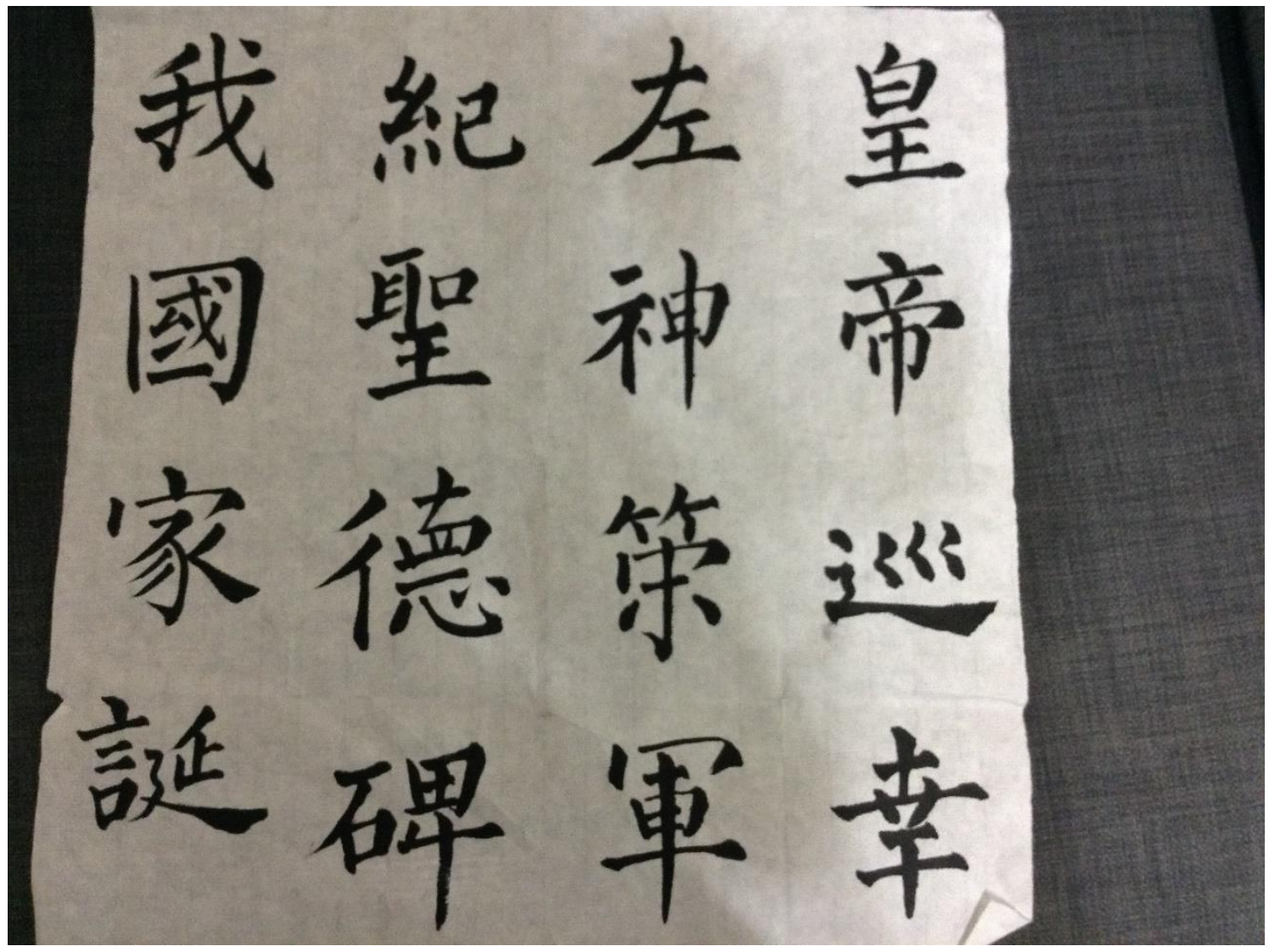

Figure 9. Sample of Work Done by Participant in the $6^{\text {th }}$ Week 


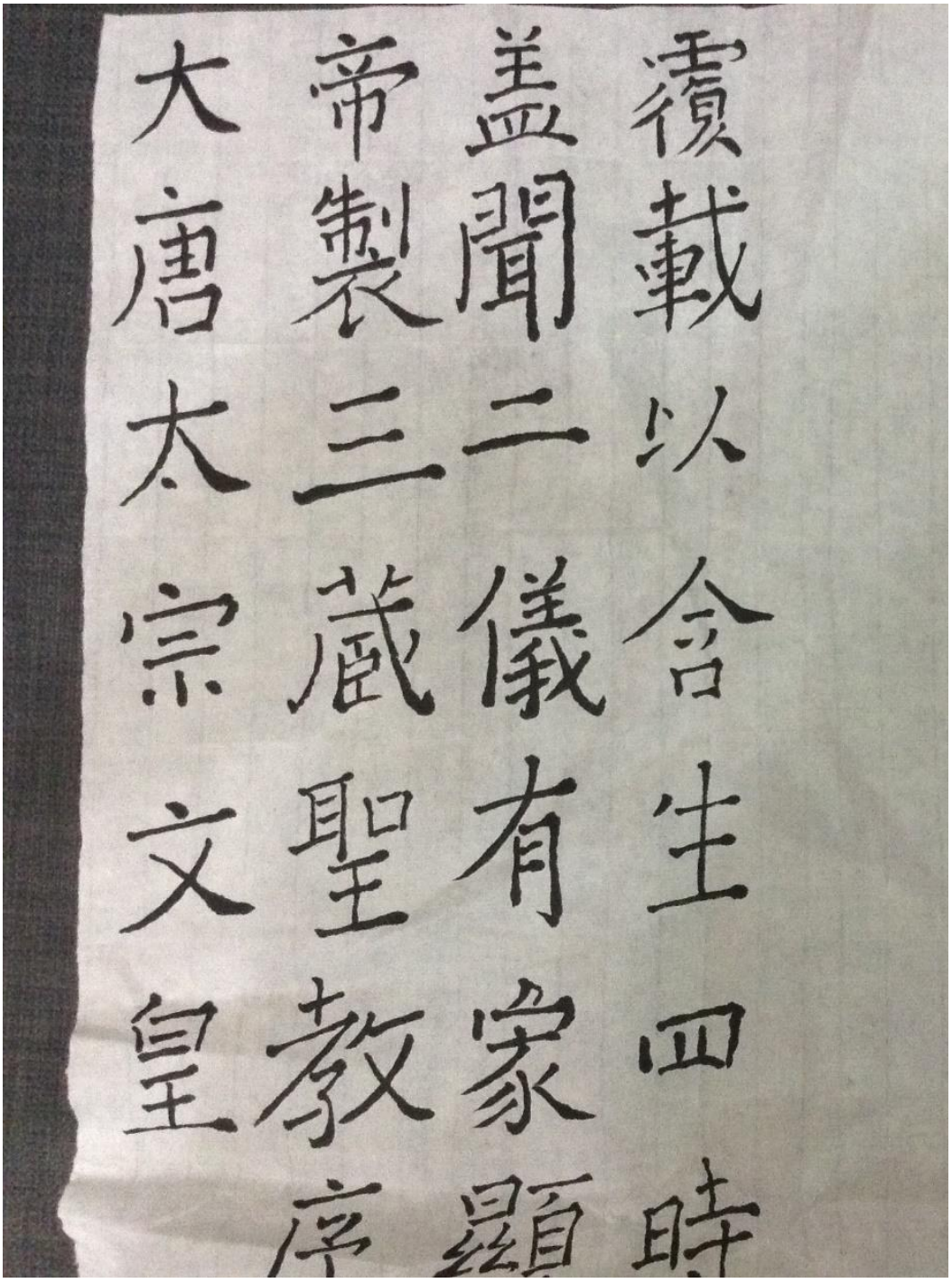

Figure 10. Sample of Work Done by Participant in the $7^{\text {th }}$ Week 


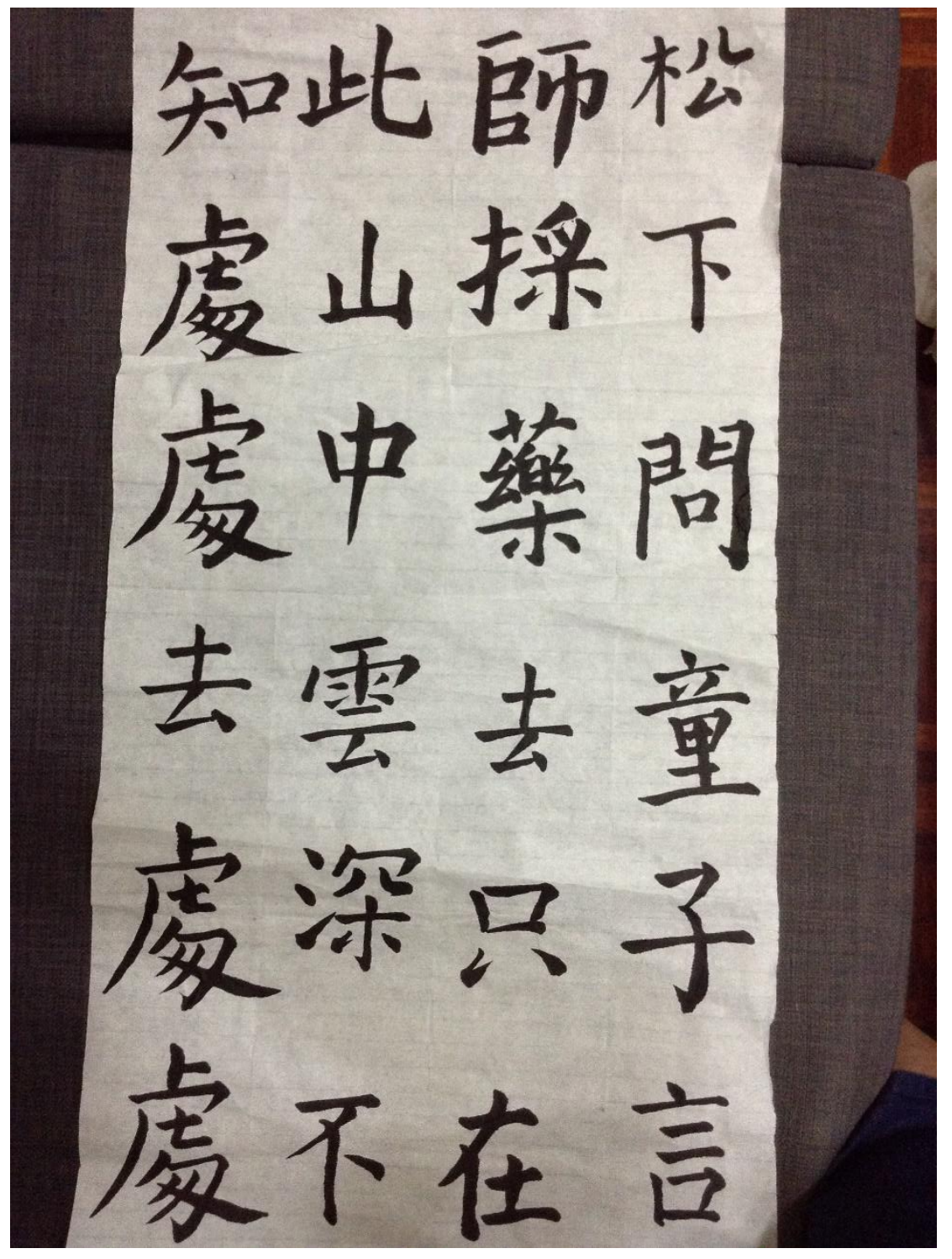

Figure 11. Sample of Work Done by Participant in the $8^{\text {th }}$ Week 


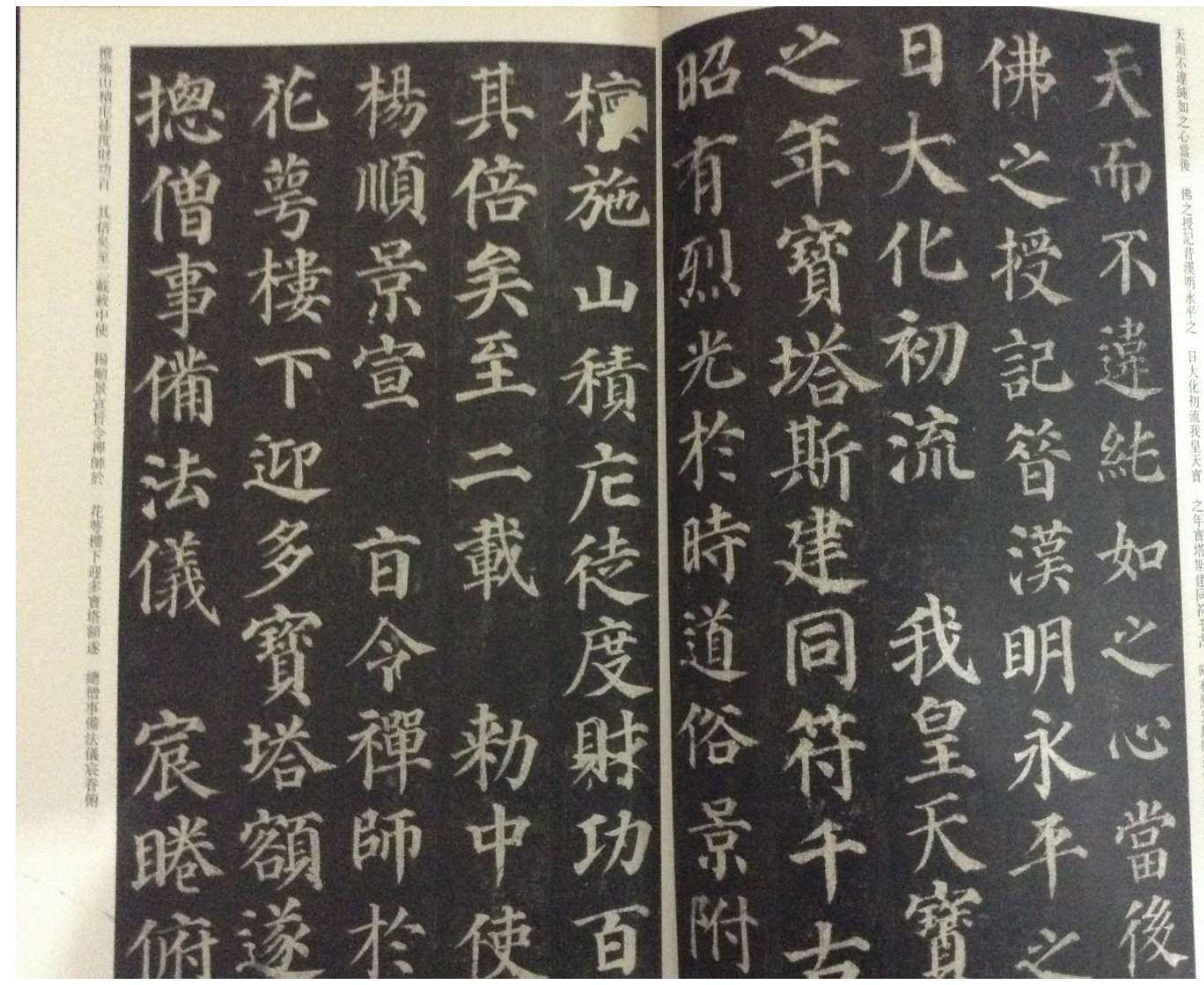

Figure 12. Example of Chinese Calligraphy Handbook Used for Imitation 


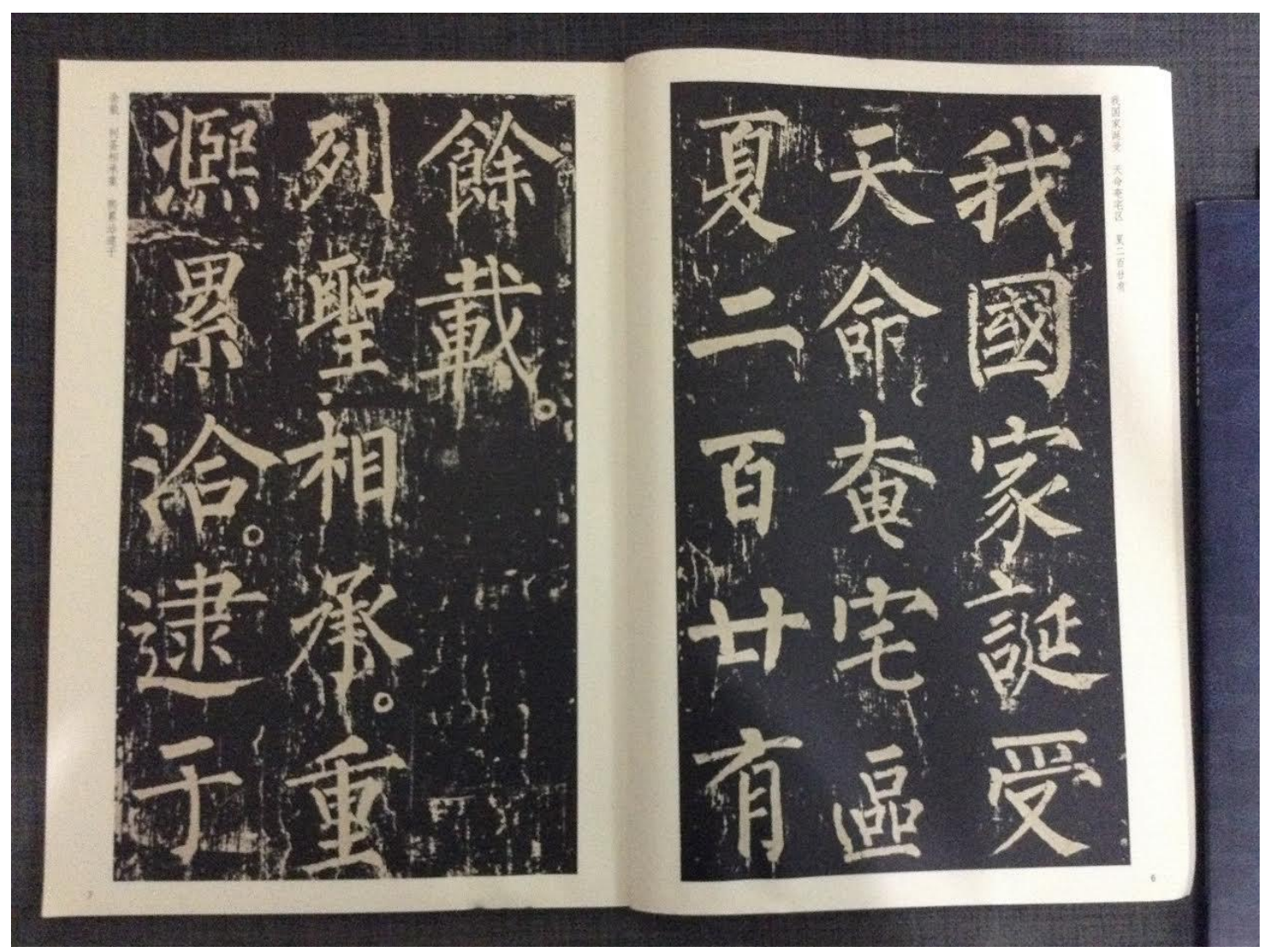

Figure 13. Example of Chinese Calligraphy Handbook Used for Imitation

During the eight weeks of calligraphy intervention, physiological measurements, heart rate, respiratory rate, and blood pressure were measured before (pre-test) and after (posttest) each session, for 8 weeks. Heart rate and blood pressure were measured by a digital sphygmomanometer. The respiratory rate was counted. All physiological measurements were mainly collected by one of the two registered nurses in the cancer caring center, depending which of two nurses was more available at the moment the measurements were taken. To avoid the impact of diurnal fluctuation of physiological parameters, the interventions and measures were set at a fixed time period across 8 weeks. To avoid the influence of physical activity on physiological parameter, participants were 
asked to sit quietly for about 5 minutes before the measurements. All physiological measurements were collected individually at the back of the room.

For psychological measurement, the full battery of the STAI (see Appendix B), and the DASS 21 (See Appendix C) were measured at the pre-intervention (3 times for baseline measurements), mid-intervention (the $4^{\text {th }}$ week) and post-intervention (the $8^{\text {th }}$ week) phases. In this study, the Chinese versions of the STAI and DASS 21 were used.

\section{Treatment of Data}

The demographic survey and psychological data which measured by the STAI and the DASS 21 were collected by the researcher. Physiological data, including heart rate, respiratory rate and blood pressure were collected by a registered nurse in the cancer caring center. All collected data were entered, stored and sorted into the computer, using Microsoft Excel, then transferred to Statistical Package for the Social Science (SPSS version 23) for analysis. Research participants with incomplete data were still entered into SPSS for data analysis with data from their unattended sessions left blank.

\section{Data Analysis}

The aim of this research was to explore the effects of Chinese Calligraphy on reducing the anxiety level of breast cancer patients. It was hypothesized that breast cancer patients participating in the eight-week Chinese calligraphy intervention program would report a reduction of anxiety and comorbid depression levels. This hypothesis was tested by comparing the pre-intervention, mid-intervention $\left(4^{\text {th }}\right.$ week $)$ and post-intervention $\left(8^{\text {th }}\right.$ week) scores on the STAI and DASS 21. In addition to this hypothesis, this study also hypothesized that there would be a calming or slowing effect of Chinese calligraphy 
handwriting on physiological arousal parameters (measured by heart rate, respiration rate and blood pressure).

Physiological arousal parameters (heart rate, respiration rate, and blood pressure)

and psychological measurement (total scale and subscale scores on the STAI and the DASS 21) were analyzed via repeated measures analysis of variance and paired samples t-test, using SPSS. Demographic information of age, education, marital status, handedness, medical information and treatment modality were described using frequency statistics.

\section{Summary of Chapter 3}

This chapter presents the description of the research design, population and sample, as well as the instrumentations, procedures, treatment of data, data analysis and the time line of the research. A quasi-experimental design was employed to explore the changes in anxiety level in breast cancer patients who had participated in an 8-week Chinese calligraphy program, using physiological and self-report psychological assessments. 


\section{CHAPTER 4}

\section{RESULTS}

\section{Introduction}

The purpose of this study is to examine the effects of Chinese calligraphy on reducing the anxiety and comorbid depression levels among breast cancer patients in Hong Kong. This chapter presents the results of the assessments from the participants studied. It is divided into five parts, beginning with the participants' characteristics, assessments results found in the study that include both the physiological and selfreported psychological measurements, the interviews of the participants, the testing of hypotheses, and the summary of major findings.

\section{Participant Characteristics}

A total of 45 breast cancer patients participated in the research. The participants were all local Chinese from a cancer caring support center in the New Territories area of Hong Kong. The age of the participants ranged from 38 to 65 years old with a mean age of 52.58 years $(S D=6.17)$. Among the 45 participants, 30 of them had completed all 8 weeks of Chinese calligraphy intervention. The ages of these 30 participants ranged from 38 to 65 years old with a mean age of 51.9 years $(S D=5.97)$. Some of the SPSS computations, such as paired samples t-test, were using the data of only 30 participants who had completed all 8 weeks of intervention. 
The sample $(n=45)$ consisted of Chinese female patients who were undergoing some kind of breast cancer treatment. Among all the participants, 18 were receiving chemotherapy, 6 receiving radiotherapy, 6 receiving targeted therapy, and 14 receiving hormone therapy. Twenty-nine patients reported that their illness was at the early stage (stage one or two), and 10 reported the $3^{\text {rd }}$ cancer stage, and 1 reported that her cancer was at the $4^{\text {th }}$ stage. Five patients reported that they did not know their cancer stage at the time of reporting. Eighty-seven percent of the participants had at least secondary school education. Two participants were left-handed. Ninety-one percent had never joined any Chinese calligraphy programs or classes before.

For the participants who had completed the whole calligraphy intervention $(n=$ $30), 19$ of them $(63.3 \%)$ were married. One participant $(3.3 \%)$ reported she was lefthanded. Twenty of them $(74.1 \%)$ reported that their illness was at the early stage, 6 reported the $3^{\text {rd }}$ stage, and 1 reported that her cancer was at the $4^{\text {th }}$ stage. Regarding their treatment methods, 11 participants $(36.7 \%)$ were receiving chemotherapy, 5 receiving radiotherapy, 5 receiving targeted therapy, and 8 were receiving hormone therapy. Ninety percent $(90 \%)$ of the participants had at least secondary school education. Eighty-seven percent $(87 \%)$ of the participants reported that they had never joined any Chinese calligraphy classes before. Nineteen participants $(63.3 \%)$ reported that they had home practices during the calligraphy intervention period.

\section{Assessment Results}

This section describes the assessment results of the research showing the effects of calligraphy on physiological measurements, including the systolic and diastolic blood pressure, heart rate, respiratory rate, and the self-reported psychological measurements, 
including the STAI (state and trait anxiety) and DASS 21 (depression, anxiety, stress) results.

\section{Blood Pressure}

\section{Systolic Measures (pre-tests)}

A one-way repeated measures analysis of variance was conducted in order to compare the effects of Chinese calligraphy on the systolic measures of the baselines and all the pre-test conditions. The means and standard deviations of the systolic measures in the pre-tests are presented in Table 2. There was no significant time effect for Chinese calligraphy, $F=1.403, p=.187$ (see Table 2); Wilks' Lambda $=.610, F(9,21)=1.492$, $p=.215$ (see Table 3 ). The results show that there was no significant change in systolic pressure across all measures taken at pre-test periods of the Chinese calligraphy sessions.

\section{Systolic Measures (post-tests)}

A one-way repeated measures analysis of variance was conducted in order to compare the effects of Chinese calligraphy on the systolic measures across the baselines and the post-tests (after each of the calligraphy intervention session) in an eight-week period. The means and standard deviations are presented in Table 4. There was no time significant effect for Chinese calligraphy found, $F=.99, p=.457$ (see Table 5); Wilks'

Lambda $=.643, F(10,20)=1.111, p=.401$. The results suggest that Chinese calligraphy intervention did not reduce the systolic blood pressure of breast cancer patients in an eight-week period. Figure 13 shows the systolic measures in both before and after each intervention across the baselines during the intervention period. The figure shows decrease of the systolic pressure during the $3^{\text {rd, }}$ the $4^{\text {th }}$ and the $6^{\text {th }}$ week of the calligraphy intervention (see Figure 14). 
Table 2

Mean, Standard Deviation of Blood Pressure (Systolic-Pretests)

\begin{tabular}{lllll}
\hline Variable & Definition & $N$ & Mean & $S D$ \\
\hline Time 1 & Systolic-pre at baseline 1 & 30 & 109.83 & 17.71 \\
Time 2 & Systolic-pre at baseline 2 & 30 & 114.50 & 21.32 \\
Time 3 & Systolic-pre at baseline 3 (T1) & 30 & 109.77 & 16.98 \\
Time 4 & Systolic at pre-treatment 2 & 30 & 112.10 & 18.01 \\
Time 5 & Systolic at pre-treatment 3 & 30 & 112.90 & 20.25 \\
Time 6 & Systolic at pre-treatment 4 & 30 & 112.67 & 17.42 \\
Time 7 & Systolic at pre-treatment 5 & 30 & 114.53 & 19.42 \\
Time 8 & Systolic at pre-treatment 6 & 30 & 115.97 & 19.72 \\
Time 9 & Systolic at pre-treatment 7 & 30 & 113.23 & 17.16 \\
Time 10 & Systolic at pre-treatment 8 & 30 & 111.03 & 15.94 \\
\hline
\end{tabular}

Table 3

ANOVA Summary Table of Blood Pressure (Systolic-Pretests)

\begin{tabular}{lrrrrrr}
\hline Source & \multicolumn{1}{c}{$S S$} & \multicolumn{1}{c}{$d f$} & \multicolumn{1}{c}{$M S$} & $F$ & $p$ & $\eta^{2}$ \\
\hline Time (Pre) & 1126.08 & 9 & 125.12 & 1.403 & .187 & .046 \\
Error & 23278.72 & 261 & 89.19 & & & \\
Total & 24404.80 & 270 & 214.31 & & & \\
\hline
\end{tabular}

Several follow-up paired t-tests were conducted to explore if there were significant differences in the pre and posttest conditions at the $3^{\text {rd }}, 4^{\text {th }}$ and $6^{\text {th }}$ interventions (see Table 6). There was not a significant difference in the systolic blood pressure for the pretest $(M=112.98, S D=19.41)$ and the posttest $(M=110.55, S D=$ $20.87)$ at the $3^{\text {rd }}$ intervention condition; $t(39)=1.44, p=.158$. The paired t-tests results also showed that there was not a significant difference in the systolic blood pressure for the pretest $(M=115.91, S D=18.97)$ and the posttest $(M=112.74, S D=18.03)$ at the 6 th 
Table 4

Mean, Standard Deviation of Blood Pressure (Systolic-Posttest)

\begin{tabular}{lllll}
\hline Variable & Definition & $N$ & Mean & $S D$ \\
\hline Time 1 & Systolic-pre at baseline 1 & 30 & 109.83 & 17.71 \\
Time 2 & Systolic-pre at baseline 2 & 30 & 114.50 & 21.32 \\
Time 3 & Systolic-pre at baseline 3 & 30 & 109.77 & 16.98 \\
Time 4 & Systolic at post-treatment 1 & 30 & 110.80 & 17.76 \\
Time 5 & Systolic at post-treatment 2 & 30 & 112.17 & 21.67 \\
Time 6 & Systolic at post-treatment 3 & 30 & 110.03 & 22.42 \\
Time 7 & Systolic at post-treatment 4 & 30 & 109.80 & 18.37 \\
Time 8 & Systolic at post-treatment 5 & 30 & 112.93 & 18.58 \\
Time 9 & Systolic at post-treatment 6 & 30 & 112.03 & 18.89 \\
Time 10 & Systolic at post-treatment 7 & 30 & 113.00 & 18.98 \\
Time 11 & Systolic at post-treatment 8 & 30 & 112.30 & 18.61 \\
\hline
\end{tabular}

Table 5

ANOVA Summary Table of Blood Pressure (Systolic-Posttest)

\begin{tabular}{lrrrrrr}
\hline Source & \multicolumn{1}{c}{$S S$} & \multicolumn{1}{c}{$d f$} & \multicolumn{1}{c}{$M S$} & $F$ & $p$ & $\eta^{2}$ \\
\hline Time (Post) & 778.39 & 10 & 77.84 & .99 & .457 & .033 \\
Error & 22920.71 & 290 & 79.04 & & & \\
Total & 23699.10 & 300 & 156.88 & & & \\
\hline
\end{tabular}

intervention condition; $t(33)=1.57, p=.126$. However, the paired t-test results showed that there was a significant difference in the systolic blood pressure for the pretest $(M=$ $115.30, S D=20.74)$ and the posttest $(M=110.30, S D=17.69)$ at the $4^{\text {th }}$ intervention condition; $t(39)=2.12, p=.041)$. The effect size is small (cohen's $d=0.33$ ). The results suggest that the systolic blood pressure decreased at the $4^{\text {th }}$ calligraphy intervention, and the effect is immediate. 


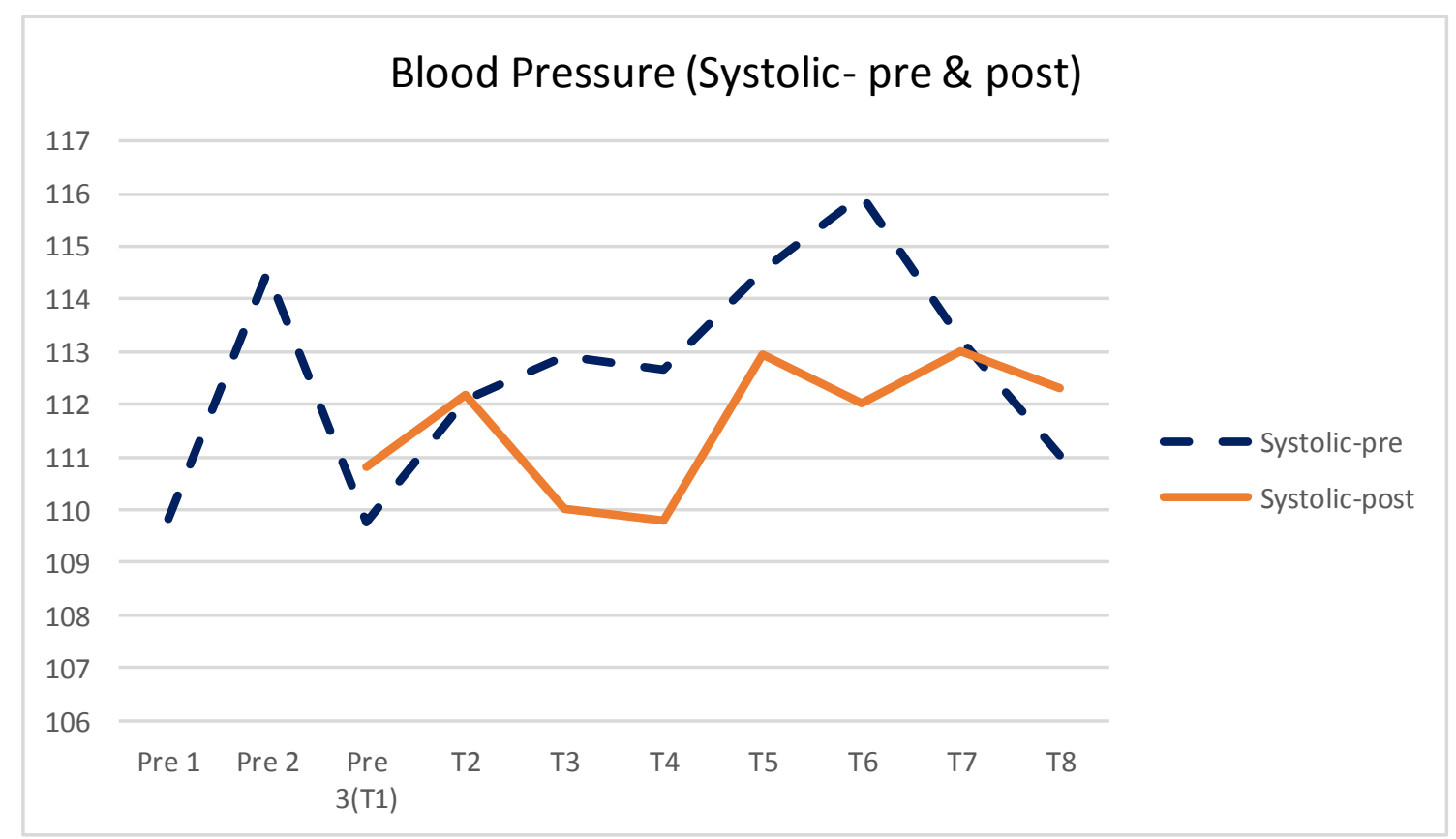

Figure 14. Blood Pressure (Systolic- Pre- \& Posttest)

Table 6

Paired t-tests Results of Systolic Pressure at the $3^{\text {rd }}, 4^{\text {th }} \& 6^{\text {th }}$ Interventions

\begin{tabular}{llllrrr}
\hline & & Mean & SD & t & df & p (2-tailed) \\
\hline T 3 & Pretest & 112.98 & 19.41 & 1.44 & 39 & .158 \\
& Posttest & 110.55 & 20.87 & & & \\
& & & & & & \\
T4 & Pretest & 115.30 & 20.74 & 2.12 & 39 & .041 \\
& Posttest & 110.30 & 17.68 & & & .126 \\
& & 115.91 & 18.97 & 1.57 & 33 & \\
T 6 & Pretest & 112.74 & 18.03 & & & \\
& Posttest & & & & & \\
\end{tabular}




\section{Diastolic Measures (pre-tests)}

A one-way repeated measures analysis of variance was conducted in order to compare the effects of Chinese calligraphy on the diastolic measures in the baselines and all the pre-test conditions. The means and standard deviations of the diastolic measures in the pre-tests are presented in Table 7. There was no significant time effect for Chinese calligraphy, $F=1.13, p=.341$ (see Table 8); Wilks' Lambda $=.768, F(9,21)=.704, p=$ .699. The results suggest that there was no significant change in the diastolic pressure across all the pre-test conditions.

\section{Diastolic Measures (post-tests)}

A one-way repeated measures analysis of variance was conducted in order to compare the effect of Chinese calligraphy on the diastolic measures across the baselines and after each of the calligraphy intervention session in an 8 weeks period. The means and standard deviations are presented in Table 9. There was no time significant effect for

Table 7

Mean, Standard Deviation of Blood Pressure (Diastolic-Pretest)

\begin{tabular}{llllr}
\hline Variable & Definition & $N$ & Mean & $S D$ \\
\hline Time 1 & Diastolic-pre at baseline 1 & 30 & 71.40 & 10.99 \\
Time 2 & Diastolic-pre at baseline 2 & 30 & 71.47 & 10.21 \\
Time 3 & Diastolic-pre at baseline 3 (pre-T1) & 30 & 69.50 & 10.25 \\
Time 4 & Diastolic at pre-treatment 2 & 30 & 70.47 & 10.23 \\
Time 5 & Diastolic at pre-treatment 3 & 30 & 70.73 & 10.03 \\
Time 6 & Diastolic at pre-treatment 4 & 30 & 71.00 & 9.48 \\
Time 7 & Diastolic at pre-treatment 5 & 30 & 73.17 & 8.48 \\
Time 8 & Diastolic at pre-treatment 6 & 30 & 72.47 & 10.27 \\
Time 9 & Diastolic at pre-treatment 7 & 30 & 72.80 & 8.70 \\
Time 10 & Diastolic at pre-treatment 8 & 30 & 72.47 & 8.60 \\
\hline
\end{tabular}


Table 8

ANOVA Summary Table of Blood Pressure (Diastolic-Pretest)

\begin{tabular}{lrrllll}
\hline Source & \multicolumn{1}{c}{$S S$} & \multicolumn{1}{c}{$d f$} & \multicolumn{1}{c}{ MS } & \multicolumn{1}{c}{$F$} & $p$ & $\eta^{2}$ \\
\hline Time (Pre) & 460.34 & 9 & 51.15 & 1.13 & .341 & .038 \\
Error & 11804.36 & 261 & 45.23 & & & \\
Total & 12264.70 & 270 & 96.38 & & & \\
\hline
\end{tabular}

Chinese calligraphy, $F=1.64, p=.09$ (see Table 10); Wilks' Lambda $=.725, F(10,20)=$ $.757, p=.666$. The results suggest that Chinese calligraphy intervention did not reduce the diastolic blood pressure of the breast cancer patients in an eight-week period.

Figure 15 shows the diastolic measures in both before and after each intervention across the baselines and the post-test conditions. The figure shows an increase of the diastolic blood pressure after each of the intervention session (see figure 15). Paired t-

Table 9

Mean, Standard Deviation of Blood Pressure (Diastolic-Posttest)

\begin{tabular}{llllr}
\hline Variable & Definition & $N$ & Mean & \multicolumn{1}{c}{$S D$} \\
\hline Time 1 & Diastolic-pre at baseline 1 & 30 & 71.40 & 10.99 \\
Time 2 & Diastolic-pre at baseline 2 & 30 & 71.47 & 10.21 \\
Time 3 & Diastolic-pre at baseline 3 & 30 & 69.50 & 10.25 \\
Time 4 & Diastolic at post-treatment 1 & 30 & 70.77 & 8.60 \\
Time 5 & Diastolic at post-treatment 2 & 30 & 72.23 & 8.12 \\
Time 6 & Diastolic at post-treatment 3 & 30 & 71.17 & 10.03 \\
Time 7 & Diastolic at post-treatment 4 & 30 & 72.40 & 7.76 \\
Time 8 & Diastolic at post-treatment 5 & 30 & 74.00 & 8.89 \\
Time 9 & Diastolic at post-treatment 6 & 30 & 73.90 & 7.76 \\
Time 10 & Diastolic at post-treatment 7 & 30 & 73.93 & 8.25 \\
Time 11 & Diastolic at post-treatment 8 & 30 & 73.63 & 9.16 \\
\hline
\end{tabular}


Table 10

ANOVA Summary Table of Blood Pressure (Diastolic-Posttest)

\begin{tabular}{lrrrrrr}
\hline Source & \multicolumn{1}{c}{$S S$} & \multicolumn{1}{c}{$d f$} & \multicolumn{1}{c}{$M S$} & $F$ & $p$ & $\eta^{2}$ \\
\hline Time (Post) & 684.49 & 10 & 68.45 & 1.64 & .09 & .054 \\
Error & 12003.33 & 290 & 41.39 & & & \\
Total & 12687.82 & 300 & 109.84 & & & \\
\hline
\end{tabular}

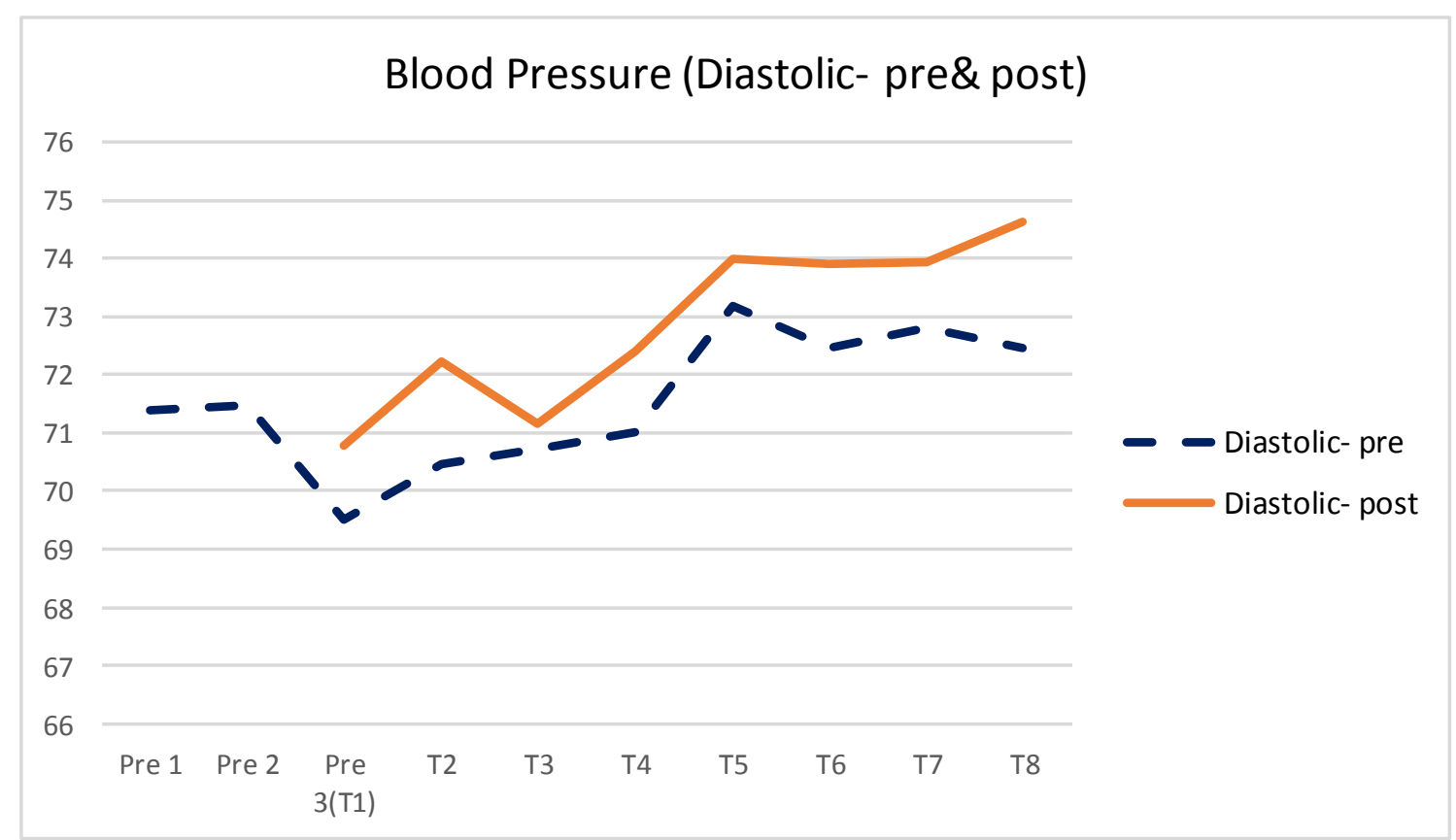

Figure 15. Blood Pressure (Diastolic- Pre- \& Posttest)

tests were conducted to compare the diastolic blood pressure in the pre- and posttests at each intervention. No significant difference in any intervention session was found. 


\section{Heart Rate}

\section{Pre-tests}

A one-way repeated measures analysis of variance was conducted in order to compare the effects of Chinese calligraphy on heart rate in the baselines and the pre-test conditions. The means and standard deviations of heart rate in the pre-test are presented in Table 11. There was a significant time effect for Chinese calligraphy, $F=4.85, p<$ $.001, \eta^{2}=.143($ see Table 12$) ;$ Wilks' Lambda $=.61, F(9,21)=9.595, p<.001$. The results suggest that there was a significant increase in heart rate across the Chinese calligraphy pre-test conditions.

Several follow-up paired samples t-tests were conducted to compare the heart rate in different pre-test time periods. There was a significant difference in heart rate between the $1^{\text {st }}$ baseline $(M=73.70, S D=10.13)$, and the $2^{\text {nd }}$ baseline $(M=77.50, S D=10.23)$ conditions; $t(29)=-2.27, p=.031$. Also, another paired t-test showed that there was a significant difference between the $1^{\text {st }}$ baseline and the $3^{\text {rd }}$ baseline $(M=77.57, S D=9.87)$

Table 11

Mean, Standard Deviation of Heart Rate (Pretest)

\begin{tabular}{llllr}
\hline Variable & Definition & $N$ & Mean & \multicolumn{1}{l}{$S D$} \\
\hline Time 1 & Heart Rate-pre at baseline 1 & 30 & 73.70 & 10.13 \\
Time 2 & Heart Rate-pre at baseline 2 & 30 & 77.50 & 10.23 \\
Time 3 & Heart Rate-pre at baseline 3 (T1) & 30 & 77.57 & 9.87 \\
Time 4 & Heart Rate at pre-treatment 2 & 30 & 82.00 & 8.87 \\
Time 5 & Heart Rate at pre-treatment 3 & 30 & 79.23 & 9.91 \\
Time 6 & Heart Rate at pre-treatment 4 & 30 & 80.60 & 11.43 \\
Time 7 & Heart Rate at pre-treatment 5 & 30 & 80.37 & 12.25 \\
Time 8 & Heart Rate at pre-treatment 6 & 30 & 83.53 & 15.08 \\
Time 9 & Heart Rate at pre-treatment 7 & 30 & 81.90 & 12.12 \\
Time 10 & Heart Rate at pre-treatment 8 & 30 & 83.20 & 11.85 \\
\hline
\end{tabular}


Table 12

ANOVA Summary Table of Heart Rate (Pretest)

\begin{tabular}{lrrrlll}
\hline Source & \multicolumn{1}{c}{$S S$} & \multicolumn{1}{c}{$d f$} & \multicolumn{1}{c}{$M S$} & $F$ & $p$ & $\eta^{2}$ \\
\hline Time (Pre) & 2497.85 & 9 & 277.54 & 4.85 & .000 & .143 \\
Error & 14949.95 & 261 & 57.28 & & & \\
Total & 17447.80 & 270 & 334.82 & & & \\
\hline
\end{tabular}

conditions; $t(29)=-2.35, p<.026$. These results suggest that heart rate significantly increased before the calligraphy intervention ( 3.8 beats from baseline 1 to baseline 2 , and 3.87 beats from baseline 1 to baseline 3 ).

Similarly, a paired samples t-test was conducted to compare the heart rates in the $3^{\text {rd }}$ baseline and the $2^{\text {nd }}$ pre-test conditions (after the $1^{\text {st }}$ intervention, before the $2^{\text {nd }}$ intervention was given). There was a significant difference in heart rate for the $3^{\text {rd }}$ baseline $(M=77.57, S D=9.87)$ and the $2^{\text {nd }}$ pre-test $(M=82.0, S D=8.87)$ condition; $t(29)=-2.68, p=.012$. The results suggest that heart rate increased significantly at the $2^{\text {nd }}$ pre-test condition. Several paired t-tests were conducted to compare the baselines and different pre-test conditions. The results showed that there was no significant difference in heart rate between the $3^{\text {rd }}$ baseline and the $3^{\text {rd }}$ pre-test condition; the $3^{\text {rd }}$ baseline and the $4^{\text {th }}$ pre-test condition; the $3^{\text {rd }}$ baseline and the $5^{\text {th }}$ pre-test condition.

However, significant differences were found between the $3^{\text {rd }}$ baseline $(M=77.57$, $S D=9.87)$ and the $6^{\text {th }}$ pre-test $(M=83.53, S D=15.08)$ condition; $t(29)=-2.71, p=.011$; the $3^{\text {rd }}$ baseline $(M=77.57, S D=9.87)$ and the $7^{\text {th }}$ pre-test $(M=81.90, S D=12.12)$ condition; $t(29)=-2.30, p=.029 ;$ also between the $3^{\text {rd }}$ baseline $(M=77.57, S D=9.87)$ and the $8^{\text {th }}$ pre-test $(M=83.20, S D=11.85)$ condition; $t(29)=-4.15, p<.001$. 
These results show that the heart rates of participants increased significantly across the ten-week period in the pre-test conditions. Specifically, the heart rate increased across the baselines and the very early stage of the intervention ( $2^{\text {st }}$ pre-test). It did not significantly increase during the middle stage $\left(3^{\text {rd }}, 4^{\text {th }}\right.$, and $\left.5^{\text {th }}\right)$ of the intervention, but it increased significantly again in the final stage $\left(6^{\text {th }}, 7^{\text {th }}\right.$ and $8^{\text {th }}$ pre-test $)$ of the intervention.

\section{Post-tests}

A one-way repeated measures analysis of variance was conducted in order to compare the effects of Chinese calligraphy on heart rate across the baselines and after each of the calligraphy intervention sessions. The means and standard deviations are presented in Table 13. There was a significant time effect for Chinese calligraphy, $F=$ $2.535, p=.006, \eta^{2}=.08$ (see Table 14); Wilks' Lambda $=.144, F(10,20)=11.843, p<$ .001 . The results suggest that there was a significant decrease in heart rate across the baseline and that measured at the Chinese calligraphy post-intervention condition. The effect size is medium.

Figure 16 shows the heart rate measured both before and after each intervention across the baseline and in the intervention period. A follow-up paired t-test was conducted to compare the group means of pre-intervention to the group means of post intervention condition for each session administered to confirm statistical significance. There was a significant difference in the mean of pre-intervention $(M=81.04, S D=2.03)$ and post intervention $(M=73.86, S D=1.51)$ conditions; $t(7)=12.76, p<.001$. The heart rate of the participants decreased 7.18 beats per minute in average after each Calligraphy intervention. The results suggest that Chinese calligraphy does reduce heart rate. 
Table 13

Mean, Standard Deviation of Heart Rate (Posttest)

\begin{tabular}{llllr}
\hline Variable & Definition & $N$ & Mean & \multicolumn{1}{c}{$S D$} \\
\hline Time 1 & Heart Rate-pre at baseline 1 & 30 & 73.70 & 10.13 \\
Time 2 & Heart Rate-pre at baseline 2 & 30 & 77.50 & 10.23 \\
Time 3 & Heart Rate-pre at baseline 3 & 30 & 77.57 & 9.87 \\
Time 4 & Heart Rate at post-treatment 1 & 30 & 72.57 & 9.91 \\
Time 5 & Heart Rate at post-treatment 2 & 30 & 74.80 & 10.16 \\
Time 6 & Heart Rate at post-treatment 3 & 30 & 71.73 & 9.40 \\
Time 7 & Heart Rate at post-treatment 4 & 30 & 75.10 & 9.96 \\
Time 8 & Heart Rate at post-treatment 5 & 30 & 72.23 & 10.85 \\
Time 9 & Heart Rate at post-treatment 6 & 30 & 73.70 & 11.27 \\
Time 10 & Heart Rate at post-treatment 7 & 30 & 75.67 & 12.50 \\
Time 11 & Heart Rate at post-treatment 8 & 30 & 75.07 & 12.86 \\
\hline
\end{tabular}

Table 14

ANOVA Summary Table of Heart Rate (Posttest)

\begin{tabular}{lcrrrrr}
\hline Source & \multicolumn{1}{c}{$S S$} & \multicolumn{1}{c}{$d f$} & \multicolumn{1}{c}{$M S$} & $F$ & $p$ & $\eta^{2}$ \\
\hline Time (Post) & 1150.352 & 10 & 115.035 & 2.53 & .006 & .080 \\
Error & 13157.648 & 290 & 45.371 & & & \\
Total & 14308 & 300 & 160.406 & & & \\
\hline
\end{tabular}

Paired t-tests were conducted to compare the heart rate in the pre- and posttest conditions at each intervention. Results of the paired-sample t-tests showed that the mean of the posttests decreased significantly from that of the pretest condition at each intervention (see Table 15). Heart rate decreased significantly from 6.00 to 9.56 beats. The results suggest that heart rate decreased immediately each time after Chinese calligraphy writing 


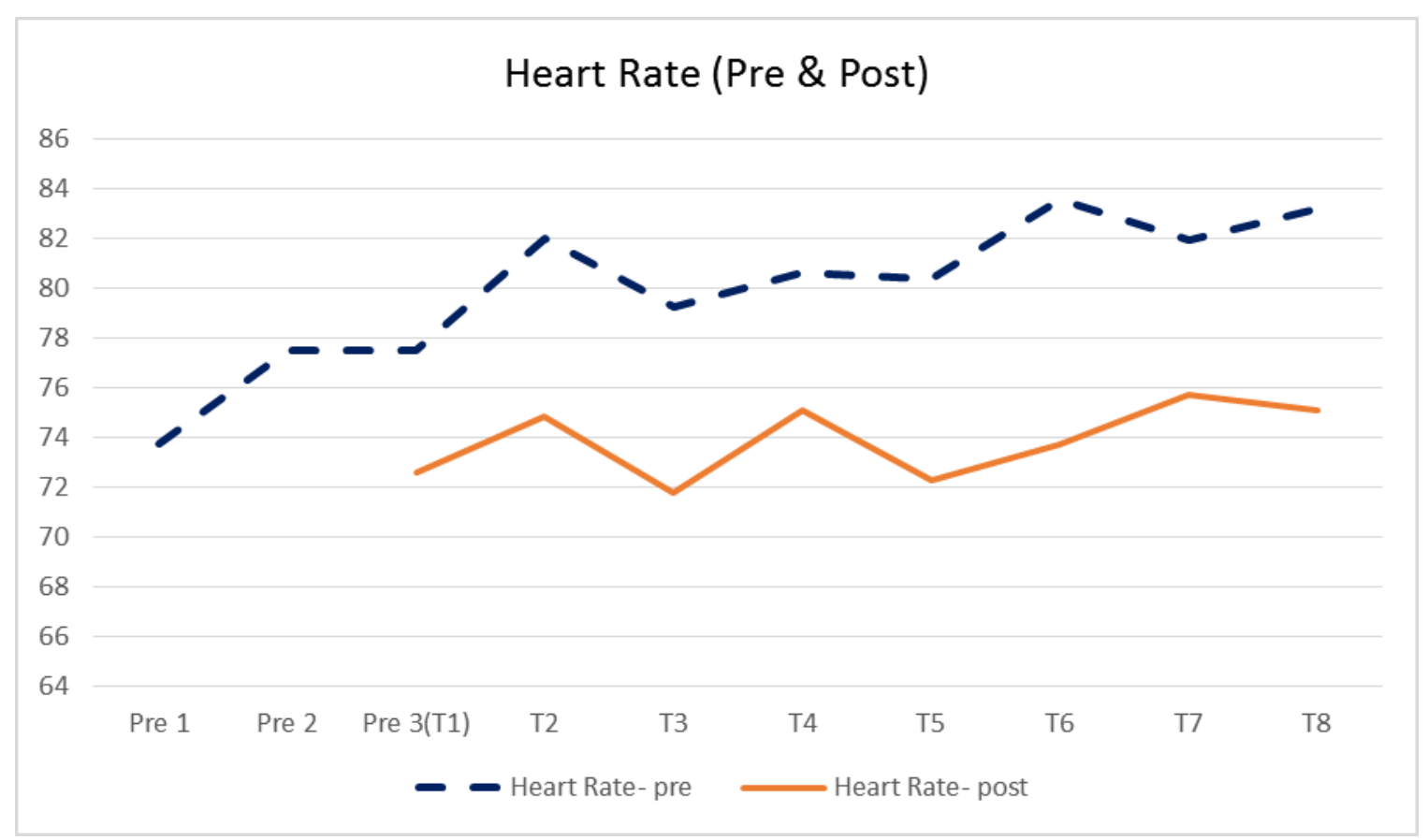

Figure 16. Heart Rate (Pre- \& Posttest)

Table 15

Paired t-test Results of Heart Rate (Pre-\& Posttest)

\begin{tabular}{llllclc}
\hline & & Mean & $S D$ & $t$ & $d f$ & $p$ (2-tailed) \\
\hline T 1 & Pre/ Posttest & 6.59 & 5.67 & 7.72 & 43 & .000 \\
T 2 & Pre/ Posttest & 7.46 & 6.90 & 6.92 & 40 & .000 \\
T 3 & Pre/ Posttest & 7.73 & 6.54 & 7.47 & 39 & .000 \\
T 4 & Pre/ Posttest & 6.00 & 7.32 & 5.19 & 39 & .000 \\
T 5 & Pre/ Posttest & 7.63 & 7.93 & 5.69 & 34 & .000 \\
T 6 & Pre/ Posttest & 9.56 & 7.49 & 7.44 & 33 & .000 \\
T 7 & Pre/ Posttest & 6.23 & 6.42 & 5.40 & 30 & .000 \\
T 8 & Pre/ Posttest & 8.13 & 6.44 & 6.92 & 29 & .000 \\
& & & & & & \\
\hline
\end{tabular}




\section{Respiratory Rate}

\section{Pre-tests}

A one-way repeated measures analysis of variance was conducted to compare the effect of Chinese calligraphy on respiratory rate in all pre-test conditions. The means and standard deviations of respiration rate in the pre-tests are presented in Table 16. There was no significant time effect for Chinese calligraphy in pre-test conditions, $F=1.28, p=$ .249 (see Table 17); Wilks' Lambda $=.661, F(9,21)=1.196, p=.348$. The results suggest that respiration rate does not change before Chinese calligraphy writing.

Table 16

Mean, Standard Deviation of Respiration Rate (Pretest)

\begin{tabular}{lllll}
\hline Variable & Definition & $N$ & Mean & $S D$ \\
\hline Time 1 & Respiration Rate-pre at baseline 1 & 30 & 17.90 & 1.51 \\
Time 2 & Respiration Rate-pre at baseline 2 & 30 & 17.73 & 1.87 \\
Time 3 & Respiration -pre at baseline 3 (T1) & 30 & 17.37 & 1.75 \\
Time 4 & Respiration Rate at pre-treatment 2 & 30 & 17.77 & 1.52 \\
Time 5 & Respiration Rate at pre-treatment 3 & 30 & 18.33 & 1.49 \\
Time 6 & Respiration Rate at pre-treatment 4 & 30 & 18.00 & 1.46 \\
Time 7 & Respiration Rate at pre-treatment 5 & 30 & 18.37 & 1.45 \\
Time 8 & Respiration Rate at pre-treatment 6 & 30 & 17.93 & 1.44 \\
Time 9 & Respiration Rate at pre-treatment 7 & 30 & 17.73 & 1.95 \\
Time 10 & Respiration Rate at pre-treatment 8 & 30 & 18.27 & 1.36 \\
\hline
\end{tabular}

Table 17

ANOVA Summary Table of Respiration Rate (Pretest)

\begin{tabular}{lrrrrrr}
\hline Source & \multicolumn{1}{c}{$S S$} & $d f$ & $M S$ & $F$ & $p$ & $\eta^{2}$ \\
\hline Time (Pre) & 26.79 & 9 & 2.98 & 1.28 & .249 & .042 \\
Error & 607.81 & 261 & 2.33 & & & \\
Total & 634.60 & 270 & 5.30 & & & \\
\hline
\end{tabular}




\section{Post-tests}

A one-way repeated measures analysis of variance was conducted to compare the effect of Chinese calligraphy on the respiration rate across the baselines and after each of the calligraphy intervention session. The means and standard deviations are presented in Table 18. There was a significant time effect for Chinese calligraphy on respiration rate, $F=4.67, p<.001, \eta^{2}=.14($ see Table 19); Wilks' Lambda $=.436, F(10,20)=2.585, p=$ .034. The effect size is large. The results suggest that respiration rate decreases after Chinese calligraphy writing over time.

Figure 17 shows the respiration rate measured both before and after each intervention across the baseline and the intervention periods. A follow-up paired samples t-test was conducted to compare the group means of pre-intervention to the group means of their post intervention condition for each session administered to confirm statistical significance. There was a significant difference in the mean for pre-intervention $(M=$

Table 18

Mean, Standard Deviation of Respiration Rate (Posttest)

\begin{tabular}{lllll}
\hline Variable & Definition & $N$ & Mean & $S D$ \\
\hline Time 1 & Respiration Rate-pre at baseline 1 & 30 & 17.90 & 1.51 \\
Time 2 & Respiration Rate-pre at baseline 2 & 30 & 17.73 & 1.87 \\
Time 3 & Respiration Rate-pre at baseline 3 & 30 & 17.37 & 1.75 \\
Time 4 & Respiration Rate at post-treatment 1 & 30 & 16.17 & 1.78 \\
Time 5 & Respiration Rate at post-treatment 2 & 30 & 16.33 & 1.73 \\
Time 6 & Respiration Rate at post-treatment 3 & 30 & 17.03 & 1.35 \\
Time 7 & Respiration Rate at post-treatment 4 & 30 & 16.77 & 1.38 \\
Time 8 & Respiration Rate at post-treatment 5 & 30 & 16.70 & 1.47 \\
Time 9 & Respiration Rate at post-treatment 6 & 30 & 16.30 & 1.56 \\
Time 10 & Respiration Rate at post-treatment 7 & 30 & 16.43 & 1.85 \\
Time 11 & Respiration Rate at post-treatment 8 & 30 & 16.73 & 1.11 \\
\hline
\end{tabular}


Table 19

ANOVA Summary Table of Respiration Rate (Posttest)

\begin{tabular}{lcrrrrc}
\hline Source & \multicolumn{1}{c}{$S S$} & \multicolumn{1}{c}{$d f$} & \multicolumn{1}{c}{$M S$} & $F$ & $p$ & $\eta^{2}$ \\
\hline Time (Post) & 103.06 & 10 & 10.31 & 4.67 & .000 & .14 \\
Error & 640.04 & 290 & 2.21 & & & \\
Total & 734.10 & 300 & 12.52 & & & \\
\hline
\end{tabular}

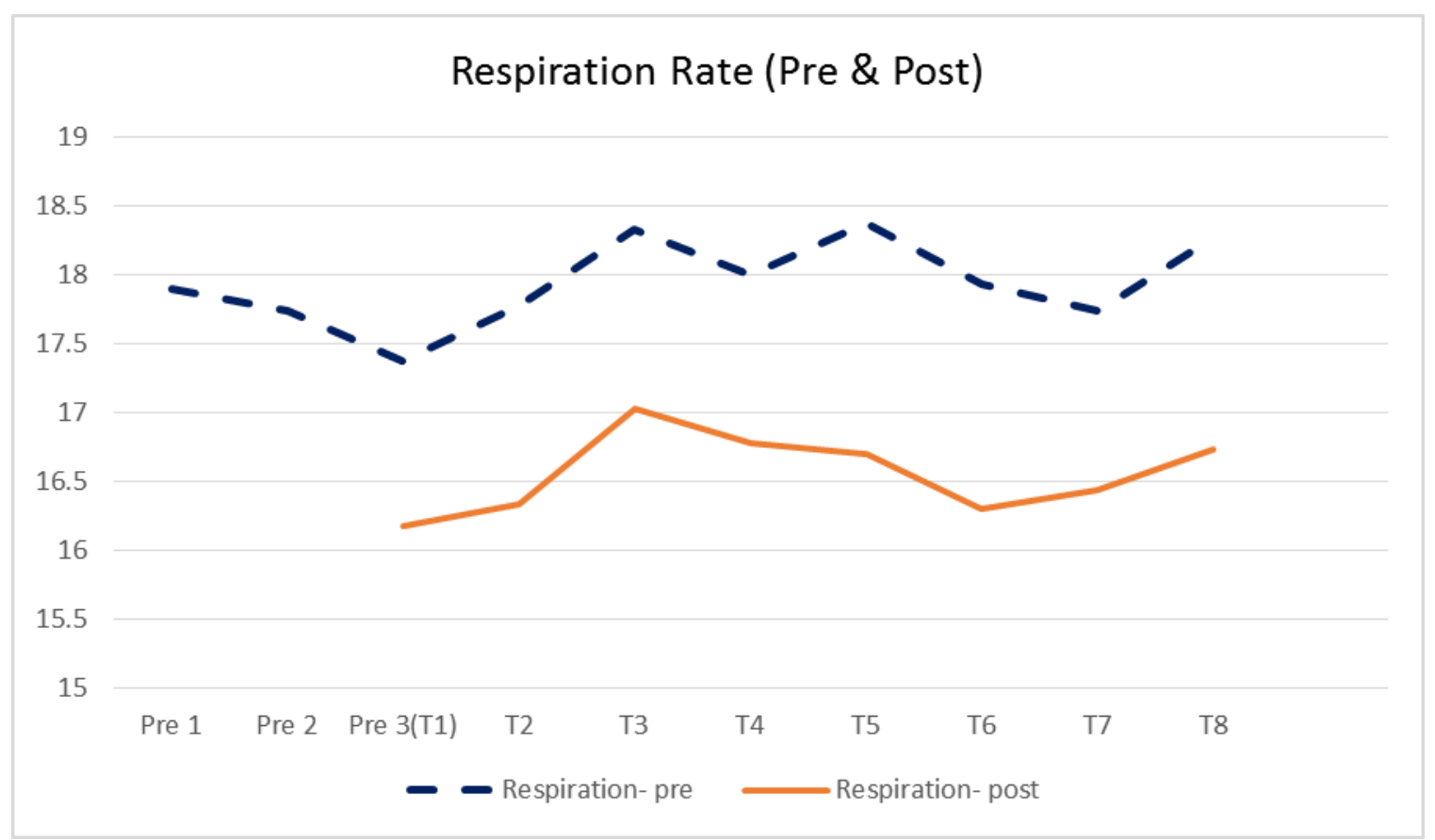

Figure 17. Respiratory Rate (Pre- \& Posttest)

17.97, $S D=.35)$ and post intervention $(M=16.56, S D=.29 ; t(7)=21.63, p<.001$. The results suggest that Chinese calligraphy does reduce respiration rate.

Follow-up paired t-tests were conducted to compare the respiration rate in the pre- and posttest conditions at each intervention. Results of the paired-sample t-tests showed that the mean of the posttests decreased significantly from that of the pretest conditions at 
each intervention (see Table 20). Specifically, the results suggest that Chinese calligraphy decreases respiration rate, and the effect is immediate.

Table 20

Paired t-tests Results of Respiration Rate (Pre- \& Posttest)

\begin{tabular}{llllllr}
\hline & & Mean & SD & t & df & p (2-tailed) \\
\hline T 1 & Pre/ Posttest & 1.32 & 1.60 & 5.48 & 43 & .000 \\
T 2 & Pre/ Posttest & 1.48 & 1.42 & 6.73 & 40 & .000 \\
T 3 & Pre/ Posttest & 1.13 & 1.18 & 6.03 & 39 & .000 \\
T 4 & Pre/ Posttest & 1.33 & 1.44 & 5.82 & 39 & .000 \\
T 5 & Pre/ Posttest & 1.60 & 1.14 & 8.28 & 34 & .000 \\
T 6 & Pre/ Posttest & 1.62 & 1.30 & 7.24 & 33 & .000 \\
T 7 & Pre/ Posttest & 1.26 & 1.37 & 5.13 & 30 & .000 \\
T 8 & Pre/ Posttest & 1.53 & 1.14 & 7.39 & 29 & .000 \\
\hline
\end{tabular}

State-Trait Anxiety Inventory Results

\section{State Anxiety}

A one-way repeated measures ANOVA was conducted to evaluate the score of state anxiety in the pre-, mid- and the post calligraphy intervention. The means and standard deviation for state anxiety scores are shown in Table 17. The results for the ANOVA in Table 21 showed a significant time effect on the state anxiety level, $F=9.31$, $p<.001, \eta^{2}=.24$ (see Table 22); Wilks' Lambda $=.437, F(4,26)=8.367, p<001$. The scores of the state anxiety decreased significantly from 41.00 to 32.87 . The effect size is large. The pairwise comparisons results in Table 23 show that there is a significant difference between the baselines and mid-intervention period; baselines and the final intervention period; as well as the mid-intervention and the final intervention period. No significant differences are found between baselines before the intervention was 
implemented. The results suggest that Chinese calligraphy writing does reduce state anxiety level over time. Figure 18 shows the scores of the State anxiety scale in the STAI

Table 21

Mean, Standard Deviation of State Anxiety

\begin{tabular}{lllll}
\hline Variable & Definition & $N$ & Mean & $S D$ \\
\hline Time 1 & State Anxiety-pre at baseline 1 & 30 & 41.00 & 12.55 \\
Time 2 & State Anxiety-pre at baseline 2 & 30 & 42.43 & 15.41 \\
Time 3 & State Anxiety-pre at baseline 3 & 30 & 41.07 & 10.56 \\
Time 4 & State Anxiety- mid-intervention & 30 & 36.23 & 10.41 \\
Time 5 & State Anxiety- final intervention & 30 & 32.87 & 8.81 \\
\hline
\end{tabular}

Table 22

ANOVA Summary Table of State Anxiety

\begin{tabular}{lcrrrrr}
\hline Source & \multicolumn{1}{c}{$S S$} & \multicolumn{1}{c}{$d f$} & \multicolumn{1}{c}{$M S$} & $F$ & $p$ & $\eta^{2}$ \\
\hline Time (State) & 1948.17 & 4 & 487.04 & 9.31 & .000 & .243 \\
Error & 6071.83 & 116 & 52.34 & & & \\
Total & 8020.00 & 120 & 539.38 & & & \\
\hline
\end{tabular}

Table 23

Pairwise Comparison (State Anxiety)

\begin{tabular}{|c|c|c|c|c|c|}
\hline 1 Time & Mean & 2 & 3 & 4 & 5 \\
\hline 1 Base 1 & 41.00 & & & $*$ & $*$ \\
\hline 2 Base 2 & 42.43 & & & $*$ & $*$ \\
\hline 3 Base 3 & 41.07 & & & $*$ & $*$ \\
\hline $4 \mathrm{Mid}$ & 36.23 & & & & $*$ \\
\hline 5 Final & 32.87 & & & & \\
\hline
\end{tabular}




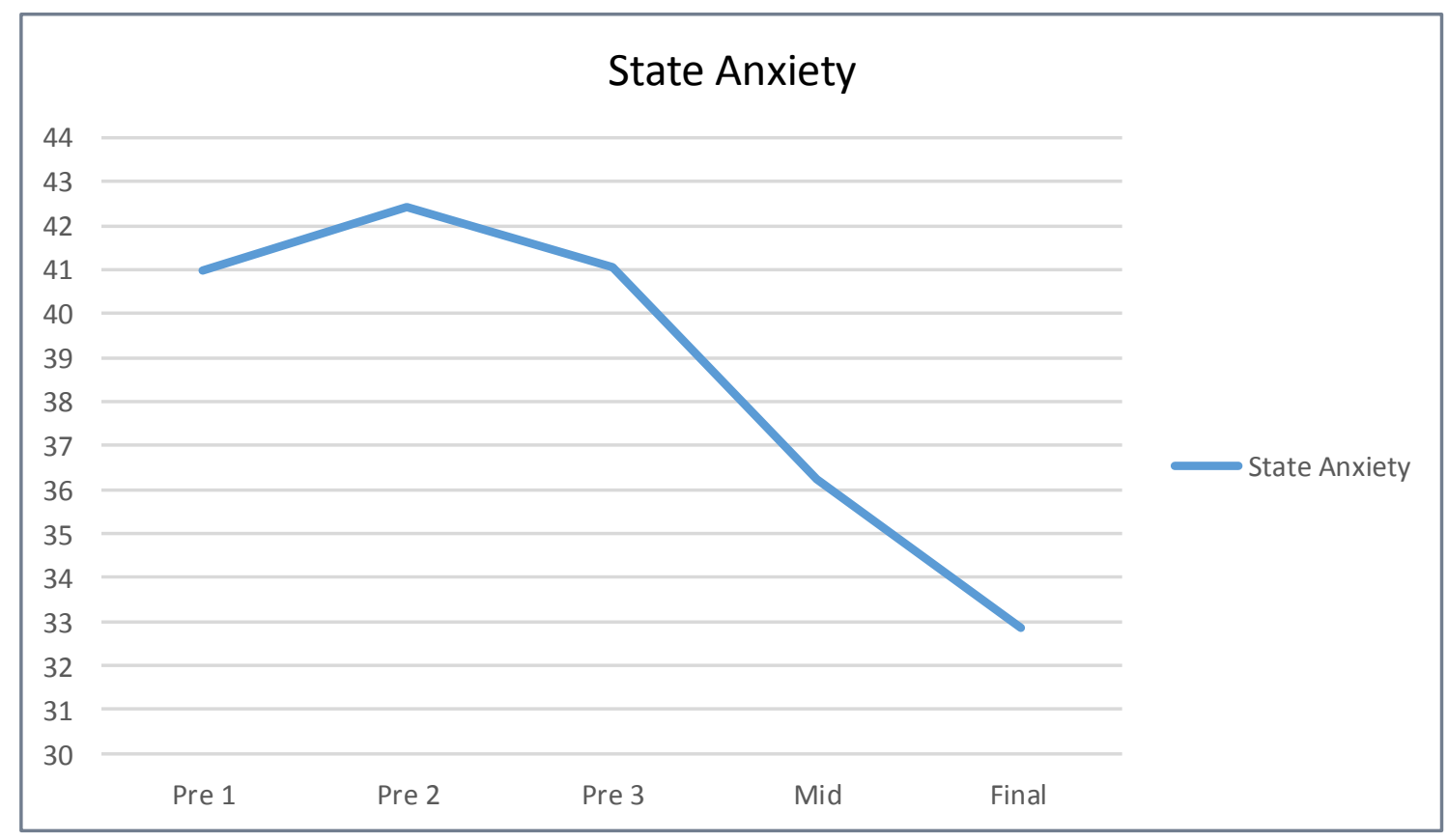

Figure 18. State Anxiety

across the baselines, mid ( 4 weeks) and post ( 8 weeks) intervention of Chinese calligraphy.

\section{Trait Anxiety}

A one-way repeated measures ANOVA was conducted to evaluate the trait anxiety scores under the pre-, mid- and post calligraphy intervention conditions. The mean and standard deviation for the trait scores are shown in Table 24. The results for the ANOVA in Table 25 showed a significant time effect on the trait anxiety level, $F=8.7, p$ $<.001, \eta^{2}=.23$; Wilks' Lambda $=.58, F(4,26)=4.7, p=.005$. The scores of the trait anxiety decreased significantly from 46.73 to 40.83 . The effect size is large. The pairwise comparisons results in Table 26 show that there are significant differences between the baselines and mid-intervention period; baselines and the final intervention period; as well 
Table 24

Mean, Standard Deviation of Trait Anxiety

\begin{tabular}{lllll}
\hline Variable & Definition & $N$ & Mean & $S D$ \\
\hline Time 1 & Trait Anxiety-pre at baseline 1 & 30 & 46.73 & 11.97 \\
Time 2 & Trait Anxiety-pre at baseline 2 & 30 & 46.10 & 10.68 \\
Time 3 & Trait Anxiety-pre at baseline 3 & 30 & 45.93 & 9.92 \\
Time 4 & Trait Anxiety- mid-intervention & 30 & 42.63 & 8.62 \\
Time 5 & Trait Anxiety- final intervention & 30 & 40.83 & 8.21 \\
\hline
\end{tabular}

Table 25

ANOVA Summary Table of Trait Anxiety

\begin{tabular}{lrrrrrr}
\hline Source & \multicolumn{1}{c}{$S S$} & \multicolumn{1}{c}{$d f$} & \multicolumn{1}{c}{$M S$} & $F$ & $p$ & $\eta^{2}$ \\
\hline Time (Trait) & 759.51 & 4 & 198.88 & 8.70 & .000 & .23 \\
Error & 2664.09 & 116 & 22.97 & & & \\
Total & 3423.60 & 120 & 221.85 & & & \\
\hline
\end{tabular}

Table 26

Pairwise Comparison (Trait Anxiety)

\begin{tabular}{|c|c|c|c|c|c|}
\hline Time & Mean & 2 & 3 & 4 & 5 \\
\hline 1 Base 1 & 46.73 & & & $*$ & $*$ \\
\hline 2 Base 2 & 46.10 & & & $*$ & $*$ \\
\hline 3 Base 3 & 45.93 & & & $*$ & $*$ \\
\hline Mid & 42.63 & & & & $*$ \\
\hline Final & 40.83 & & & & \\
\hline
\end{tabular}

as the mid-intervention and the final intervention period, but no differences are found between the baselines. The results suggest that Chinese calligraphy writing reduces trait 


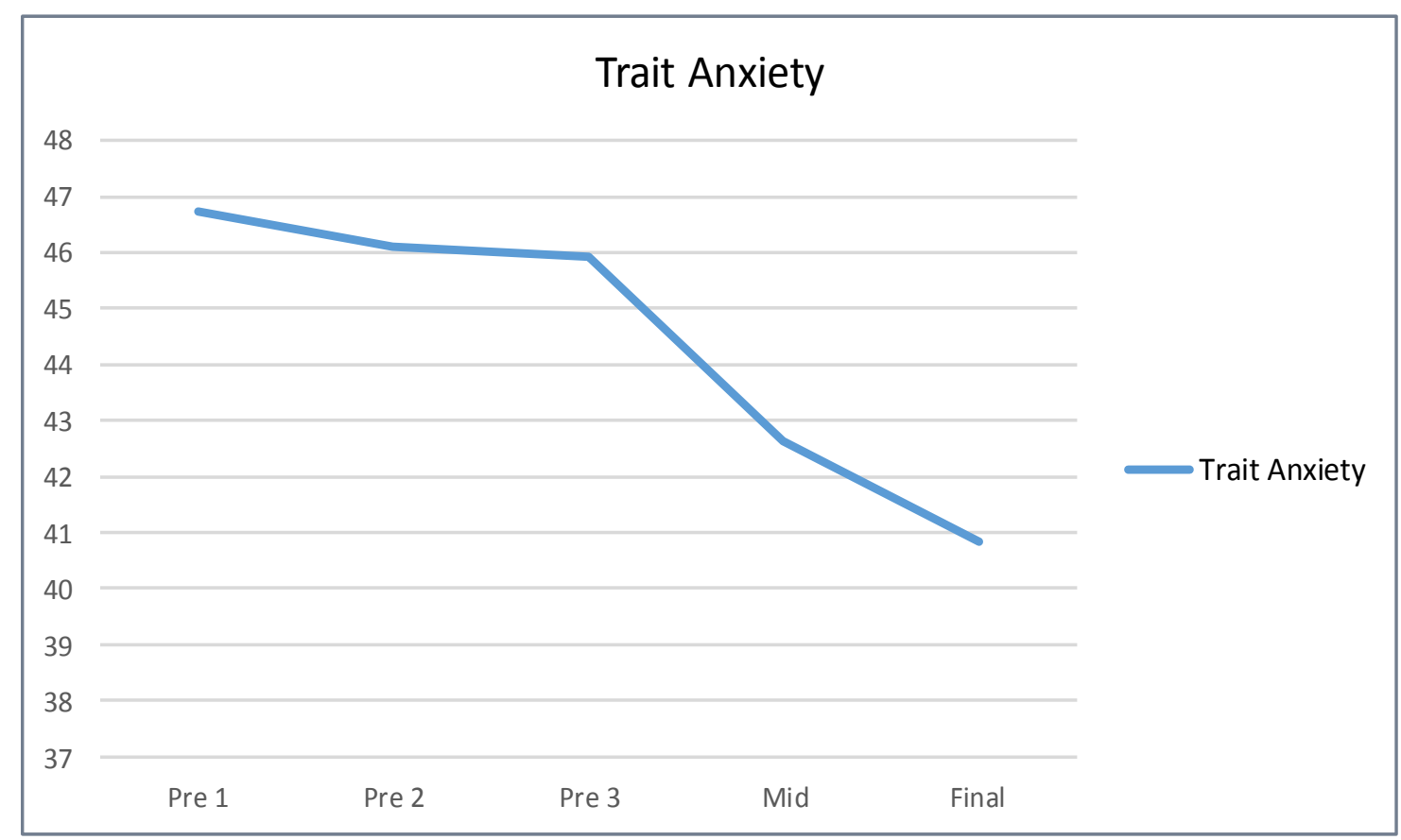

Figure 19. Trait Anxiety

anxiety level over time. Figure 19 shows the scores of the Trait anxiety scale in the STAI across the baselines, mid (4 weeks) and post ( 8 weeks) intervention of Chinese calligraphy.

\section{Depression Anxiety Stress Scale 21 Results}

\section{Depression Scores}

A one-way repeated measures ANOVA was conducted to evaluate the scores on the depression subscale of DASS 21 under pre-, mid- and the post calligraphy intervention conditions. The mean and standard deviation for depression scores are shown in Table 27. The results for the ANOVA in Table 28 show a significant time effect on the depression subscale, $F=9.97, p=.000, \eta^{2}=.26$; Wilks' Lambda $=.53, F(4,26)=5.72$, $p=002$. The scores for depression significantly reduced from 10.2 (mild) to 4.8 (normal). The effect size is large. 
Table 27

Mean, Standard Deviation of Depression Subscale in DASS 21

\begin{tabular}{lllrl}
\hline Variable & Definition & $N$ & Mean & $S D$ \\
\hline Time 1 & Depression-pre at baseline 1 & 30 & 10.20 & 8.52 \\
Time 2 & Depression-pre at baseline 2 & 30 & 8.60 & 6.50 \\
Time 3 & Depression-pre at baseline 3 & 30 & 10.07 & 7.66 \\
Time 4 & Depression- mid-intervention & 30 & 6.73 & 6.73 \\
Time 5 & Depression- final intervention & 30 & 4.80 & 4.80 \\
\hline
\end{tabular}

Table 28

ANOVA Summary Table of Depression Subscale in DASS 21

\begin{tabular}{lrrrrrr}
\hline Source & \multicolumn{1}{c}{$S S$} & $d f$ & \multicolumn{1}{c}{$M S$} & $F$ & $p$ & $\eta^{2}$ \\
\hline Time (depress) & 638.51 & 4 & 159.63 & 9.97 & .000 & .256 \\
Error & 1856.69 & 116 & 16.01 & & & \\
Total & 2495.20 & 120 & 175.64 & & & \\
\hline
\end{tabular}

The pairwise comparisons results in Table 29 show that there are significant differences between the baselines and mid-intervention period; baselines and the final intervention period; as well as the mid-intervention and the final intervention period, but no differences are found between baselines. The results suggest that Chinese calligraphy reduces depression level over time. Figure 20 shows the scores of the DASS 21 depression subscales across the baselines, mid ( 4 weeks) and post ( 8 weeks) intervention of Chinese calligraphy.

\section{Anxiety Scores}

A one-way repeated measures ANOVA was conducted to evaluate the scores on the anxiety subscale of DASS 21 under pre- (before), mid- (after 4 weeks) and post (after 
Table 29

Pairwise Comparison (Depression)

\begin{tabular}{|c|c|c|c|c|c|}
\hline$\overline{\text { Time }}$ & Mean & 2 & 3 & 4 & 5 \\
\hline 1 Base 1 & 10.20 & & & $*$ & $*$ \\
\hline 2 Base 2 & 8.60 & & & $*$ & $*$ \\
\hline 3 Base 3 & 10.07 & & & $*$ & $*$ \\
\hline Mid & 6.73 & & & & $*$ \\
\hline Final & 4.80 & & & & \\
\hline
\end{tabular}

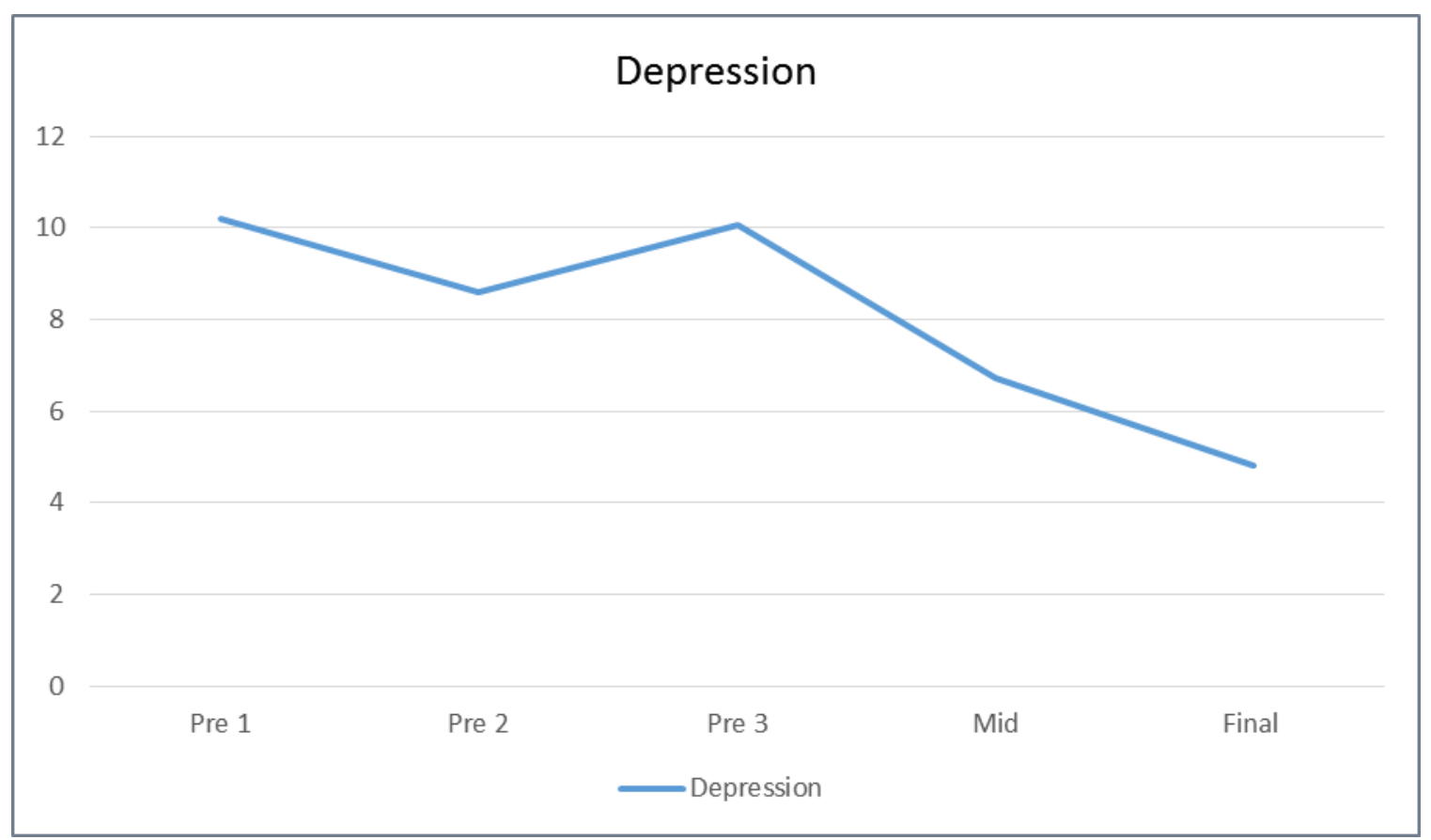

Figure 20. Depression Subscale in DASS 21

8 weeks) calligraphy intervention conditions. The mean and standard deviation for anxiety scores are shown in Table 30 . The results for the ANOVA in Table 31 show a significant time effect on the Anxiety subscale, $F=9.91, p<.001, \eta^{2}=.26$; Wilks' Lambda $=.39, F(4,26)=10.40, p<001$. The scores of anxiety reduced significantly 
Table 30

Mean, Standard Deviation of Anxiety Subscale in DASS 21

\begin{tabular}{lllll}
\hline Variable & Definition & $N$ & Mean & $S D$ \\
\hline Time 1 & Anxiety-pre at baseline 1 & 30 & 11.50 & 7.79 \\
Time 2 & Anxiety-pre at baseline 2 & 30 & 9.93 & 6.53 \\
Time 3 & Anxiety-pre at baseline 3 & 30 & 11.07 & 7.02 \\
Time 4 & Anxiety- mid-intervention & 30 & 8.13 & 4.84 \\
Time 5 & Anxiety- final intervention & 30 & 6.33 & 5.54 \\
\hline
\end{tabular}

Table 31

ANOVA Summary Table of Anxiety Subscale in DASS 21

\begin{tabular}{lrrrrrr}
\hline Source & \multicolumn{1}{c}{$S S$} & $d f$ & \multicolumn{1}{c}{$M S$} & $F$ & $p$ & $\eta^{2}$ \\
\hline Time (Anxiety) & 554.43 & 4 & 138.61 & 9.91 & .000 & .26 \\
Error & 1622.37 & 116 & 13.99 & & & \\
Total & 2176.80 & 120 & 152.60 & & & \\
\hline
\end{tabular}

from 11.5 (moderate) to 6.33 (normal). The effect size is large.

The pairwise comparison results in Table 32 show that there are significant differences between the anxiety scale in baselines and mid-intervention period; baselines and the final intervention period; as well as the mid-intervention and the final intervention period, but no significant differences between baselines are found. The results suggest that Chinese calligraphy reduces anxiety level over time. Figure 21 shows the scores of the DASS 21 anxiety subscales across the baselines, mid (4 weeks) and post (8 weeks) intervention of Chinese calligraphy. 
Table 32

Pairwise Comparison (Anxiety)

\begin{tabular}{|c|c|c|c|c|c|}
\hline Time & Mean & 2 & 3 & 4 & 5 \\
\hline 1 Base 1 & 11.50 & & & $*$ & $*$ \\
\hline 2 Base 2 & 9.93 & & & $*$ & $*$ \\
\hline 3 Base 3 & 11.07 & & & $*$ & $*$ \\
\hline Mid & 8.13 & & & & $*$ \\
\hline Final & 4.80 & & & & \\
\hline
\end{tabular}

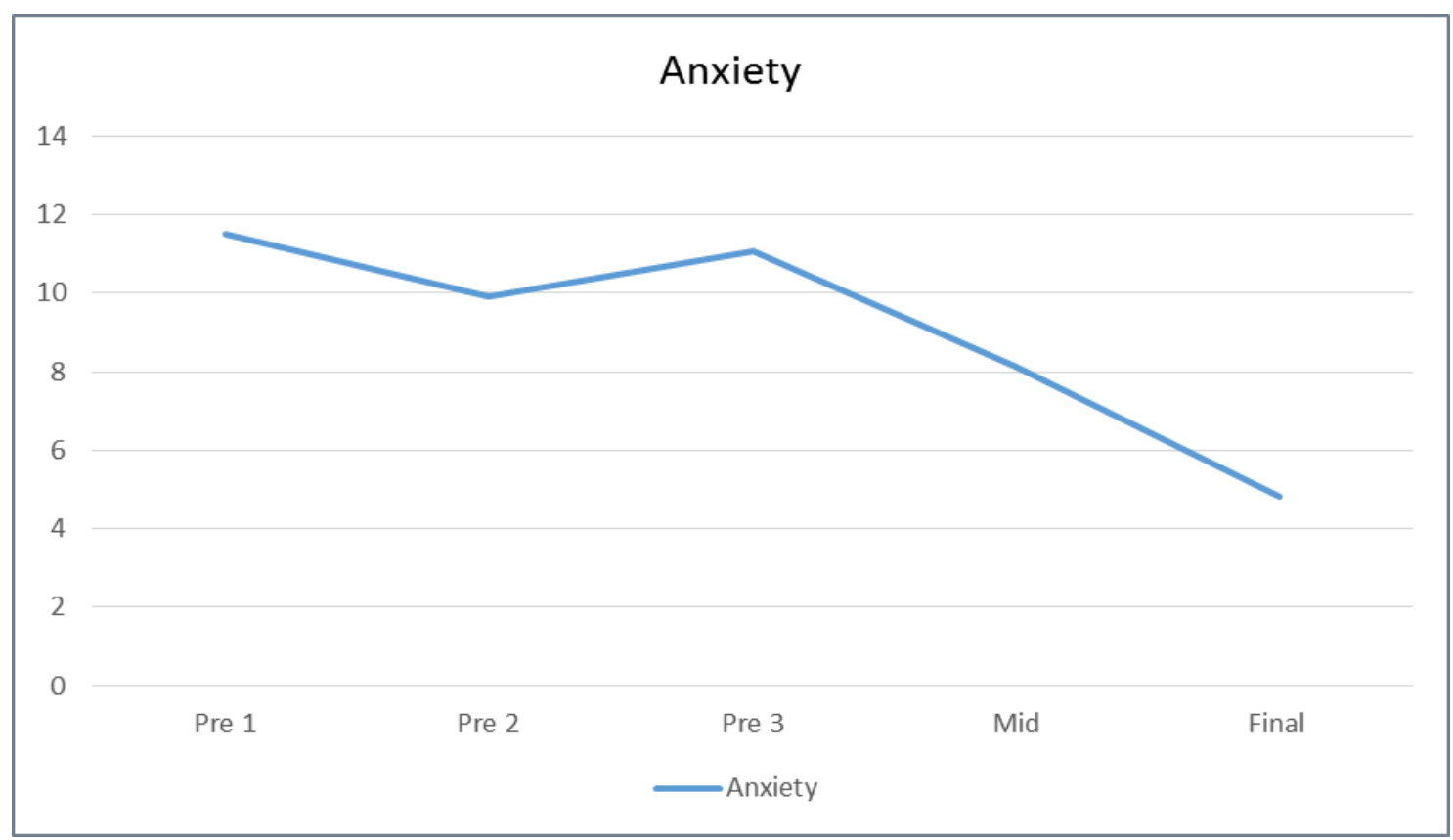

Figure 21. Anxiety Subscale in DASS 21

\section{Stress Scores}

A one-way repeated measures ANOVA was conducted to evaluate the scores on the stress subscale of DASS 21under pre- (before), mid- (after 4 weeks) and post (after 8 weeks) calligraphy intervention conditions. The mean and standard deviation for anxiety scores are shown in Table 33. The results of the ANOVA in Table 34 showed a 
Table 33

Mean, Standard Deviation of Stress Subscale in DASS 21

\begin{tabular}{lllll}
\hline Variable & Definition & $N$ & Mean & $S D$ \\
\hline Time 1 & Stress-pre at baseline 1 & 30 & 15.80 & 9.93 \\
Time 2 & Stress-pre at baseline 2 & 30 & 14.07 & 8.15 \\
Time 3 & Stress-pre at baseline 3 & 30 & 13.67 & 7.76 \\
Time 4 & Stress- mid-intervention & 30 & 10.87 & 6.78 \\
Time 5 & Stress- final intervention & 30 & 7.30 & 5.91 \\
\hline
\end{tabular}

Table 34

ANOVA Summary Table of Stress Subscale in DASS 21

\begin{tabular}{lcrrrrr}
\hline Source & $S S$ & $d f$ & $M S$ & $F$ & $p$ & $\eta^{2}$ \\
\hline Time (Stress) & 1328.56 & 4 & 332.14 & 16.17 & .000 & .36 \\
Error & 2382.64 & 116 & 20.54 & & & \\
Total & 3711.20 & 120 & 352.68 & & & \\
\hline
\end{tabular}

significant time effect on the subscale, $F=16.17, \mathrm{p}<.001, \eta^{2}=.39 ;$ Wilks' Lambda $=$ $.37, F(4,26)=11.21, p<001$. The scores of the stress decreased significantly from 15.8 (mild) to 7.3 (normal). The effect size is large.

The pairwise comparison results in Table 35 show that there are significant differences between the stress scale of baselines and mid-intervention period; baselines and the final intervention period; as well as the mid-intervention and the final intervention period. The results suggest that Chinese calligraphy reduces the level of stress over time. Figure 22 shows the scores of the DASS 21 stress subscales across the baselines, mid (4 weeks) and post ( 8 weeks) intervention of Chinese calligraphy. 
Table 35

Pairwise Comparison (Stress)

\begin{tabular}{|c|c|c|c|c|c|}
\hline Time & Mean & 2 & 3 & 4 & 5 \\
\hline 1 Base 1 & 15.80 & & & $*$ & $*$ \\
\hline 2 Base 2 & 14.07 & & & $*$ & $*$ \\
\hline 3 Base 3 & 13.67 & & & $*$ & $*$ \\
\hline Mid & 10.87 & & & & $*$ \\
\hline Final & 7.30 & & & & \\
\hline
\end{tabular}

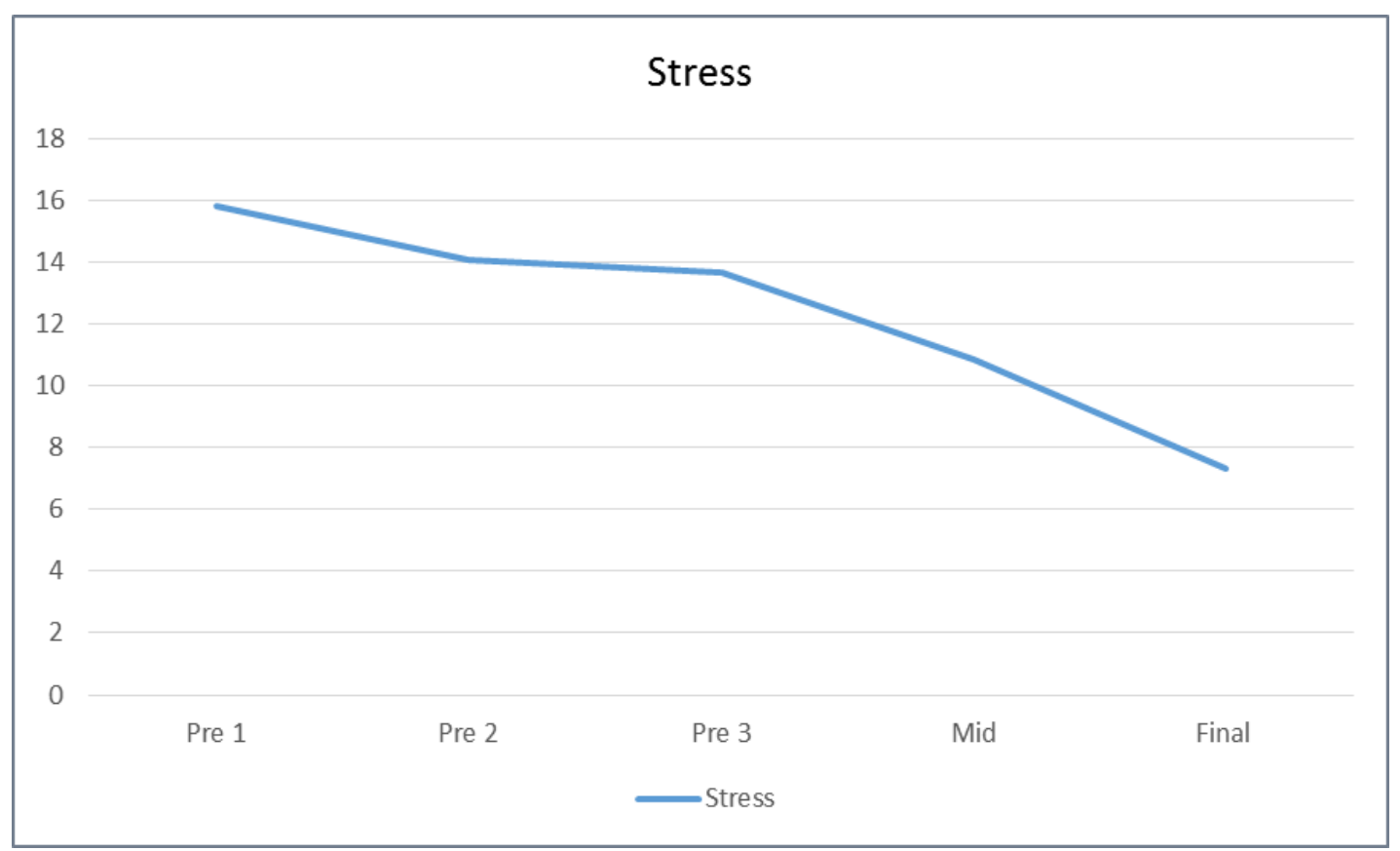

Figure 22. Stress Subscale in DASS 21

\section{Qualitative Data: Interviews}

Follow-up interviews were made in order to provide further information on the participants about their personal experience of Chinese calligraphy writing. A Pheonomenological approach was used to explore the lived experiences of 5 breast cancer patients who had undergone the calligraphy intervention. The method describes 
what the participants have common as they experience a phenomenon. A description of each participant, their background information, as well as cancer treatment and their response to the calligraphy is presented. All interviewees who attended all eight session, were Chinese and right-handed.

\section{Participant 1}

Participant \#1 was a 49-year-old single, secondary school teacher who lived with her sister. She was diagnosed with $1^{\text {st }}$ stage breast cancer. She has always been interested in learning Chinese calligraphy, but was too busy to develop this interest because of her schedule. She had taken four periods of calligraphy class in the school where she taught, then she quitted.

Participant \#1 reported that when she joined the research study, she had just finished chemotherapy, starting with radiotherapy. She said her experience of chemotherapy was not too bad, as she saw that many patients were relatively weak. However, she experienced a lot of discomfort on her skin during radiotherapy, including dryness of skin and radiation burns. Since she did not expect radiotherapy to cause so much side effects, she considered it the most difficult treatment stage for her.

According to Participant \#1, she was a highly anxious person in terms of personality. She used to worry too much. She experienced intense anxiety when she was first diagnosed with breast cancer. She worried about placing too much of a burden on her younger sister, as she needed to take care of her. The situation became better, when she hired a part-time domestic helper to do the house chores and to look after her.

Participant 1 attended all eight calligraphy sessions. She reported 1 to 2 home practices during the intervention period. She said that since Chinese calligraphy writing 
helped her focus on the present moment, she was able to forget about the things that made her worry during writing. She appeared to benefit from Chinese calligraphy, as both of her state and trait anxiety levels show substantial reduction. She said practicing calligraphy made her relax, and focus on the here and now. During the practice process, she was able to "empty" herself, concentrating on how to improve her writing by using the soft-tipped brush. In order to do that, she had to slow down and stay focused on her writing.

Participant \#1 said that she enjoyed the writing process, and also she enjoyed looking at the finished products of her writing, especially when she saw improvement. Hence, she loved to share her artworks with her friends by sending pictures to them. With the high technological devices, she always received immediate responses from her friends. This process made her happy. She concluded that Chinese calligraphy can reduce anxiety based on her own experience. However, Participant \#1 believed that in order to have such results, people have to practice it persistently, especially when personality is an issue.

\section{Participant 2}

Participant \#2, aged 63, was a married, retired kindergarten teacher with two grown-up children. She had never taken a Chinese calligraphy lesson before. She was diagnosed with $2^{\text {nd }}$ stage breast cancer. As recommended by the doctor, she had to go through all treatment stages, beginning with chemotherapy, then the surgery, following with radiotherapy, targeted and hormone therapy. At the time of the calligraphy intervention, she had just finished radiotherapy, and was beginning to receive targeted therapy. She had to get the injection every 3 weeks over 1 year. She considered 
chemotherapy the most difficult treatment stage for her, as she has almost finished all of the necessary treatment phases.

Participant \#2 indicated feeling anxious, particularly in anticipation of future treatment and uncertainty about the future. She was afraid of the "unknown"- not knowing what will happen, and not knowing whether she will recover or not. Her anxiety was at its peak when receiving chemotherapy, because of the complications of the treatment, such as ulcers all over the mouth, not being able to eat, loss of taste buds, numbness of hand and pain of the bones etc. Since chemotherapy was the $1^{\text {st }}$ treatment she had, she was very afraid of the following treatments and worried if she could really get well. The social worker of the cancer support center thought calligraphy may help her reduce anxiety, so she was invited to participate in the study.

She said that calligraphy helped her focus on the present moment, without worrying about things that used to bother to her. Concentrating on writing with a brush pen prevented her from the negative influence of intrusive thoughts. She enjoyed the process of writing very much. It is worth mentioning that participant 2 experienced numbness of the hand after chemotherapy. She was even not able to control a ball pen well. The symptom made her frustrated and powerless. She indicated that calligraphy writing was a good exercise to help her to have a better control over her hand. She said she didn't have confidence to handle calligraphy writing at the beginning of the intervention because of her hand's condition. However, as the research continued, her handwriting improved. She was very excited about the situation. Home practice several times a week helped her have a better control with her hand. Although full recovery was not yet achieved, she was happy with the progress. 
When the researcher asked her to describe the difference between home practice and group practice (calligraphy intervention at the center). She said she preferred practicing in a group because she can be easily detracted practicing at home alone by herself. Further, there were other positive effects of practicing in a group. She suggested that her blood pressure increased because of the group effects. Participants including herself were very happy and excited when they saw the improvement of their work after the calligraphy session. They were all affected by the joyful atmosphere.

\section{Participant 3}

Participant \#3 was 52-year-old, married with no children. She was an accountant with university education. She was diagnosed with $3^{\text {rd }}$ stage of breast cancer 6 months ago before participating in the research study. She had gone through surgery and chemotherapy, and was undergoing radiotherapy and targeted therapy at the same time while joining the study.

Participant \#3 said that she was very depressed when she was first diagnosed with breast cancer. She was so lost that she did not know what to do. Unfortunately, her physician was not a caring person, his lack of empathy made her extremely sad and anxious. She was very afraid to die. Then, she decided to see another doctor. She found an experienced physician with a good reputation on treating breast cancer on the internet. After changing her attending physician, her anxiety subsided. She accepted the illness and decided to face all treatment phases positively. She considered radiotherapy as the most difficult treatment for her, for she did not expect radiation to burn skin.

Participant \#3 has never had learned Chinese calligraphy before the intervention. She enjoyed the process of writing. She said she felt peaceful, comfortable and calm 
when she practiced. Chinese calligraphy helped her enter into a new dimension of existence where she can be totally undisturbed by the surrounding environment. She was happy about discovering her newfound hobby for her life. After the research, she continued to learn calligraphy, attending classes twice a week. She said she also enjoyed looking at the products of her handwriting. She was especially happy when people showed appreciation for her artworks. When the researcher asked her to compare the differences between home practice and group practice, she said she enjoyed learning calligraphy in a group setting, but practicing at home by herself.

\section{Participant 4}

Participant \#4 was 54-year-old, married with no children. She was a clerk with a high school education. She was diagnosed with the $1^{\text {st }}$ stage of breast cancer 3 months ago before participating in the research study. At the period of calligraphy intervention, she had gone through surgery and began chemotherapy treatment. She indicated that her anxiety was at its peak at the time when she joined the calligraphy intervention.

Participant \#4 said that she experienced anxiety at different phases of the treatment. First, she was shocked when she was suspected to have breast cancer, as she was such a healthy person who never got sick. When the doctor told her she had to go through all the treatment stages, she was devastated. Then she found that diagnosing with an earlier stage of cancer does not mean the cancer will be less serious, although the tumor size will be smaller. The information bothered her. She said she was not an anxious person in terms of her personality, and was able to stay positive during difficulties in life. However, she was getting more and more anxious when she was not able to receive her chemotherapy treatment on schedule. To her, chemotherapy did not 
bring too much physical discomfort, as she saw other patients were very weak and tired. However, the chemotherapy treatment always needed to be postponed because her leukocyte index could not meet the standard. The continuing postpone of the treatment

increased her anxiety level. When she knew that she could not receive the $4^{\text {th }}$ injection of chemotherapy on schedule, she collapsed. She worried that her body was not responding to the treatment well and she might eventually die because of the chemotherapy treatment.

She found calligraphy helped her to calm her emotions. She concluded that calligraphy writing could reduce her anxiety level, as her focus was on the writing. She also enjoyed looking at her writing, and amazed that her handwriting had improved as she used to think that her handwriting was very ugly.

Interestingly, calligraphy writing also helped Participant \#4 discover that she had carpal tunnel syndrome, which is a common occupational disease mainly found in the computer users. She said she first experienced numbness of her hand in the middle of the calligraphy intervention. Then, she asked her doctor about the situation, and found out the problem after several physical checkups. Because of the condition of her hand, she did not practice calligraphy at home. However, she enjoyed practicing with the group, and was very happy every time she came to participate in the study.

\section{Participant 5}

Participant \#5 was a 46-year-old Chinese, married with 2 children. She was a school teacher with university education. Participant \#5 was diagnosed with $1^{\text {st }}$ stage breast cancer and had gone through surgery. Chemotherapy was not needed. At the 
period of calligraphy intervention, she was undergoing radiotherapy and hormone therapy at the same time.

Participant \#5 indicated feeling anxious about suffering from radiation burns. She also indicated that she was frequently worrying about her current life situation, including work, finances, her relationships with her children, academics issues of her children, and the health of her mother. She said that most of her worries came from her work. Since her job was very stressful, she considered her illness was a sign that her life was too busy. She worried about taking sick leave and that it would put extra burdens on her colleagues. She was struggling about resigning from work, however, she would be facing financial problems.

Participant \#5 had taken a few calligraphy lessons when she was in secondary school, but she seldom practiced. She decided to join the research study because she wanted to reduce her anxiety. She said calligraphy writing could help her temporarily forgot about her worries, and it also made her more relaxed. Hence, practicing calligraphy in a group setting was a happy experience for her for participants could share and show appreciations for each other's artworks after the sessions. Also, she often took photos of her artwork and sent them to her daughters. The experience of sharing with others extended her happiness. She indicated that she enjoyed practicing calligraphy both in the group and at home. While practicing in a group setting made her happier, practicing at home alone made her calmer. In general, she believed that calligraphy writing could help her to slow down.

After reviewing all interviews, results indicate that breast cancer patients experienced a lot of anxiety while facing their illness and treatments. Chinese calligraphy 
writing effectively helped them calm down their emotions. Bringing their focus of attention to the present moment helps them to slow down and forget about their worries. Participant enjoyed the process of writing, feeling relaxed, calm and peaceful. All interviewees liked the group atmosphere. They also enjoyed looking at their artworks and sharing their artworks to the group and family members.

\section{Testing of Hypotheses}

Two hypotheses were tested in this research study. Hypothesis 1 stated that there would be a physiological slowing effect in blood pressure, heart rate, and respiration rate on breast cancer patients after practicing Chinese calligraphy handwriting. Hypothesis 1 was supported by the results of this study. Participants' systolic blood pressure, heart rate and respiration rate decreased significantly after Chinese calligraphy intervention. The effects were immediate. Although it was only shown at the $4^{\text {th }}$ intervention that Chinese calligraphy could decrease participants' systolic blood pressure, heart rate and respiration rate decreased after each intervention.

Hypothesis 2 stated that participants would have a reduction on their anxiety and comorbid level after Chinese calligraphy intervention. This hypothesis was supported by both self-reported instruments, the full version of STAI and DASS 21 in all the anxiety subscale scores, including state and trait anxiety levels. In addition, the DASS 21 also encompassed the areas of depression and stress levels. The findings suggest that Chinese calligraphy writing decreases the levels of state and trait anxiety, as well as the levels of depression and stress. 


\section{Summary of Major Findings}

In this chapter, the participants' characteristics, the assessment results of the study, including the systolic and diastolic blood pressure, heart rate, respiration rate, the STAI and DASS 21 results, interview content of five participants, and testing of the hypotheses are presented.

\section{Blood Pressure}

The one-way repeated measures ANOVA results show that there was no time significant effect for Chinese calligraphy found in the systolic blood pressure, $F=.99, p$ $=.457($ see Table 4); Wilks' Lambda $=.643, F(10,20)=1.111, p=.401$. However, the paired t-test results showed that there was a significant difference in the systolic blood pressure for the pretest $(M=115.30, S D=20.74)$ and the posttest $(M=110.30, S D=$ $17.69)$ at the $4^{\text {th }}$ intervention condition; $t(39)=2.12, p=.041$. The effect size is small (cohen's $d=0.33$ ). The results suggest that Chinese calligraphy intervention did not reduce the systolic blood pressure of breast cancer patients over time in an eight-week period. However, it has an immediate effect on reducing the systolic pressure during a certain period of intervention.

The one-way repeated measures ANOVA results showed no time significant effect on the diastolic pressure for Chinese calligraphy, $F=1.64, p=.09$; Wilks' Lambda $=.725, F(10,20)=.757, p=.666$. The results of paired t-tests also showed that there was no significant effect in the pre- and posttests in the diastolic blood pressure at any intervention period. The results suggest that Chinese calligraphy intervention did not reduce the diastolic blood pressure. 


\section{Heart Rate}

Chinese Calligraphy had a significant effect on reducing heart rate in the post-test conditions. The results of the one-way repeated measures ANOVA indicated that there was a significant time effect for Chinese calligraphy, $F=2.535, p=.006, \eta^{2}=.08$ (see Table 14); Wilks' Lambda $=.144, F(10,20)=11.843, p<.001$. The results suggest that there was a significant decrease in heart rate across the baseline and of that measured at the Chinese calligraphy post-intervention condition. The effect size is medium. The follow-up paired t-test showed a significant difference in the mean of pre-test $(M=81.04$, $S D=2.03)$ and post-test $(M=73.86, S D=1.51)$ conditions; $t(7)=12.76, p<.001$. The heart rate of the participants decreased 7.18 beats per minute in average after each Calligraphy intervention. Paired t-tests were conducted to compare the heart rate in the pre- and posttest conditions at each intervention. Results showed that the mean of the posttests decreased significantly from that of the pretest condition at each intervention (see Table 15). Heart rate decreased significantly from 6 to 9.56 beats. The results suggest that Chinese calligraphy reduces heart rate. Specifically, heart rate decreases immediately after Chinese calligraphy writing every time.

Interestingly, the one-way repeated measures ANOVA results indicate that there was an overall significant increase in heart rate in the pre-test conditions, $F=4.85, p<$ $.001, \eta^{2}=.143($ see Table 12$)$; Wilks' Lambda $=.61, F(9,21)=9.595, p<.001$.

Followed-up paired samples t-tests showed that there was a significant difference in heart rate between the $1^{\text {st }}$ baseline $(M=73.70, S D=10.13)$, and the $2^{\text {nd }}$ baseline $(M=77.50, S D$ $=10.23)$ conditions; $t(29)=-2.27, p=.031$; and the $1^{\text {st }}$ baseline and the $3^{\text {rd }}$ baseline $(M=$ $77.57, S D=9.87)$ conditions; $t(29)=-2.35, p<.026$; and a significant difference between 
the $3^{\text {rd }}$ baseline $(M=77.57, S D=9.87)$ and the $2^{\text {nd }}$ pre-test $(M=82.0, S D=8.87)$ condition; $t(29)=-2.68, p=.012$.

Significant increases were also found between the $3^{\text {rd }}$ baseline $(M=77.57, S D=$ $9.87)$ and the $6^{\text {th }}$ pre-test $(M=83.53, S D=15.08)$ condition; $t(29)=-2.71, p=.011$; the $3^{\text {rd }}$ baseline $(M=77.57, S D=9.87)$ and the $7^{\text {th }}$ pre-test $(M=81.90, S D=12.12)$ condition; $t(29)=-2.30, p=.029 ;$ also between the $3^{\text {rd }}$ baseline $(M=77.57, S D=9.87)$ and the $8^{\text {th }}$ pre-test $(M=83.20, S D=11.85)$ condition; $t(29)=-4.15, p<.001$.

These results suggest that the heart rates of participants increased significantly across the ten-week period from the baselines in the pre-test conditions. Specifically, the heart rate increased in the baselines before the intervention, and the very early stage of the intervention $\left(2^{\text {nd }}\right.$ pre-test). It did not significantly increase during the middle stage $\left(3^{\text {rd }}, 4^{\text {th }}\right.$, and $\left.5^{\text {th }}\right)$ of the intervention, but it increased significantly again in the final stage $\left(6^{\text {th }}, 7^{\text {th }}\right.$ and $8^{\text {th }}$ pre-test $)$ of the intervention.

\section{Respiratory Rate}

The one-way repeated measures ANOVA results show that there was no significant time effect for Chinese calligraphy in pre-test conditions, $F=1.28, p=.249$ (see Table 16); Wilks' Lambda $=.661, F(9,21)=1.196, p=.348$. The results suggest that respiration rate does not change before the Chinese calligraphy intervention, but a significant time effect was found across the post-test conditions, $F=4.67, p<.001, \eta^{2}$ $=.14($ see Table 18); Wilks' Lambda $=.436, F(10,20)=2.585, p=.034$. The effect size is large. The results suggest that respiration rate decreases after Chinese calligraphy intervention over time. Follow-up paired samples t-test results show that there was a significant difference in the mean for pre-intervention $(M=17.97, S D=.35)$ and post 
intervention $(M=16.56, S D=.29 ; t(7)=21.63, p<.001$. Follow-up paired t-tests were also conducted to compare the respiration rate in the pre- and posttest conditions at each intervention. Results showed that respiration rate decreased every time after intervention, from 1.13 to 1.62 beats (see Table 16a). Specifically, the results suggest that Chinese calligraphy decreases respiration rate, and the effect is immediate (see Figure 20).

\section{STAI Results}

\section{State Anxiety}

The results of the STAI indicate significant decreases on the participants' both state and trait anxiety level after 4 weeks and 8 weeks of calligraphy intervention. The repeated measures ANOVA results show that there was a significant time effect on the state anxiety level, $F=9.31, p<.001, \eta^{2}=.24$ (see Table 22); Wilks' Lambda $=.437$, $F(4,26)=8.367, p<001$. The scores of state anxiety decreased significantly from 41.00 to 32.87. The effect size is large. The follow-up pairwise comparisons results (see Table 23) show that there was no significant difference found between 3 baselines, but significant differences are found between the baselines and mid-intervention (after 4 weeks) period; baselines and the final intervention (after 8 weeks) period; as well as the mid-intervention and the final intervention period (see Figure 18). The results suggest that Chinese calligraphy writing reduces state anxiety level over time.

\section{Trait Anxiety}

The one-way repeated measures ANOVA results also show that there was a significant time effect on trait anxiety level, $F=8.7, p<.001, \eta^{2}=.23$ (see Table 25); Wilks' Lambda $=.58, F(4,26)=4.7, p=005$. The scores of trait anxiety decreased 
significantly from 46.73 to 40.83 . The effect size is also large. The follow-up pairwise comparison results (see Table 26) show that there was no significant difference found between 3 baselines, but significant differences are found between the baselines and midintervention period; baselines and the final intervention period; as well as the midintervention and the final intervention period (see Figure 19). The results suggest that Chinese calligraphy writing reduces trait anxiety level over time.

\section{DASS 21 Results}

\section{Depression Subscale}

Similarly, the results of the DASS 21 also indicate significant decreases on the participants' depression, anxiety and stress scores after 4 weeks and 8 weeks of calligraphy intervention. The one-way repeated measures ANOVA results show that there was a significant time effect on the depression subscale, $F=9.97, p=.000, \eta^{2}=.26$ (see Table 28); Wilks' Lambda $=.53, F(4,26)=5.72, p=002$. The scores for depression significantly reduced from 10.2 (mild) to 4.8 (normal). The effect size is large. The pairwise comparison results in Table 29 show that there are significant differences between the baselines and mid-intervention period; baselines and the final intervention period; as well as the mid-intervention and the final intervention period (see Figure 20). The results suggest that Chinese calligraphy reduces depression level over time.

\section{Anxiety Subscale}

Similar results are also found in the anxiety and stress subscales. The one-way repeated measures ANOVA results showed a significant time effect on the anxiety subscale, $F=9.91, p<.001, \eta^{2}=.26($ see Table 31$)$; Wilks' Lambda $=.39, F(4,26)=$ 
$10.40, p<001$. The Anxiety score reduced significantly from 11.5 (moderate) to 6.33 (normal). The effect size is large.

\section{Stress Subscale}

For the stress subscale, the one-way repeated measures ANOVA results also showed a significant time effect, $F=16.17, p<.001, \eta^{2}=.39$ (see Table 34 ); Wilks' Lambda $=.37, F(4,26)=11.21, p<001$. The scores of stress decreased significantly from 15.8 (mild) to 7.3 (normal). The effect size is large.

Follow-up pairwise comparison results for the anxiety (see Table 32) and stress (see Table 35) levels showed no significant differences among the three baselines, but differences between baselines and mid-intervention period; baselines and the final intervention period; as well as the mid-intervention and the final intervention period. These results suggest that Chinese calligraphy reduces the level of anxiety (see Figure 21) and stress (see Figure 22) over time.

\section{Interviews}

The follow-up interviews recognized that breast cancer patients experienced anxiety when facing their illness and treatment. The participants acknowledged that Chinese calligraphy writing was an enjoyable process that helped them to focus on the present moment and put aside their worries, making them feel calm, relaxed and peaceful. Being in a group setting was a joyful experience to many participants, and sharing their artworks after the session make them happy.

Two hypotheses were tested in this research study: 1) There is a physiological slowing effect in blood pressure, heart rate and respiration rate on breast cancer patients 
after practicing Chinese Calligraphy handwriting for 8 weeks; and 2) breast cancer patients will have a reduction score on self-reported measures on anxiety and comorbid depression levels after Chinese calligraphy intervention. Hypothesis 1 supported by the reduction of heart rate and respiration rate, systolic blood pressure with larger effects on heart and respiration. Hypothesis 2 was supported by the reduction scores on both STAI and DASS 21 in all the anxiety subscales, including state and trait anxiety levels, and the depression subscales in DASS 21. 


\section{CHAPTER 5}

\section{CONCLUSIONS, DISCUSSION, IMPLICATIONS}

\section{AND RECOMMENDATIONS}

\section{Introduction}

This chapter presents the summary, discussion of findings, implications, and recommendations for further research. The summary briefly describes the purpose of the study, summary of literature review, and summary of major results. The discussion covers the major findings, strengths and limitations. Implications of the current study, and finally, directions for further research are suggested.

\section{Summary: Purpose of the Study}

Breast cancer is the most common cancer among women worldwide, and suffering from breast cancer and going through treatment create many challenges in patients' lives. Anxiety is a common psychological symptoms, and it has been shown to cause fatigue, poor treatment outcome, and has a negative impact on the quality of life, and affecting the immune systems of breast cancer patients (McGregor \& Antoni, 2009). Further, anxiety is frequently comorbid with depression, particularly in clinical settings (Hales et al., 2014; Ingram, 2009). Research showed that cancer patients with coexisting anxiety and depression tend to have severe symptoms, extended healing times, worse outcomes and greater burden on healthcare resources (Hirschfeld, 2001). 
As anxiety and comorbid depression are common psychological symptoms and have negative impacts on breast cancer patients, effective interventions are needed for this population (Pedersen et al, 2010). Previous research show that Chinese calligraphy has significant effects on writers' cognitive activation, perceptual sharpening, physiological slowing and emotional stability (Kao, 2010). It may turn out to be an effective approach for breast cancer patients in terms of anxiety and comorbid depression reduction. The purpose of this study is to examine to what extent Chinese calligraphy can reduce the anxiety and comorbid depression levels of breast cancer patients in Hong Kong.

\section{Summary of Literature Review}

Chinese calligraphy is handwriting of Chinese characters with ink using a softtipped brush. It is historically a tool of communication in ancient China, and regarded as a respected traditional art. Traditionally, Chinese calligraphy is considered as an activity for enhancing self-cultivation and self-reflection, promoting longevity and improving quality of life as the writing process requires full concentration and mind-body harmony of the writer (Hough, 2008).

After conducting research on Chinese calligraphy for the last three decades, Henry Kao (2010) asserts that the effects of practicing Chinese calligraphy have many benefits, including cognitive activation, physiological slowdown, emotional stability and perceptual sharpening. Research have been done with different clinical and nonclinical populations. The results show that Chinese calligraphy has promising effects on two major areas: (1) facilitating a state of physiological slowdown and psychological quiescence, and (2) increasing cognitive activation and perceptual sharpening. 
Since Chinese calligraphy constantly keeps the writer's focus of attention at the present moment, it is considered as an art inextricably linked to the practice of mindfulness (Hue, 2009). For the last two decades, mindfulness based stress reduction (MBSR) program is effective in reducing stress, distress, state-trait anxiety, and mood disturbance for breast cancer survivors (Lengacher et al., 2009). The question is thus to ask: Can calligraphy practice reduce the anxiety level of breast cancer patients?

\section{Summary of Procedures}

The study was a one-group repeated-measures design using a quasi-experimental method to explore the changes in anxiety levels in a sample of 45 breast cancer patients, and 30 of them had completed the whole calligraphy intervention. The study was carried out from October 2014 to October 2015 at Maggie's Cancer Caring Centre in the New Territory area of Hong Kong. Breast cancer patients who were under cancer treatment were invited to participate in this study. All the participants gave their informed consent (see Appendix A) to participate in this study. Demographic and clinical data were collected from the participants prior to the interventions. Table 1a shows the demographic characteristics of the participants.

Physiological measurements, including blood pressure, heart rate and respiration rate and self-reported psychological assessments, including the full version of State-Trait Anxiety Inventory (STAI), and the brief version of Depression, Anxiety Stress Scale (DASS 21) were used. Before the intervention, all participants underwent baseline measurements of both physiological and self-report psychological assessments 3 times in 3 consecutive weeks. During the 8-week intervention, the physiological changes, blood pressure, heart rate and respiration rate were measured before (pre-test) and after 
(posttest) each calligraphy session. To avoid the impact of diurnal fluctuation of physiological parameters, the interventions and measures were set at a fixed time period across 8 weeks. To avoid the influence of physical activity on physiological parameter, participants were asked to sit quietly for about 5 minutes before the measurements. All physiological measurements were collected individually at the back of the room by a registered nurse. For psychological measurement, the Chinese version of the full battery of STAI (see Appendix B), and the Chinese version of DASS 21 (see Appendix C) were assessed at the pre-intervention ( 3 times for baseline measurements), mid-intervention (after the $4^{\text {th }}$ session) and post-intervention (after the $8^{\text {th }}$ session) phases by the researcher.

Participants were taught the basic strokes and practiced Chinese calligraphy in a quiet room for eight 90 -minute sessions in 8 consecutive weeks. The content of the Chinese calligraphy characters were chosen at random from handbooks of classic calligraphy writing in standard script (see Figure $12 \& 12 \mathrm{a}$ ). All participants used the same sized brushes and normal rice paper throughout the eight 90-minute interventions. Data analysis was conducted using Repeated Measures one-way ANOVA and paired samples t-test.

\section{Summary of Major Results}

\section{Physiological Measures}

The physiological changes, systolic and diastolic blood pressure, heart rate and respiration rate were measured before (pre-test) and after (post-test) each calligraphy session for 8 weeks. 


\section{Blood Pressure (Systolic and Diastolic)}

The results showed that Chinese calligraphy intervention did not reduce the systolic and diastolic blood pressure of breast cancer patients over time in an 8-week period. However, it showed an immediate effect in reducing the systolic pressure at the pre-test $(M=115.3, S D=20.74)$ and posttest $(M=110.3, S D=17.69 ; t(39)=2.12, p=$ .041) measures at a certain period (the $4^{\text {th }}$ intervention) of intervention. The effect size is small (cohen's, $d=0.33$ ). The results showed no significant effect in the pre- and posttest measures in the diastolic blood pressure throughout intervention period.

\section{Heart Rate}

The results show that Chinese calligraphy demonstrated an overall significant decrease in heart rate in the post-test conditions $\left(F=2.535, p=.006, \eta^{2}=.08\right.$ (see Table 10); Wilks' Lambda $=.144, F(10,20)=11.843, p<.001)$. The effect size is medium. Followed-up t-tests results showed that heart rate decreased significantly at each intervention from 6 to 9.56 beats in the pre- and posttest measures (see Table 12a). The results suggest that Chinese calligraphy reduces heart rate. Specifically, heart rate decreased immediately after Chinese calligraphy writing every time (see Figure 16).

Interestingly, results showed that there was an overall significant increase in heart rate in the pre-test conditions $\left(F=4.85, p<.001, \eta^{2}=.143\right.$; Wilks' Lambda $=.61, F(9$, 21) $=9.595, p<.001$, see Table 10a). Follow-up paired samples t-tests showed that participants' heart rate increased at the pre-test conditions before the intervention, at the beginning stage $\left(2^{\text {nd }}\right.$ pre-test $)$, and the final stage $\left(6^{\text {th }}, 7^{\text {th }} \& 8^{\text {th }}\right.$ pre-test $)$ of the intervention. 


\section{Respiratory Rate}

The results show that Chinese calligraphy demonstrated an overall significant decrease in respiratory rate in the post-test conditions, $F=4.67, p<.001, \eta^{2}=.14$ (see Table 15); Wilks' Lambda $=.436, F(10,20)=2.585, p=.034)$. The effect size is large. The results suggest that Chinese calligraphy reduces respiration rate over time. Follow-up paired t-tests results showed that respiration rate decreased at each intervention, from 1.13 to 1.62 beats in the pre- and posttest measures (see Table 16a). The results suggest that Chinese calligraphy intervention decreases respiration rate, and the effect is immediate (see Figure 16).

\section{Self-reported Psychological Measures}

The self-reported instruments, full battery of the STAI and DASS 21 were used at the pre, mid and post intervention phases. The results show that Chinese calligraphy had significant effects on reducing breast cancer patients' anxiety (both state and trait), depression, and stress levels. The effect sizes for all areas are large.

\section{State and Trait Anxiety- STAI}

The results of the STAI indicate that both state and trait anxiety scores decreased significantly after 4 and 8 weeks of calligraphy intervention. The repeated measures ANOVA results show that Chinese calligraphy reduced state anxiety $(F=9.31, p<.001$, $\eta^{2}=.24 ;$ Wilks' Lambda $\left.=.437, F(4,26)=8.367, p<001\right)$ and trait anxiety $(F=8.7, p<$ $.001, \eta^{2}=.23$; Wilks' Lambda $\left.=.58, F(4,26)=4.7, p=005\right)$. These results suggest that Chinese calligraphy reduces breast cancer patients' self-reported state and trait anxiety levels. The effects size are large. 


\section{Depression, Anxiety, and Stress Scales- DASS 21}

Similarly, the results of the DASS 21 also indicate significant decreases on the participants' depression $\left(F=9.97, p<.000, \eta^{2}=.26\right.$; Wilks' Lambda $=.53, F(4,26)=$ 5.72, $p=002)$, anxiety $\left(F=9.91, p<.001, \eta^{2}=.26\right.$; Wilks' Lambda $=.39, F(4,26)=$ $10.40, p<001)$, as well as stress $\left(F=16.17, p<.001, \eta^{2}=.39\right.$; Wilks' Lambda $=.37$, $F(4,26)=11.21, p<001)$ scores. These results suggest that Chinses calligraphy reduces breast cancer patients' self-reported depression, anxiety and stress levels. The effect size are large.

Interviews

The follow-up interviews revealed that breast cancer patients experienced anxiety when facing their illness and treatment. The participants reported that Chinese calligraphy writing was an enjoyable process that helped them to focus on the present moment and put aside their worries, making them feel calm, relaxed and peaceful. Being in a group setting was a joyful experience to many participants, sharing artworks after the session made them happy.

\section{Discussion of Major Findings}

Anxiety is a common psychological concern for breast cancer patients and survivors. As many breast cancer patients suffered from anxiety symptoms, effective interventions are needed to support this population. As mindfulness meditation and mindfulness based interventions has been found effective in reducing anxiety, distress and stress levels in breast cancer patients and survivors (Matchim et al., 2011; Zainel et 
al., 2013; Lesiuk, 2015; Bower et al., 2015; Zhang et al., 2017), Chinese calligraphy writing can be a helpful intervention as it is linked to mindfulness practice (Hue, 2009). Thich Nhat Hanh (2017), a Zen master mentioned, "In my calligraphy, there is ink, tea, breathing, mindfulness, and concentration. Writing calligraphy is a practice of meditation. I write the words or sentences that can remind people about the practice. For instance, breathe and enjoy the kingdom of God in the here and the now or breathe and enjoy this wonderful moment." Because of similarities of focusing the present moment (here and now), calligraphy may have similar effects with those in mindfulness-based interventions.

After conducting research on Chinese calligraphy for the last three decades, Henry Kao (2010) asserts that practicing Chinese calligraphy has many benefits, including cognitive activation, physiological slowdown, emotional stability and perceptual sharpening. In a more recent study, Kao and colleagues (2014) found that 8 weeks of Chinese calligraphy had a significant attenuating effect on physiological parameters of arousal (heart rate, electromyographic scores, skin temperature, and respiration) in a group of graduate students and academic staff members $(n=30)$ in Taiwan who suffered from stress on a daily basis. The results showed that calligraphy writing is found equally effective in reducing stress as comparing with meditation intervention. The results matched the traditional belief that calligraphy can be regarded as a meditative practice.

In a study of Chinese nasopharyngeal carcinoma patients $(n=90)$, Yang et al. (2010) found that Chinese calligraphy had a significant slowdown effect on physiological parameters, including heart rate, systolic blood pressure and respiration. Furthermore, it 
was also effective in improving concentration level, and reducing mood disturbance scores on depression, anger and fatigue subscales, In light of these findings, Chinese calligraphy may be an effective intervention to reduce anxiety for breast cancer patients.

The current study, designed as a one-group repeated measures, sought to examine the effects of Chinese calligraphy intervention on reducing the anxiety levels in a sample of 45 Hong Kong breast cancer patients, and 30 of them had completed the whole intervention. The results confirm that calligraphy had significant effects in reducing heart rate and respiration rate after each intervention. Further, self-reported anxiety level, including state and trait anxiety, as well as depression and stress levels were also significantly reduced. These findings are encouraging for breast cancer patients who are vulnerable to anxiety and other mood disturbances during their illness and different treatment periods.

These results are consistent with the findings of a previous study with cancer patients (Yang et al., 2010) and other research with different groups of participants (Kao, 2010; Kao et al., 2014). The positive effects may be due to the fact that Chinese calligraphy writing requires focus on attention. Kao (2006) mentioned, "The act of brushing required heightened attention and concentration on the part of the practitioner, and thus resulted in emotional stabilization and physical relaxation." Using a soft-tipped brush with ink, writers have to be calm and focused.

Different from previous research, Chinese calligraphy seemed less effective in reducing blood pressure (Yang et al., 2010; Kao et al., 2014). Results showed that there was the systolic blood reduced only one time (after the $4^{\text {th }}$ intervention). Similar to Yang's study, no reduction on the diastolic blood pressure was found. There are reasons 
that could be accounted for the minor reduction in blood pressure. The blood pressure of the participants were not high at the baselines on both systolic $(M=111.37)$ and diastolic ( $M=70.79)$ blood pressure, as normal healthy adults are recommended to keep their systolic and diastolic blood pressure around 120 and 80 (120/80) respectively in Hong Kong (Central Health Education, 2013). Therefore, there was less of a chance to see decreases in these measures. In fact, Chinese calligraphy might have an effect of regulating participants' blood pressure in this current study.

Another possible explanation for the lack of reduction in blood pressure may be attributed to the effects of a group setting. That is, the participants were excited to see and share each other's artworks at the end of the session. Even though the participants were told to sit and wait quietly for the physiological measurements, their blood pressure may be still affected because of the excitement. Finally, some research show that blood pressure and heart rate are not good parameters to evaluate anxiety for some patient groups and in general population (De Jong, Moser, An \& Chung, 2004; Conceicao, Schonhorst, Conceicao, \& Filho, 2004; Hildrum, Romild \& Holmen, 2011).

De Jong and colleagues (2004) argued that anxiety is not manifested by elevated heart rate and blood pressure in acutely ill cardiac patients $(n=54)$. The study showed that there were no correlations between anxiety and heart rate or diastolic blood pressure. In fact, higher anxiety was associated with lower systolic blood pressure in patients with acute myocardial infarction $(r=-0.23, p<0.05)$ and in healthy individuals $(r=-0.27, p<$ 0.05). In a large study ( $n=60,799)$ of adults showed that high blood pressure increases with age, especially in women. However, low blood pressure was found to be associated with anxiety and depression in the general population with anxiety and depression 
symptoms (cut-offs: systolic < 120, 120 - 139 (reference) and > 140, diastolic < 75, 75 84 (reference) and > $85 \mathrm{~mm} \mathrm{Hg}$ ) (Hildrum et al., 2011). These findings indicate that blood pressure and heart rate may not be an accurate indicator of anxiety. Therefore, other measurements are also needed for more accurate assessment.

\section{Strengths}

The current study has several strengths. First, in using a multiple baseline design, participants were able to serve as their own controls. That is, since baseline data were collected prior to the calligraphy intervention, participant results following the treatment could be compared to pre-intervention conditions. The use of a multiple baseline design allowed for close examination for participants' responses to the eight-week calligraphy intervention program. The baseline data were collected in a three-week period, and there were no significant changes in the environment that could have accounted for the study outcomes.

Another strength of the study is the use of both physiological and self-reported psychological measures for anxiety. The use of reliable and valid measures for data collection was an important consideration. This study utilized multiple measures to assess for the same construct- anxiety, can be a recognized design strength (Kazdin, 1981). Although self-reported measures used in this study were valid and reliable, the nature of these type of assessments is often thought to be highly susceptible to bias and may not reflect actual conditions. Even though participants were instructed to report how they had been feeling, there is a chance that their responses may have been biased to please the researcher. Adding physiological measures which are considered as alternative accurate assessments of anxiety is another strength of the study. 
The nature in which participants were recruited to participate in the calligraphy program could be another possible strength. Most of the participants were referred by their medical doctors in the hospital, nurses or staff in the cancer caring center. The participants may have been less biased toward the intervention than self-referred individuals who seek out for a particular treatment of interest.

\section{Limitations}

Despite these encouraging findings, there are several limitations to the current research design that should be considered. First, this was a one-group quasi-experimental study with a small sample size in Hong Kong, so we should be cautious about generalizing the findings to the all breast cancer patients. A lack of controlled group is a major limitation of this study.

Second, another major limitation is the lack of specificity of the cancer and treatment stages of the participants. Since the participants were breast cancer patients who were undergoing some kind of cancer treatment, the study was not able to target on a specific group of breast cancer patients who are under a particular cancer treatment, e.g. early stage breast cancer patients who are undergoing chemotherapy. This is another weakness of the study.

Third, since Chinese calligraphy is not an established therapy, there is no specific guideline for using it as a therapeutic intervention in psychotherapy. Therefore, lack of established procedures to implement the intervention is another limitation. Fourth, this study in an outpatient setting measures the immediate effect of Chinese calligraphy interventions in the slowing down of physiological measurements and reduction of selfreported scores but it fails to measure the duration of the effect on a consistent basis. 
Whereas an inpatient research taking daily measures would more accurately depict the duration of the intervention's effects and its wear-off time, and also allow experiment on the long-term effects on persistent daily intervention (Yang et al., 2010). Finally, Chinese calligraphy is regarded as a traditional art. According to Yang et al. (2010), for people who are unfamiliar with calligraphy, the process may create stress.

\section{Implications}

Implications for Applied Practice

This research is considered to be of value for many reasons. First of all, while research showed that anxiety and comorbid depression are common (Baqutayan, 2012; Drageset et al., 2010; Lim et al., 2011) and have negative impacts on breast cancer patients (Segerstrom \& Miller, 2004; Baum et al., 2012; Pedersen et al., 2010), reducing their anxiety level has become an important aspect in the treatment. Chinese calligraphy presented in the current study served as an effective intervention to the breast cancer patients who participated in the program. The results of this study suggest that Chinese calligraphy can be another effective approach for breast cancer patients in terms of anxiety reduction in Hong Kong.

In a broader sense, this study provides support for an alternative approach for anxiety reduction for the Chinese breast cancer patients in other countries. Chinese calligraphy may turn out to be an effective state-trait anxiety reduction approach to breast cancer patients with Chinese background, as it is considered as an art but it is much cheaper and easier than other forms of art, such as painting or sculpturing, in terms of equipment and techniques. 
Secondly, the findings of this research show that Chinese calligraphy reduces state anxiety and more surprisingly anxiety at the trait level. Common belief is that psychological interventions reduces your current state anxiety but may have less effect on trait anxiety level as personality traits are believed to be stable and more permanent (Schultz \& Schultz, 2017) .

Although this research's findings of trait anxiety reduced only after 4 weeks of intervention may contradict with common belief that personality traits do not easily change, its results are actually in line with the effects of Chinese calligraphy under the traditional Chinese concept. Chinese calligraphy has always been recognized as a meaningful practice which 'moderates emotions and cultivates temperament' (修心養 性，陶冶性情) in Chinese people (洪量豐, 2017; Zeng \& Zeng, 2011; 高尚仁, 2000). Traditionally, Chinese people believe that calligraphy is helpful in 'cheering the heart and calming anxiety” (怡情悅性, 清心靜慮), as well as managing emotions and molding one's temperament into one of virtue (高尚仁, 2000; 侯吉諒, 2012).

More recent research backs the findings suggesting that personality traits can be changed through psychological interventions (Roberts, Luo, Briley, Chow, Su \& Hill, 2017). The study found that all forms of therapy showed similar levels of efficacy in changing personality traits. Particularly, patients presenting with anxiety disorders changed the most. Roberts et al. (2017) found that personality trait can and do change more quickly through intervention than commonly thought. Most of the changes were found within the first month of therapy. The results of this meta-analysis of 207 studies contradict the widely held assumption that personality traits typically change slowly and gradually over many years (Roberts, 2006). In the current research, the trait anxiety of 
breast cancer patients was found to be decreased after 4 weeks of intervention. This suggests that short-term intervention, in this case, practicing Chinese calligraphy may have more significant impact on the trait anxiety level then most might imagine due to the popular belief that personality traits do change dramatically.

Finally, the findings of this research show that Chinese calligraphy improves physiological indicators of anxiety including heart rate and respiratory rate immediately after each intervention but does not show reduction on these physiological indicators for the overall eight 90-minute interventions. The results are understandable since the research participants were all breast cancer patients undergoing treatment. Deterioration of health and physiological factors over time could be expected as a result of their sickness and other medical cancer treatments underway that may affect the patient's health. Chinese calligraphy may be effective in improving their physiological factors during intervention but expectation on the positive outcome of the interventions to override their sickness' physiological effect in eight weeks would be unrealistic.

Chinese calligraphy's improvement on patients' psychological factors, on the other hand, is much more significant in an eight-week period as measured in postintervention conditions. The practicing of Chinese calligraphy showed positive effects such as the decrease of stress, depression and anxiety scores on the state and trait level. This confirms that Chinese calligraphy produces overall psychological improvements for breast cancer patients' mental health.

\section{Recommendations for Future Research}

Previous studies suggested that the therapeutic effects of Chinese calligraphy are promising in clinical populations, including children with childhood disorders (Kao, 
2010), patients with elderly disorder (Kao, 2003), patients with psychosomatic disease (Guo, Kao \& Liu, 2001; Kao, Ding \& Cheng, 2000a), patients with mental and mood disorders (Fan, Kao \& Guo, 1999) patients with nasopharyngeal carcinoma (Yang et al, 2010), and non-clinical populations (Guan, Ng \& Kao, 2000; Huang, Chan \& Kao, 2000, Yum \& Kao, 1999; Kao, 2010). The current study provided a preliminary exploration of Chinese calligraphy for anxiety reduction for breast cancer patients. While the study has furthered our understanding that Chinese calligraphy writing can indeed be effective for anxiety reduction by decreasing heart rate, respiration rate, systolic blood pressure, state and trait anxiety levels, depression level, and stress level, additional research in this area will further our understanding of the method that can promote positive emotions.

Future research should also explore the amount of calligraphy intervention necessary for a change of emotions. While this study followed the prescribed eight-week intervention model and immediate effects are found in physiological measurements, it would be helpful to determine if a shorter program length could be beneficial. In this study, significant reduction of anxiety scores was shown after 4 weeks of the intervention. A future study might present a condensed version of the program, and compare this to an eight-week intervention.

Another implication of research is that cultural background influences our experience and expression of emotions (Holfmann \& Hinton, 2014). Contemporary psychological interventions including individual and group psychotherapy mostly originate and are developed from the West, focusing on exploring and expressing one's emotions and needs through talk therapy. However, in most Asian countries and collective societies including the Chinese, moderation of emotions is considered a virtue 
and restraint is highly valued (Soto, Levenson \& Ebling, 2005). Children at a young age are often reprimanded for being emotional or expressing their feelings. The effectiveness of talk therapy for clients who are exposed to such cultural backgrounds is put into question.

Further research could be targeted on comparing the effectiveness on expressive psychotherapy (e.g. talk therapy, group therapy) versus reflective or mindfulness based practices (e.g. meditation \& Chinese calligraphy) on patients with an Asian cultural background to observe if one's culture comes into play in deciding the effectiveness of different types of psychological intervention.

Finally, research may wish to examine the effects of Chinese calligraphy in individual settings. The current study was designed in a group setting due to the fact that group intervention is found beneficial to breast cancer patients. According to the interviews of the participants, the group setting did create a happy atmosphere. However, group intervention may also create psychological impacts, such as feeling proud when doing better than others, or disappointed when doing worse than others (Osho News, 2011). Although all interviewees said that they prefer a group setting, practicing calligraphy alone may potentially make participants feel calmer. Therefore, the effect of reducing anxiety may even be stronger in an individual settings.

\section{Summary of Chapter 5}

This study suggests that Chinese calligraphy is an effective intervention for the reduction of anxiety and comorbid depression levels among Chinese breast cancer patients in Hong Kong. Both hypotheses one and two are supported by this research. Hypothesis 1: Chinese calligraphy is effective in the immediate slowing of physiological 
measurements of anxiety (systolic blood pressure, heart rate, and respiratory rate). Hypothesis 2: Chinese calligraphy in an eight 90-minute intervention period has a positively effect on psychological measurements on anxiety namely, the reduction of selfreported scores on state and trait anxiety and comorbid depression and stress levels. The effects are large.

The results of this study suggest that Chinese calligraphy handwriting can be an effective alternative intervention for anxiety and comorbid depression in Hong Kong breast cancer patients. Further implications of this study suggests that an individual's cultural receptiveness should be considered in the selection of psychotherapy interventional methods. Further research could be done to explore the role that an individual's cultural receptiveness plays on the effectiveness of different psychotherapy interventional methods. 
APPENDIX A

INFORMED CONSENT FORM 


\section{Informed Consent Form}

Summer 2014

The following research study is an investigation of the effects of Chinese calligraphy on reducing anxiety levels for breast cancer patients. The study is part of a doctoral dissertation being conducted through Andrews University Department of Graduate Psychology \& Counseling by Anna Liu, PhD student.

As a participant, you will receive eight, weekly, one and half hour Chinese calligraphy practice sessions over the course of eight weeks. A group format will be utilized. You will be asked to complete questionnaires describing your experience with anxiety and the extent to which the experience interferes with you daily life. You will also be asked to answer some questions about your personal and occupational background. In this study, your blood pressure, heart rate, and respiration will be measured before and after each calligraphy session. Also, you will be asked to fill out two inventories which measure your anxiety levels at the beginning, during and after the 8-week of calligraphy practice sessions. The results of the study will add to our knowledge about the effects of Chinese calligraphy on anxiety reduction for breast cancer patients and will help in developing more effective interventions in the management of anxiety.

All of the results will be held in confidence. None of your personal information will be released to anyone without your expressed, written consent. In addition, you may withdraw from the study at any time without penalty. Chinese calligraphy itself does not have potential harm. However, if you have experience emotional discomfort, psychological support will be provided when necessary. Thank you so much for your participation and I will be happy to answer any question that you may have. In addition, if you would like, I would be happy to share the findings of the study with you. Thank you for your cooperation.

Sincerely,

Anna Liu

$\mathrm{PhD}$ student in Counseling Psychology 
I have read and understand the information given above and agree to participate in this study. I also understand that if for any reason I am unable to, or think it is unwise to engage in these training and practices, I am under no obligation to engage in these practices. I also understand that the unlikely event that I have any discomfort, problems, or research related injuries, I will report them immediately to my physician and request that he/she provide me with the customary medical care. I realize that psychological support will be provided by Maggie's Cancer Caring Center, when I need it. I am aware that I can contact the research supervisor, Dr. Woolford-Hunt at 1(269)471-6074 or the researcher, Anna Liu at 1(269)605-3637 for answers to questions related to this study.

Print Name:

Signed:

Date:

Witness: 
APPENDIX B

STAI- Y1 \& Y2 Form (ENGLISH \& CHINESE VERSIONS) 
SELF-EVALUATION QUESTIONNAIRE STAI Form Y-1

\section{Please provide the following information:}

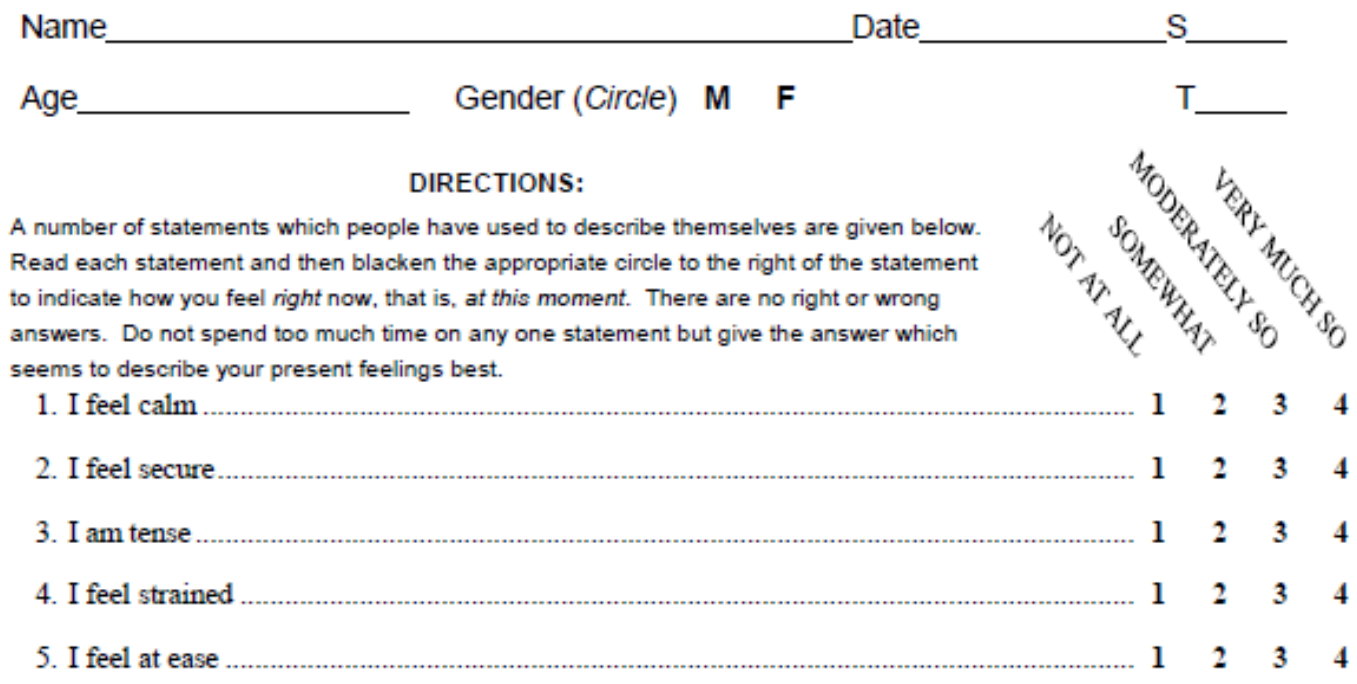

6.

7.

8.

19.

20. 
For use by Anna Liu only. Received from Mind Garden, Inc. on July 25, 2014

SELF-EVALUATION QUESTIONNAIRE

STAI Form Y-2

Name

Date

\section{DIRECTIONS}

A number of statements which people have used to describe themselves are given below. Read each statement and then blacken in the appropriate circle to the right of the statement to indicate you generally feel.

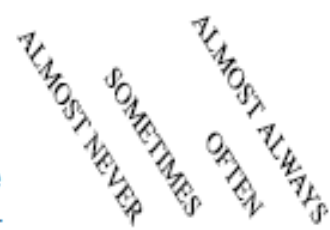

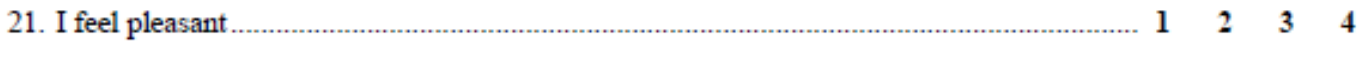

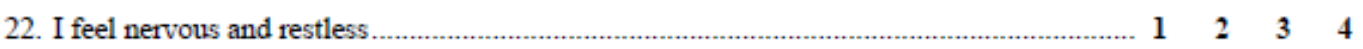

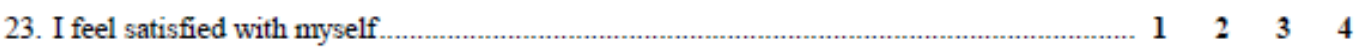

24. I wish I could be as happy as others seem to be ................................................... $11 \quad 2 \quad 3 \quad 4$

25. I feel like a failure ............................................................................................... 1

26

27.

28.

29.

38.

39.

40. 
For use by Anna Liu only. Received from Mind Garden, Inc. on July 25, 2014

\section{SELF-EVALUATION QUESTIONNAIRE}

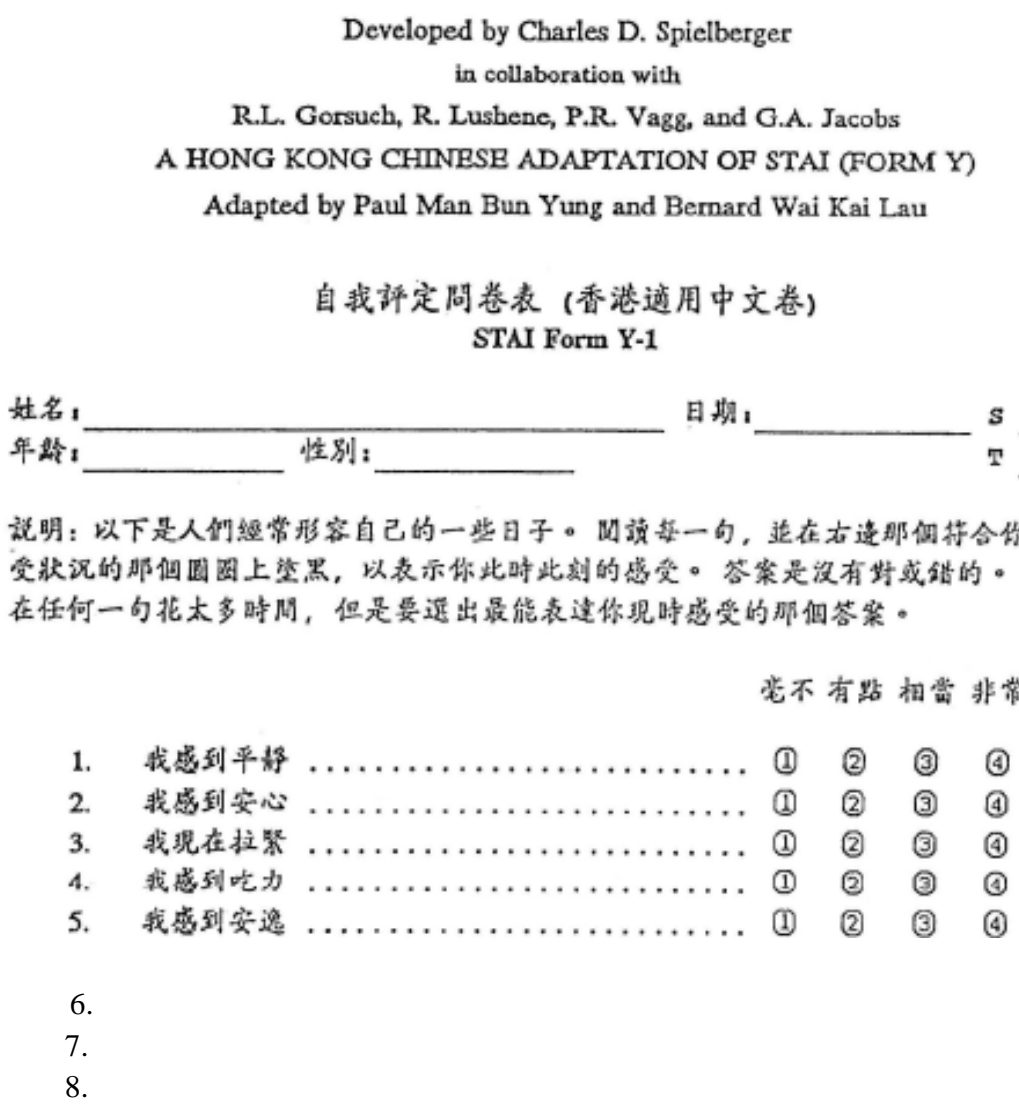

18.

19.

20. 


\section{SELF-EVALUATION QUESTIONNAIRE}

自我评定問卷表 (香港道用中文卷)

(STAI Form Y-2)

妵名、

日期

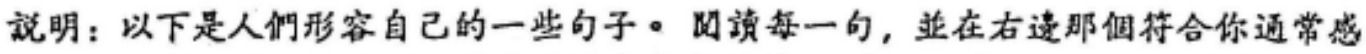
受狀沉的那佃国图上望黑，答案是没有㘧或销的。你不要在任何一句花太多時间， 但是要遥出能表连你平洔一般感受的那㑑答案。

從不有時 俭常缕是

21. 我感到愉快 $\ldots \ldots \ldots \ldots \ldots \ldots \ldots \ldots \ldots \ldots \ldots \ldots \ldots \ldots \ldots$ (1) (2) (3)

22. 我感到祭張和不安定 $\ldots \ldots \ldots \ldots \ldots \ldots$ (1) (2) (3) (4)

23. 我钓自己感到湖意 $\ldots \ldots \ldots \ldots \ldots \ldots \ldots$ (1) (2) (3) (4)

24. 我希望我能像别人那棪快然 $\ldots \ldots \ldots \ldots \ldots$ (1) (2) (3) (4)

25. 我似一值失败者 $\ldots \ldots \ldots \ldots \ldots \ldots \ldots \ldots$ (1) (2) (3) (4)

26.

27.

28.

39.

40. 
APPENDIX C

DASS 21 (ENGLISH \& CHINESE VERSIONS) 
Please read each statement and circle a number $0,1,2$ or 3 which indicates how much the statement applied to you over the past week. There are no right or wrong answers. Do not spend too much time on any statement.

The rating scale is as follows:

0 Did not apply to me at all - NEVER

1 Applied to me to some degree, or some of the time - SOMETIMES

2 Applied to me to a considerable degree, or a good part of time - OFTEN

3 Applied to me very much, or most of the time - ALMOST ALWAYS

FOR OFFICE USE

\begin{tabular}{|c|c|c|c|c|c|}
\hline & & $\mathrm{N}$ & s & 0 & AA \\
\hline 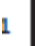 & I found it hard to wind down & 0 & 1 & 2 & 3 \\
\hline 2 & I was aware of dryness of my mouth & 0 & 1 & 2 & 3 \\
\hline 3 & I couldn't seem to experience any positive feeling at all & 0 & 1 & 2 & 3 \\
\hline 1 & $\begin{array}{l}\text { I experienced breathing difficulty (eg, excessively rapid breathing, } \\
\text { breathlessness in the absence of physical exertion) }\end{array}$ & 0 & 1 & 2 & 3 \\
\hline 5 & I found it difficult to work up the initiative to do things & 0 & 1 & 2 & 3 \\
\hline 5 & I tended to over-react to situations & 0 & 1 & 2 & 3 \\
\hline ? & I experienced trembling (eg, in the hands) & 0 & 1 & 2 & 3 \\
\hline 3 & I felt that I was using a lot of nervous energy & 0 & 1 & 2 & 3 \\
\hline$\Rightarrow$ & $\begin{array}{l}\text { I was worried about situations in which I might panic and make a fool of } \\
\text { myself }\end{array}$ & 0 & 1 & 2 & 3 \\
\hline 0 & I felt that I had nothing to look forward to & 0 & 1 & 2 & 3 \\
\hline 1 & I found myself getting agitated & 0 & 1 & 2 & 3 \\
\hline 2 & I found it difficult to relax & 0 & 1 & 2 & 3 \\
\hline 3 & I felt down-hearted and blue & 0 & 1 & 2 & 3 \\
\hline 14 & $\begin{array}{l}\text { I was intolerant of anything that kept me from getting on with what I was } \\
\text { doing }\end{array}$ & 0 & 1 & 2 & 3 \\
\hline 15 & I felt I was close to panic & 0 & 1 & 2 & 3 \\
\hline 16 & I was unable to become enthusiastic about anything & 0 & 1 & 2 & 3 \\
\hline 17 & I felt I wasn't worth much as a person & 0 & 1 & 2 & 3 \\
\hline 18 & I felt that I was rather touchy & 0 & 1 & 2 & 3 \\
\hline 19 & $\begin{array}{l}\text { I was aware of the action of my heart in the absence of physicalexertion (eg, } \\
\text { sense of heart rate increase, heart missing a beat) }\end{array}$ & 0 & 1 & 2 & 3 \\
\hline 20 & I felt scared without any good reason & 0 & 1 & 2 & 3 \\
\hline 21 & I felt that life was meaningless & 0 & 1 & 2 & 3 \\
\hline
\end{tabular}

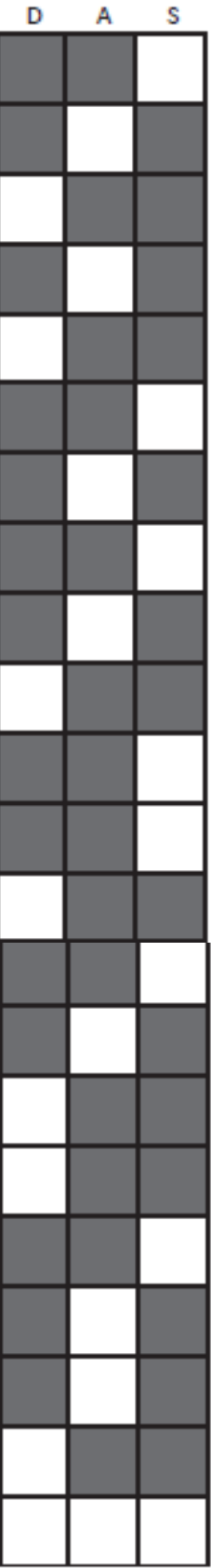

document may be freely downlosded and distributed on condrion no change is made to the conient. The iffomation in this document intended as a substhide for professionsl medical sdvice, dognosis or bestment. Not bo be used for commercial purposes and not io

TOTALS

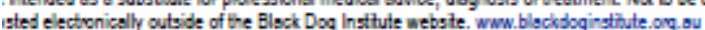




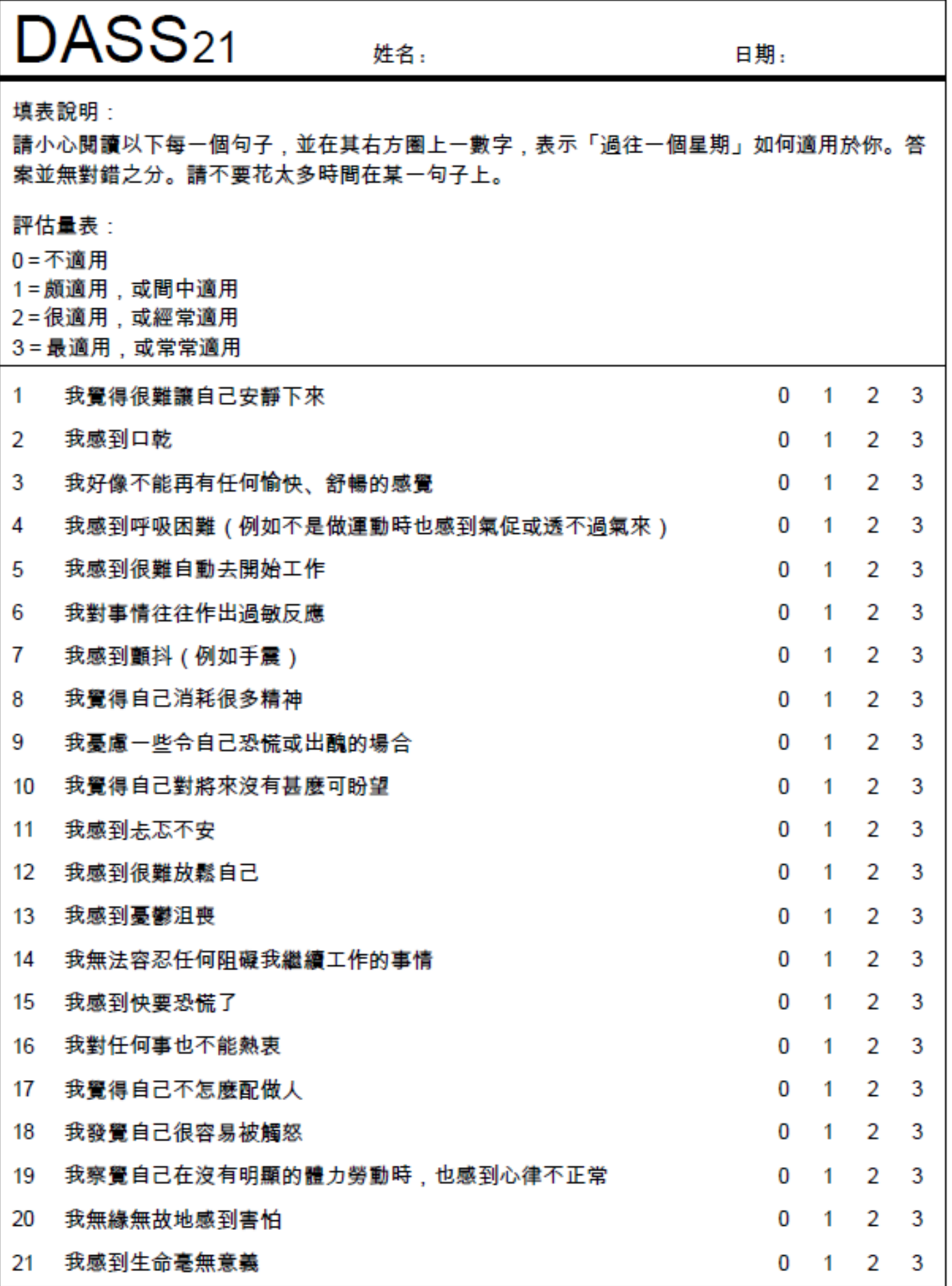




\section{REFERENCES}

American Cancer Society. (2014). Breast cancer facts \& figures. Retrieved from http://www.cancer.org/acs/groups/content/@research/documents/document/acspc040951.pdf

American Psychological Association. (2017). Understanding psychotherapy and how it works. Retrieved from http://www.apa.org/helpcenter/understandingpsychotherapy.aspx

Andersen, S. R., Wurtzen, H., Steding-Jessen, M., Christensen, J., Andersen, K. K., Flyger, H., \& Dalton, S. O. (2013). Effect of mindfulness-based stress reduction on sleep quality: Results of a randomized trail among Danish breast cancer patients. Acta Oncologica, 52, 336-344. doi: 10.3109/0284186X.2012.745948.

Alexander, C. N., Robinson, P., \& Rainforth, M. (1994). Treating and preventing alcohol, nicotine, and drug abuse through transcendental meditation: A review and statistical meta-analysis. Alcoholism Treatment Quarterly, 11, 13-88.

Bankart, C. P. (1997). Talking cures- A history of western and eastern psychotherapies. Pacific Grove, CA: Brooks/ Cole.

Baqutayan, S. (2012). The effect of anxiety on breast cancer patients. Indian Journal of Psychological Medicine, 32 (2), 119-123. doi:10.4103/0253-7176.101774

Barnes, L. L. B., Harp, D., \& Jung, W. S. (2002). Reliability generalization of scores on the Spielberg state-trait anxiety inventory. Educational and Psychological Measurement, 62, 603-618. Retrieved from http://journals.sagepub.com

Baum, A., Revenson, T. A., \& Singer, J. (2012). Handbook of health psychology $\left(2^{\text {nd }}\right.$ ed.). New York, NY: Taylor \& Francis Group.

Beck, A. T., Ward, C. H. Mendelson, M., Mock, J., \& Erbaugh, J. (1961). An inventory for measuring depression. Archives of General Psychiatry, 4, 561-571. Retrieved from https://www.ncbi.nlm.nih.gov.

Beck, A. T., Steer, R. A., \& Garbin, M. G. (1988). Psychometric properties of the beck depression inventory: Twenty-five years of evaluation. Clinical Psychology Review, 8(1), 77-100. doi:10.1016/0272-7358(88)90050-5 
Birnie, K., Garland., S. N., \& Carlson, L. E. (2010). Psychological benefits for cancer patients and their partners participating in mindfulness-based stress reduction (MBSR). Psycho-Oncology, 19(9), 1004-1009. doi:10.1002/pon.1651

Blando, J. (2011). Counseling older adults. New York, NY: Taylor Francis Group.

Bond, M. H. (1988). Finding universal dimensions of individual variation in multicultural studies of values: The Rokeach and Chinese values surveys. Journal of Personality and Social Psychology, 55, 1009-1015. Retrieved from http://dx.doi.org/10.1037/0022-3514.55.6.1009

Bond, M. H. (1993). Emotions and their expression in Chinese culture. Journal of Nonverbal Behavior, 17(4), 245-262. Retrieved from https://link.springer.com

Bower, J. E., Crosswell, A. D., Stanton, A. L., Crespi, C. M., Winston, D., Arevalo, J, Ma, J., Cole., S. W., \& Ganz, P. A. (2015). Mindfulness mediation for younger breast cancer survivors: A randomized controlled trial. Cancer, 121(8), 1231- 1240. doi:10.1002/cncr.29194

Branstrom, R., Kvillemo, P., \& Moskowitz, J. T. (2011). A randomized study of the effects of mindfulness training on psychological well-being and symptoms of stress in patients treated for cancer at 6-month follow-up. International Journal of Behavioral Medicine, 19(4), 534-42. doi: 10.1007/s12529-011-9192-3.

Bridge, L. R., Benson, P., Pietroni P. C., \& Priest R. G. (1988). Relaxation and imagery in the treatment of breast cancer. British Medical Journal, 298 (6657), 1169-1172. Retrieved from https://www.ncbi.nlm.nih.gov/pmc/articles/PMC1835041/

Brown, K. W., Ryan, R. M., \& Creswell, J. D. (2007). Mindfulness: Theoretical foundation and evidence for its salutary effects. Psychological Inquiry, 18(4), 211237. Retrieved from http://dx.doi.org/10.1080/10478400701598298

Canadian Cancer Society. (2014). Breast cancer statistics. Retrieved from http://www.cancer.ca/en/cancer-information/cancer-type/breast/statistics/?region=on

Cai, X. L. (2011). The properties and realms of Chinese calligraphy. China Today, 59 (12), 68-70.

Carlson, L. E., \& Bultz, B. D. (2003). Benefits of psychosocial oncology care: Improved quality of life and medical cost offset. Health Quality of Life Outcomes. 1(8), 1-9. doi: 10.1186/1477-7525-1-8

Centre for Health Protection. (2014). Breast cancer. Retrieved from http://www.chp.gov.hk/en/content/9/25/53.html 
Centre for Health Protection. (2013). Is your blood pressure normal- high blood pressure kills but it's preventable and treatable". Retrieved from http://www.chp.gov.hk/en/view_content/28272.html

Chang, Y. (1992). The method of writing: art of heart [in Chinese]. Taipei.

Chiang, Y. (1973). Chinese calligraphy: An introduction to its aesthetic and technique. Cambridge, MA: Harvest University Press.

China Today. (2012). Calligraphy, then and now. Retrieved from http://www.chinatoday.com.cn/ctenglish/se/txt/2012-08/14/content_475928.html

Chung, S. (2006). Aesthetic practice and spirituality: Chi in traditional East Asian brushwork, Art Education, 59(4), 33-38.

Classen, C., Butler, L. D., Koopman, C., Miller, E., Di-Miceli, S., Giese-Davis, J., \& Spiegel, D. (2001). Supportive-expressive group therapy and distress in patients with metastatic breast cancer: a randomized clinical intervention trial. Archives General Psychiatry, 58(5), 494-501. Retrieved from https://www.ncbi.nlm.nih.gov/pubmed

Cohen-Katz, J., Wiley, S., Capuano, T., Baker, D., \& Shapiro, S. (2004). The effects of mindfulness-based stress reduction on nurse stress and burnout: a quantitative and qualitative study. Holistic Nursing Practice, 18(6), 301-308. Retrieved from https://www.ncbi.nlm.nih.gov/pubmed

Conceicao, D. B., Schonhorst, L., Conceicao, M. J., \& Filho, G. R. (2004). Heart rate and blood pressure are not good parameters to evaluate preoperative anxiety. Revista Brasileira de Anestesiologial, 54(6), 769-773.

Corey, G. (2005). Theory and practice of counseling and psychotherapy $\left(7^{\text {th }} \mathrm{ed}\right.$.). Belmont, CA: Thomson Brooks/ Cole

Crawford, J. R., \& Henry, J. D. (2003). The Depression Anxiety Stress Scales (DASS): Normative date and latent structure in a large non-clinical sample. British Journal of Clinical Psychology, 42, 111-131. doi:10.1348/01446650332190354

Davey, H. E. (1999). Brush meditation. Berkeley, CA: Stone Bridge Press.

De Jong, M. J., Moser, D. K., An, K., \& Chung, M. L. (2004). Anxiety is not manifested by elevated heart rate and blood in acutely ill cardiac patients. European Journal of Cardiovascular Nursing, 3(3): 247-53. doi:10.1016/j.ejcnurse.2004.06.006

Dobkin, P. L., \& Zhao, Q. (2011). Increased mindfulness- the active component of the mindfulness-based stress reduction program? Complementary Therapy Clinical Practice. 17(1), 22-27. doi:10.1016/j.ctcp.2010.03.002. 
Doctor, R. M., Kahn, A. P., \& Adamec, C. (2008). The encyclopedia of phobias, fears, and anxieties $\left(3^{\text {rd }}\right.$ ed.). New York, NY: Facts on File

Dong, X. P., Jia, J. M., Wang, J., \& Zhang, R. X. (2006). A control study of calligraphy training plus venlafaxine in the treatment of anxiety disorder. Chinese Journal of Behavioral Medical Science, 15(5). 445- 446. doi:10.1016/j.ijnurstu.2009.10.014

Dow, K. H., Ferrell, B. R., Haberman, M. R., \& Eaten, L. (1999). The meaning of quality of life in cancer survivorship. Oncology Nursing Forum, 26 (3), 519-28. Retrieved from https://www.ncbi.nlm.nih.gov/pubmed/

Drageset, S., Lindstrom, T. C., Giske, T., \& Underlid, K. (2011). Being in suspense: women's experiences awaiting breast cancer surgery. Journal of Advanced Nursing, 67(9), 1941-1951. doi:10.1111/j.1365-2648.2011.05638.x.

Ehring, T., Caffier, B. T., Schnulle, J., Fischer, S., \& Gross, J. J. (2010). Emotion regulation and vulnerability to depression: Spontaneous versus instructed use of emotion suppression and reappraisal . Emotion, 10(4): 563- 572. doi:10.1037/a0019010

Esch, L. V., Roukema, J. A., Van der Steeg, A. F. W., \& De Vries, J. D.(2011). Trait anxiety predicts disease-specific health status in early-stage breast cancer patients. Quality of Life Research, 20(6), 865-873. doi:10.1007/s11136-010-9830-2

Fan, Z. S., Kao, H. S. R., Wang, Y. L., \& Guo, N. F. (1999). Calligraphic treatment of Schizophrenic patients. In G. Leedham, M. Leung, V. Sagar, \& X. H. Xiao, (Eds.), The $9^{\text {th }}$ biennial conference of the international graphonomics society, 125-131. Singapore: Nanyang Technological University.

Freeman L., Cohen, L., Stewart, M., White, R., Link, J., \& Palmer, J. L. (2008). The experience of imagery as a post-treatment intervention in patients with breast cancer: Program, process and patient recommendation. Oncology Nursing Forum, 35(6), E116-121. doi:10.1188/08.ONF.E116-E121

Gagnon, J. I. (1998). The use of art therapy to reduce anxiety in short term psychiatric groups. (MA thesis). Available from ProQuest Dissertations and Theses database. (UMI No.1389797).

Gloster, A. T., Rhoades, H. M., Novy, D., Klotsche, J., Senior, A., Kunik., M., \& Stanley, M. A. (2008). Psychometric properties of the depression anxiety and stress scale21 in older primary care patients. Journal of Affective Disorders, 110 (3), 248259. doi:10.1016/j.jad.2008.01.023

Golden-Kreutz, D. M., \& Andersen, B. L. (2004). Depressive symptoms after breast cancer surgery: Relationships with global, cancer-related, and life event stress. Psycho-Oncology 13(3):211-20. doi:10.1002/pon.736 
Goldin, P., \& Gross, J. (2010). Effects of mindfulness-based stress reduction (MBSR) on emotion regulation in social anxiety disorder. Emotion, 10(1), 83-91. doi:10.1037/a0018441

Goodwin, P. J., Leszcz, M., Ennis, M., Koopmans, J., Vincent, L., Guther, H., \& Hunter, J. (2001). The effect of group psychosocial support on survival in metastatic breast cancer. New England Journal of Medicine, 345, 1719-1726. doi:10.1056/NEJMoa011871

Gron, A. (1952). The concept of anxiety in Soren Kierkegaard. Macon, GA: Mercer University Press.

Gros, D. F., Antony, M. M., Simms, L. J., \& McCabe, R. E. (2007). Psychometric properties of the state-trait inventory for cognitive and somatic anxiety (STICA): comparison to the state-trait anxiety inventory (STAI). Psychological Assessment, 19(4), 369-81. doi:10.1037/1040-3590.19.4.369

Gross, C., Kreitzer, M., Thomas, W., Reilly-Spong, M., Cramer-Bornemann, M., Nyman, J. A., \& Ibrahim, H. N. (2010). Mindfulness-based stress reduction for solid organ transplant recipients: A randomized controlled trail. Alternative Therapies in Health and Medicine, 16(5), 30-38. Retrieved from https://www.ncbi.nlm.nih.gov/pmc/

Guan, C. H., Ng, S. H., \& Kao, H. S. R. (2000). Calligraphy practices and emotional state of managers and administrators. International Journal of Behavioral Medicine, 7(S1), 72.

Guo, N. F., Kao, H. S. R., \& Liu, X. (2001). Calligraphy, hypertension and the type-a personality. Annals of Behavioral Medicine, 23, S159.

Hales, R. R., Yudofsky, S. C., \& Roberts, L. W. (2014). Textbook of psychiatry. Arlington, VA: American Psychiatric.

Hellhammer, D. H., Wust, S., \& Kudielka, B. M. (2009). Salivary cortisol as a biomarker in stress research. Psycho-neuroendocrinology, 34, 163-171. doi:10.1016/j.psyneuen.2008.10.026

Hewitt, M., Breen, N., \& Devesa, S. (1999). Cancer prevalence and survivorship issues: Analyses of the 1992 national health interview survey. Journal of the National Cancer Institute, 91(17), 1480-1486. Retrieved from https://www.ncbi.nlm.nih.gov/pubmed

Hewitt, M., Herdman, R., \& Holland, J. (2004). Meeting psychological needs of women with breast cancer. Washington D.C.: The National Academies Press. 
Hildrum, B., Romild, U. \& Holmen, J. (2011) Anxiety and depression lowers blood: 22year follow-up of the population based Hunt study, Noray. BMC Public Health, 11:601. doi: 10.1186/1471-2458-11-601

Hilsden, R. J., \& Verhoef, M. J. (1999). Complementary therapies: Evaluating their effectiveness in cancer. Education and Counseling, 38, 101-108. Retrieved from https://www.ncbi.nlm.nih.gov/pmc

Hirschfeld, R. M. A. (2001). The comorbidity of major depression and anxiety disorder: Recognition and management in primary care. Primary Care Companion to the Journal of Psychiatry, 3(6), 244-254. Retrieved from https://www.ncbi.nlm.nih.gov/pmc

Ho, C. W., \& Lopez, V. (2004). The reliability and validity of the Chinese version of trait anxiety scale for children. Research in Nursing \& Health, 27(6), 426- 434. doi:10.1002/nur.20045

Ho, C. W., \& Lopez, V. (2004). Psychometric evaluation of Chinese version of the state anxiety scale for children. Research in Nursing \& Health, 27(3), 198- 207. doi:10.1002/nur.20015

Hofmann, S. G. \& Hinton, D. E. (2014). Cross-cultural aspects of anxiety disorder. Current Psychiatry Report, 16(6), 450. doi:10.1007/s11920-014-0450-3

Hough, J. (2008). Practicing Chinese calligraphy \& its longevity benefits. Retrieved from http://www.art-virtue.com/introduction/5-longevity.htm

Huang, G. Y., Chen, C. J., \& Kao, H. S. R. (2000). Chinese brush handwriting of children with varying hyperactivity. In H. S. R. Kao, (Ed.), Chinese Calligraphy Therapy, 131-143. Hong Kong: Hong Kong University Press.

Hue, M. T. (2009). Promotion of spiritual development: exploration of the self and spiritualism through the practice of Chinese calligraphy. Pastoral Care in Education, 27(1), 63-76. Retrieved from http://dx.doi.org/1.1080/0264390902733886

Ingram, R. E. (2009). The international encyclopedia of depression. New York, NY: Springer.

Julian, L. J. (2004). Measures of Anxiety. Arthritis Care \& Research (Hoboken), 63(011). 10.1002/acr.20561.doi:10.1002/acr20561

Kabat-Zinn, J. (1982). An out-patient program in behavioral medicine for chronic pain patients based on the practice of mindfulness meditation: Theoretical considerations and preliminary results. General Hospital Psychiatry, 4, 33-47. Retrieved from https://www.ncbi.nlm.nih.gov/pubmed 
Kabat-Zinn, J. (2003). Mindfulness-based interventions in context: Past, present, and future. Clinical Psychology: Science and Practice, 10, 144-156.

doi:10.1093/clipsy.bpg016

Kabat-Zinn, J., Lipworth, L., Burney, R. (1985). The clinical use of mindfulness meditation for the self-regulation of chronic pain. Journal of Behavioral Medicine. 8, 163- 190. Retrieved from https://www.ncbi.nlm.nih.gov/pubmed

Kabat-Zinn, J., Massion, A. O., Kristeller, J., Peterson, L. G., Fletcher, K., Pbert, L., \& Santorelli, S. F. (1992). Effectiveness of a meditation-based stress reduction program in the treatment of anxiety disorders. American Journal of Psychiatry, 149, 936-943. doi:10.1176/ajp.149.7.936

Kao, H. S. R. (2003). Calligraphy psychotherapy. Hong Kong: Hong Kong University Press.

Kao, H. S. R. (2010). Calligraphy therapy: A complementary approach to psychotherapy. Asia Pacific Journal of Counseling and Psychotherapy, 1(1), 55-66. doi: $10.1080 / 2150768090350334$

Kao, H. S. R., Ding, B. K., \& Cheng, S. W. (2000a). Brush handwriting treatment of emotional problems in patients with type ii diabetes. International Journal of Behavioral Medicine, 7(S-1), 50.

Kao, H. S. R. \& Gao, D. (2000). Effects of practicing Chinese calligraphy on visualspatial ability and pictorial memory in normal aged people. International Journal of Psychology, 35(4), 302.

Kao, H. S. R., Gao, D. G., Wang, M. (2000b). Brush handwriting treatment of cognitive deficiencies in alzheimer's disease patients. Neurobiology of Aging, 21(1S), 14.

Kao, H. S. R, Gao, D., Wang, M. Q., Cheung, H. Y., \& Chiu, J. (2000c). Chinese calligraphic handwriting: Treatment of cognitive deficiencies of alzheimer's disease patients. Alzheimer's Report, 3(5/6), 281-287.

Kao, H. S. R., Lai, S. F., Fok, W. Y., Gao, D. G., \& Ma, T. H. (2000e). Brush handwriting treatment of negative behaviors in school and at home in children with autism. In Book of Abstracts, $8^{\text {th }}$ Glasgow, Autism-Europe Congress, 19-21.

Kao, H. S. R., Miao, D. M., Luo, Z. X., \& Gao, D. G. (2006). Effects of Chinese calligraphy handwriting on cadets. Annals of Behavioral Medical, 31(104).

Kao, H. S. R., Lin, Z., Chao, L. Z., Chen, H. Y., \& Zhang, M. (2014). Calligraphy and meditation for stress reduction: An experimental comparison. Psychology Research and Behavior Management, 7, 47-52. doi: 10.2147/PRBM.S55743 
Kazdin, A. E. (Ed). (2000). Encyclopedia of Psychology, 1, 209-212. Washington, D.C.: American Psychological Association.

Kieviet-Stijnen, A., Visser, A., Garssen, B., \& Hudig, W. (2008). Mindfulness-based stress reduction training for oncology patients: patients' appraisal and changes in well-being. Patient Education \& Counseling. 72(3), 436-442. doi:10.1016/j.pec.2008.05.015.

Kolcaba, K., \& Fox, C. (1999). The effects of guided imagery on comfort of women with early stage breast cancer undergoing radiation therapy. Oncology Nursing Forum, 26(1), 67-72. Retrieved from https://www.ncbi.nlm.nih.gov/pubmed

Kreitzer, M., Gross, C., Ye, X., Russas, V., \& Treesak, C. (2005). Longitudinal impact of mindfulness meditation on illness burden in solid-organ transplant recipients. Progress in Transplantation, 15(2), 166-172. Retrieved from https://www.ncbi.nlm.nih.gov/pubmed/

Langer, E. (1989). Mindfulness. Reading, MA: Addison-Wesley.

Langer, E. J., \& Moldoveanu, M. (2000). The construct of mindfulness. Journal of Social Issues, 56(1), 1-9. doi:10.1111/0022-4537.00148

Ledesma, D. \& Kumano, H. (2009). Mindfulness-based stress reduction and cancer: a meta-analysis. Psycho-Oncology, 18(6), 571-579. doi:10.1002/pon.1400

Lengacher, C.A., Johnson-Mallard, V., Post-White, Moscoso, M. S. Jacobsen, P. B., Klein, T. W., \& Kip, K. E. (2009). Randomized controlled trail of mindfulnessbased stress reduction (MBSR) for survivors of breast cancer. Psycho-oncology 18(12), 1261-72. doi:10.1002/pon.1529

Lerman, R., Jarski, R., Rea, H., Gellish, R., \& Vicini, F. (2011). Improving Symptoms and quality of life of female cancer survivors: A randomized controlled study. Annuals Surgical Oncology. doi:10.1245/s10434-011-0251-2

Lesiuk, T. (2015). The effect of Mindfulness-Based Music Therapy in attention and mood in women receiving adjuvant chemotherapy for breast cancer: a pilot study. Oncology Nursing Forum, 42(3), 276-82. doi:10.1188/15.ONF.276-282.

Li, X. M., Zhou, K. N., Yan, H., \& Zhang, Y. P. (2011). Effects of music therapy on anxiety of patients with breast cancer after radical mastectomy: A randomized clinical trial. Journal of Advanced Nursing, 68(5), 1145-1155. doi:10.111/j.13652648.2011.05824.x

Lim, C. C., Devi, M. K., \& Ang, E. (2011). Anxiety in women with breast cancer undergoing treatment: A systematic review. International Journal of EvidenceBased Healthcare, 9, 215-35. doi:10.1111/j.1744-1609.2011.00221.x 
Lindsey, A. M., West, C. M., \& Carrieri-Kohlman, V. (1993). Pathophysiological Phenomena in Nursing: Human Responses to Illness ( $2^{\text {nd }}$ ed.). Philadelphia, PA: Saunders.

Lovibond, S. H., \& Lovibond, P. F. (1995). Manual for the Depression Anxiety Stress Scales. Sydney: Psychology Foundation.

Malchiodi, C. A. (2007). The Art Therapy Sourcebook (2 ${ }^{\text {nd }}$ ed.). New York, NY: McGraw-Hill.

Martin, G., \& Pear, J. (2015). Behavior Modification (10 ${ }^{\text {th }}$ ed.). New York, NY: Taylor \& Francis.

Matchim, Y., Armer, J. M., \& Stewart, B. R. (2011). Mindfulness-based stress reduction among breast cancer survivors: a literature review and discussion. Oncology Nursing Forum, 38(2), 61-71. doi:1.1188/11.ONF.E61-E71

Matousek, R. H., Dobkin, P. L., \& Pruessner, J. (2010). Cortisol as a marker for improvement in mindfulness-based stress reduction. Complementary Therapies in Clinical Practice. 16(1), 13-13. doi: 10.1016/j.ctcp.2009.06.004

Matousek, R. H., Pruessner, J. C., \& Dobkin, P. L. (2010). Changes in cortisol awakening response (CAR) following in mindfulness-based stress reduction in women who completed treatment for breast cancer. Complementary Therapies in Clinical Practice, 17(2), 65-70. doi: 10.1016/j.ctcp.2010.10.005.

McGregor, B. A., \& Antoni, M. H. (2009). Psychological intervention and health outcomes among women treated for breast cancer: a review of stress pathways and biological mediators. Brain Behavior and Immunity, 23(2), 159-166. doi: 10.1016/j.bbi.2008.08.002

Mental Health Foundation. (2010). Be mindful report. Retrieved from: http://www.mentalhealth.org.uk/pubications.

Miller, W. R. (1999). Integrating spirituality into treatment: resources for practitioners. Washington, D.C.: American Psychological Association.

Milrod, B., Leon, A. C., Busch, F. Rudden, M., Schwalberg, M., Clarkin, J., \& Shear, M. (2007). A randomized controlled clinical trial of psychoanalytic psychotherapy for panic disorder. American Journal of Psychiatry, 164, 265-272. doi:1.1176/ajp.2007.164.2.265 
Molassiotis, A., Yung, H. P., Yam, B. M., Chan, F. Y., \& Mok, T. (2002). The effective of progressive muscle relaxation training in managing chemotherapy-induced nausea and vomiting in Chinese breast cancer patients: a randomized controlled trial. Supportive Care in Cancer, 10(3), 237-246. doi: 10.1007/s00520-001-03299

National Cancer Institute. (2014). Adjustment to cancer: Anxiety and distress. Retrieved From https://www.cancer.gov/

Nelson, E. R. (2007). Quest for the holy mountain. Dunlap, TN: Read Books.

Ng, C. G., Mohamed, S., Kaur, Kiran, Sulaiman, A. H., Zainal, N. Z., \& Taib, N. A. (2017). Perceived distress and its association with depression and anxiety in breast cancer patients. PLOS One, 12(3): eo172975. doi:10.1371/journal pone 0172975

Norton, P. J. (2007). Depression anxiety and stress scales (DASS-21): Psychometric analysis across four racial groups. Anxiety, Stress \& Coping: An International Journal, 20(3), 253-265. doi:1.1080/10615800701309279

Nosheen, R., \& Naumana, A. (2017). Cross cultural variation in emotion regulation: A systematic review. Systemic Review Annals, 23(1), 77-90.

O’Connell, D. F., \& Alexander, C. N. (1994). Self-Recovery: Treating addictions using transcendental meditation and Maharishi Ayur-Veda. Binghamton, NY: Harrington Park Press.

Oei., T. P. S., Sawang, S., Goh, Y. W., \& Mukhtar, F. (2013): Using the depression anxiety stress scale 21(DASS 21) across culture. International Journal of Psychology 48(6), 1018-1029. doi:10.1080/00207594.2012.75535

Osman, A., Wong, J. L., Bagge, C. L., Freedenthal, S., Gutierrez, P. M., \& Lozano, G. (2012). The depression anxiety stress scales-21 (DASS-21): Further examination of dimensions, scale reliability, and correlates. Journal of Clinical Psychology, 68(12), 1322-1388. doi:10.1002/jclp.21908

Osho News. (2011). Calligraphy and meditation. Retrieved from http://www.oshonews.com/2011/06/26/calligraphy-and-meditation/

Payne, S., \& Endall, M. (1998). Detection of anxiety and depression by surgeons and significant others in females attending a breast clinic. European Journal of Oncology Nursing, 2(1), 4-11. doi:10.1016/S1462-3889(98)81254-4

Pedersen, A. E., Sawatzky, J. A., \& Hack, T. F. (2010). The sequelae of anxiety in breast cancer: A human response to illness model. Oncology Nursing Forum, 37(4). 469-475. doi:10.1188/10.ONF.469-475 
Pradhan, E., Baumgarten, M., Langenberg, Handwerger, B., Gilpin, A. K., Magyari, T., \& Berman, B. M. (2007). Effect of mindfulness-based stress reduction in rheumatoid arthritis patients. Arthritis Rheum, 57(7), 77-85.

Rahmani, S., \& Talepasand, S. (2015). The effect of group mindfulness- based stress reduction program and conscious yoga on the fatigue severity and global and specific life quality in women with breast cancer. Med J Islam Republic Iran, 29, 175. Retrieved from https://www.ncbi.nlm.nih.gov/pubmed

Ravindran, L. N., \& Stain, M. B. (2010). The pharmacologic treatment disorders: A review of progress. Journal of Clinical Psychiatry, 71, 839-845. doi:10.4088/JCP.10r06218blu

Rinpoche, S. (1992). The Tibetan book of living and dying. New York, NY: HarperCollins.

Roberts, B. W. (2006). Personality development and organizational behavior. In B. M. Staw (Ed.), Research on organizational behavior, (pp. 1-41), New York, NY: Elsevier Science/ JAI Press.

Roberts B. W., Luo, J, Briley, D. A., Chow, P. I., Su, R., \& Hill, P. L. (2017). A systematic review of personal trait change through intervention. Psychological Bulletin, 143(2) 117-141. doi:10.1037/bul0000088

Rosen, J. B., \& Schulkin, J. (1998). From normal fear to pathological anxiety. Psychological Review, 105(2), 325-350. Retrieved from https://www.ncbi.nlm.nih.gov/pubmed

Salimetrics Europe. (2012). An introduction to Saliva Research. Retrieved from http://salimetricseurope.blogspot.com/2012/03/salimetrics-europe-publishintroduction.html.

Schultz, D. P., \& Schultz, S. E. (2017). Theories of personality (1 $\left.1^{\text {th }} \mathrm{ed}.\right)$. Belmont, CA: Cengage Learning.

Segerstrom, S. C., \& Miller, G. E. (2004). Psychological stress and the human immune system: a meta-analytic study of 30 years of inquiry. Psychological Bulletin, 130(4): 601-630. doi:10.1037/0033-2909/130.4.601

Sephton, S., Salmon, P., Weissbecker, I., Ulmer, C., Folyd., A., Hoover, K., \& Studts, J. L. (2007). Mindfulness mediation alleviates depressive symptoms in women with fibromyalgia: Results of a randomized clinical trial. Arthritis Rheum, 57(1), 7785. doi:10.1002/art.22478 
Sharpley C. F., Bitsika, V., \& Christie, D. R. H. (2009). Helping prostate cancer patients understand the causes vs. patient response events. Journal of Men's Health 6(4), 345-353.

Shen, H. (2004). Brush reveals heart: analysis of the artistic features of Su Shi's calligraphy. In T. Chin \& W. D. Li. East Asian calligraphy education. Bethesda, MD: University Press of Maryland.

So, W. K., Marsh, G., Ling, W. M., Leung, F. Y., Lo, J. C., \& Yeung, M., Li, G. K. (2009). The symptom cluster of fatigue, pain, anxiety, and depression and the effect on the quality of life of women receiving treatment for breast cancer: A multicenter study. Oncology Nursing Forum, 36(4), 205-14. doi: 10.1188/09.ONF.E205-E214

Soto, J. A., Levenson, R. W., \& Ebling, R. (2005). Cultures of moderation and expression: Emotional experience, behavior, and physiology in Chinese Americans and Mexican Americans. Emotion, 5(2), 254-165. doi:10.1037/15283542.5.2.154

Speca, M., Carlson, E., Goodey, E., \& Angen, M. (2000). A randomized, wait-list controlled clinical trial: The effect of a mindfulness meditation-based stress reduction program on mood and symptoms of stress in cancer outpatients. Psychosomatic Medicine, 62(5), 613-622.

Spiegel, D., Bloom, J. R., \& Yalom, I. (1981). Group support for patients with metastatic breast cancer: A randomized prospective outcome study. Archives of General Psychiatry, 38, 527-533. Retrieved from https://www.ncbi.nlm.nih.gov/pubmed

Spielberger, C. D. (1989). State-trait anxiety inventory: A comprehensive bibliography. Palo Alto, CA: Consulting Psychologists Press.

Spielberger, C. D., Sydeman, S. J., Owen, A. E., \& Marsh, B. J. (1999). Measuring anxiety and anger with the state-trait anxiety inventory (STAI) and the state-trait anger expression inventory (STAI). In M. E. Maruish (Ed.), The Use of Psychological Testing for Treatment Planning and Outcomes Assessment $\left(2^{\text {nd }}\right.$ ed., 993- 1021). Mahwah, NJ: Lawrence Eribaum Associates.

Terayama, T. (2004). Zen brushwork: Focusing the mind with calligraphy and paining. Japan: Kodansha International.

Thich, N. H. (2017). Calligraphy mediation: The mindful art of Thich Nhat Hanh. Retrieved from http://www.thichnhathanhcalligraphy.org/newyork/ 
Tacon, A. M., Caldera, Y. M., \& Ronaghan, C. (2004). Mindfulness based stress reduction in women with Breast Cancer. Families, Systems, \& Health, 22(2), $192-$ 103. doi:10.1037/1091-7527.22.2.193

Van Son, J., Nyklicek, I., Pop, VJ., \& Pouwer, F. (2011). Testing the effectiveness of a mindfulness-based intervention to reduce emotional distress in outpatients with diabetes: Design of a randomized controlled trial. BMC Public Health, 11, 131.doi:10.1186/1471-2458-11-131

Verhoef, M. J., Hilsden, R. J., \& O’Beirne, M. (1999). Complementary therapies and cancer care: An overview. Patient Education and Counseling, 38, 93-100.

Retrieved from http://www.art-virtue.com/index.html

Vollestad, J., Sivertsen, B., \& Nielsen, G. (2011). Mindfulness-based stress reduction for patients with anxiety disorder: evaluation in a randomized controlled trial. Behaviour Research Therapy, 49(4), 281-288. doi:10.1186/1471-2458-11-131

Wang, K., Shi, H. S., Geng, F. L., Zou, L. Q., Tan, S. P., Wang, Y., Neumann, D. L., Shum, D. H. K., \& Chan, R. C. K. (2015). Cross-cultural validation of the depression anxiety stress scale- 21 in China. Psychological Assessment. Advance on publication. http://dx.doi.org/10.1037/pas0000207.

Walker, L. G., Walker, M. B., Ogston, K. Heys, S. D., Ah-See, A. K., Miller, I. D., \& Eremin, O. (1999). Psychological, clinical and pathological effects of relaxation training and guided imagery during primary chemotherapy. British Journal of Cancer, 80(1-2), 262-268. doi:10.1038/sj.bjc.6690349

Wildman, W. (Ed.). (1994). Book review: The courage to be by Paul Tillich, review by JL and SC. Paul Tillich Resources. Retrieved from http://people.bu.edu/wwildman/tillich/resources/review_tillichpaul_couragetobe.htm\#Review_by_JL

Wood, B. M., Nicholas, M. K., Blyth, F., Asghari, A., \& Gibson, S. (2010). The utility of the short version of the depression anxiety stress scales (DASS 21) in elderly patients with persistent pain: Does age make a different? Pain Medicine, 11, 1780-1789. doi:10.1111/j.1526-4637.2010.01005.x

World Health Organization. (2014). Breast cancer: Prevention and control. Retrieved from http://www.who.int/cancer/detection/breastcancer/en/index 1.html

Yang, X. L., Li, H. H., Hong, M. H., \& Kao, H. (2010). The effects of Chinese calligraphy handwriting and relaxation training in Chinese nasopharyngeal carcinoma patients: A randomized controlled trail. International Journal of Nursing Studies, 47, 550-559. doi: 10.1016/j.ijnurstu.2009.10.014 
Yum, M., \& Kao, H. S. R. (1999). Emotional effects associated with writing of Chinese calligraphy on the non-Chinese people. In G. Leedham, M. Leung, V. Sagar, \& X. H. Xiao (Eds.), The $9^{\text {th }}$ biennial conference of the international graphonomics society, 119- 124. Singapore: Nanyang Technological University.

Zainal, N. Z., Booth, S., \& Huppert, F. A. (2013). The effect of mindfulness-based stress reduction on mental health of breast cancer patients: a meta-analysis. Psychooncology, 22, 1457-1466. doi: 10.1002/pon.3171

Zeng, C. Y., \& Zeng, H. (2011). Brain Doctor with Healthy Brain: Without Illness, Pain with Health, Longevity. Salt Lake City, UT: Academic Press.

Zhang, J. Y., Zhou, Y. Q., Feng, Z. W., Fan, Y. N., Zeng, G. C. \& Li, Wei. (2017). Randomized controlled trial of mindfulness-based stress reduction (MBSR) on posttraumatic growth of Chinese breast cancer survivors. Psychology, Health \& Medicine, 22(1), 94- 109. doi:10.1080/13548506.2016.1146405

Zhu, Z. H., Zong, Y., Wang, X. G., Tang, S., Zang, T. M., Chen, J., Yin, H. L., Lam, S. P. W., Chan, C. L., \& Kao, H. S. R. (2010). Calligraphy therapy of PTSD children in 2008 China earthquakes. Annals of Behavioral Medicine, 39, 2109.

陳靖(2012). 笔隸書教程。濟南: 山東教育出版社。

洪量豐(2017). 一字不舊。Retrieved from

http://stedu.stheadline.com/sec/sec_news.php?aid=16898\&friendly_print=1

高尚仁(2000). 書法心理治療。香港: 香港大學出版社。

侯吉諒(2012). 書法學堂: 誰能寫書法。Retrieved from

http://newsblog.chinatimes.com/hj1/archive/26204 


\section{Curriculum Vitae}

Anna Liu

D302 Westlands Garden,

Phone: (852) 91677027

4 Westlands Road,

e-mail: chimanna@gmail.com

Quarry Bay, Hong Kong

\section{EDUCATION AND QUALIFICATIONS}

2014 Master of Art in Educational Psychology

Andrews University

Berrien Spring, MI 49103, USA

2010- Present $\quad \mathrm{PhD}$ in Counseling Psychology (in progress)

Andrews University

Berrien Spring, MI 49103, USA

2005 - $2009 \quad$ Master of Art in Professional Counseling

Olivet Nazarene University

Hong Kong Campus

2004-2005 Certificate of Clinical Pastoral Education

Hong Kong Bethel Seminary

Kowloon, Hong Kong

1994-1998 4-year Diploma in Religion

Hong Kong Adventist College

Sai Kung, NT, Hong Kong

1984 - 1986 Tsuen Wan Adventist School of Nursing

Tsuen Wan, NT, Hong Kong

\section{WORK EXPERIENCES}

2016- present Counselor (part-time) \&Teacher (part-time), Hong Kong Adventist College

2015- 2016 Pre-doctoral Psychology Intern, Hong Kong Adventist College

2007- 2009 Counselor (part-time), Breast Health Center \& Mother-Child Clinic Tsuen Wan Adventist Hospital 
$1998-2001$

Chaplain \& Bible teacher, Hong Kong Adventist College; Chaplain, Sam Yuk Middle School

SUPERERVISED PROFESSIONAL EXPERIENCES IN COUNSELING

\begin{tabular}{|c|c|c|c|}
\hline & Types of setting & $\begin{array}{c}\text { Clinical services } \\
\text { provided }\end{array}$ & $\begin{array}{c}\text { Clinical \& cultural } \\
\text { populations }\end{array}$ \\
\hline $\begin{array}{l}\text { 2015- 2016 } \\
\text { (2000 clock } \\
\text { hours, with } 800 \\
\text { direct hours) }\end{array}$ & $\begin{array}{l}\text { College } \\
\text { Elementary school } \\
\text { High school } \\
\text { Community }\end{array}$ & $\begin{array}{l}\text { Individual, child, } \\
\text { group \& family } \\
\text { counseling } \\
\text { Psychological } \\
\text { testing }\end{array}$ & $\begin{array}{l}\text { 1. Elementary, high school } \\
\& \text { college students with } \\
\text { diverse cultural } \\
\text { background. } \\
\text { 2. Clients from Hong } \\
\text { Kong Chinese } \\
\text { community. }\end{array}$ \\
\hline $\begin{array}{l}\text { 2011- 2012 } \\
\text { (400 clock } \\
\text { hours, with } 160 \\
\text { direct hours) }\end{array}$ & $\begin{array}{l}\text { University } \\
\text { community } \\
\text { counseling center }\end{array}$ & $\begin{array}{l}\text { Individual } \\
\text { Counseling, } \\
\text { psychological } \\
\text { testing }\end{array}$ & $\begin{array}{l}\text { Community clients with } \\
\text { diverse cultural background } \\
\text { in the US }\end{array}$ \\
\hline $\begin{array}{l}\text { 2008- 2009 } \\
\text { (600 clock } \\
\text { hours, with } 200 \\
\text { direct hours) }\end{array}$ & 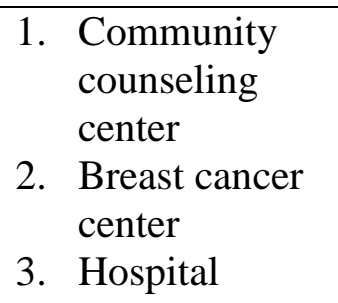 & $\begin{array}{l}\text { Individual } \\
\text { Counseling, breast } \\
\text { cancer patient } \\
\text { support services, } \\
\text { mutual support } \\
\text { group }\end{array}$ & $\begin{array}{l}\text { 1. Clients from Hong } \\
\text { Kong Chinese } \\
\text { community } \\
\text { 2. Hong Kong breast } \\
\text { cancer patients }\end{array}$ \\
\hline $\begin{array}{l}\text { 2007-2008 } \\
\text { (100 clock } \\
\text { hours, with } 40 \\
\text { direct hours) }\end{array}$ & $\begin{array}{l}\text { Community } \\
\text { counseling center }\end{array}$ & $\begin{array}{l}\text { Individual \& group } \\
\text { counseling }\end{array}$ & $\begin{array}{l}\text { Clients from Hong Kong } \\
\text { Chinese community }\end{array}$ \\
\hline $\begin{array}{l}\text { 2004- 2005 } \\
\text { (400 clock } \\
\text { hours, with } 200 \\
\text { direct hours) }\end{array}$ & Hospital & $\begin{array}{l}\text { Clinical pastoral } \\
\text { care and counseling }\end{array}$ & $\begin{array}{l}\text { Hong Kong Chinese } \\
\text { patients }\end{array}$ \\
\hline
\end{tabular}




\section{LANGUAGES}

Cantonese: Native speaker

Mandarin: Fluent to very fluent

Hakka Fluent to very fluent

English: Fluent

\section{PROFESSIONAL CETIFICATION, MEMBERSHIPS \& TRAINING ATTENDED}

- Certificate of Clinical Pastoral Education

- International Certified Crisis Chaplain

- Accredited Administrator of the Myer-Briggs Type Indicator, Step I \& II

- American Psychological Association, Student Affiliate

- Counselor for Prepare/ Enrich Inventories

- Critical Incident Stress Management: Individual Crisis Intervention and Peer Support

- Neuro-Linguistic Programming

- Interpersonal Forgiveness: Forgiving yourself and Forgiving others

- Abuse Prevention

- Anger Management

- Counseling the Depressed

- Eligibility Determination \& Intervention for Students with SLD, ASD, and ADHD

- Sleep disturbance among older adults

- Motivational Interviewing

- Using art in treatment of those affected by domestic violence

\section{PRESENTATION \& WORKSHOP HELD}

- The effects of Chinese calligraphy in reducing anxiety levels

- Parent-child communication

- Parenting

- Communication

- Posttraumatic Stress Disorder

- Marriage workshop

- Inattentional blindness

- Understanding personality

- Memory training

- Self-image and diet

- Psychology of drug use and abuse

- Addiction and addictive behavior

- Conflict models 